University of Rhode Island

DigitalCommons@URI

Open Access Dissertations

2013

\title{
MIGRATION AND STOPOVER ECOLOGY OF SONGBIRDS AND BATS ALONG A MAJOR ECOLOGICAL BARRIER
}

Adam D. Smith

University of Rhode Island, raptorbio@hotmail.com

Follow this and additional works at: https://digitalcommons.uri.edu/oa_diss

\section{Recommended Citation}

Smith, Adam D., "MIGRATION AND STOPOVER ECOLOGY OF SONGBIRDS AND BATS ALONG A MAJOR ECOLOGICAL BARRIER" (2013). Open Access Dissertations. Paper 128.

https://digitalcommons.uri.edu/oa_diss/128

This Dissertation is brought to you for free and open access by DigitalCommons@URI. It has been accepted for inclusion in Open Access Dissertations by an authorized administrator of DigitalCommons@URI. For more information, please contact digitalcommons-group@uri.edu. 


\title{
MIGRATION AND STOPOVER ECOLOGY OF SONGBIRDS AND BATS ALONG A MAJOR \\ ECOLOGICAL BARRIER \\ BY
}

ADAM D. SMITH

\begin{abstract}
A DISSERTATION SUBMITTED IN PARTIAL FULFILLMENT OF THE REQUIREMENTS FOR THE DEGREE OF DOCTOR OF PHILOSOPHY IN ENVIRONMENTAL SCIENCES
\end{abstract}

UNIVERSITY OF RHODE ISLAND 


\section{DOCTOR OF PHILOSOPHY DISSERTATION}

$\mathrm{OF}$

ADAM D. SMITH

\section{APPROVED:}

Dissertation Committee:

Major Professor $\quad$ Scott R. McWilliams

Peter W. C. Paton

Liliana M. Gonzalez

Nasser H. Zawia

DEAN OF THE GRADUATE SCHOOL

UNIVERSITY OF RHODE ISLAND

2013 


\begin{abstract}
Migration is a physiologically and energetically demanding period in the life cycle of a migratory animal. Most migrant songbirds alternate between periods of nocturnal flight, when energy is used, and stopover, when energy is accumulated for the next flight period; indeed, songbirds spend most of their time and energy on stopover. Conversely, the habits of migratory bats remain largely enigmatic, but there is reason to expect that models of songbird migration can inform bat migration research. I investigated, at multiple scales, the migration ecology of songbirds and bats and the stopover ecology of songbirds along the Atlantic Coast of southern New England. My research comprised four components: acoustic monitoring to explore the regional spatiotemporal dynamics of (1) songbird and (2) bat migration along the Rhode Island coast and relate them to synoptic weather conditions, (3) an experimental manipulation of arrowwood (Viburnum recognitum and $V$. dentatum) fruits, a preferred resource of omnivorous migratory songbirds on Block Island, to evaluate how resource consumption depends on consumer abundance at the landscape scale and the abundance and distribution of that resource at a neighborhood (local) scale, and (4) a field experiment that manipulated Hermit Thrush (Catharus guttatus) body condition (fuel stores) during stopover to isolate and evaluate its influence on subsequent stopover movement behavior and departure decisions on Block Island.

Patterns of warbler and sparrow nocturnal flight call (NFC) detections largely supported our expectations in that NFC detections associated positively and strongly with wind conditions that influence the intensity of coastal bird migration and negatively with regional precipitation; increased during conditions with reduced
\end{abstract}


visibility (e.g., high cloud cover); decreased with higher wind speeds, presumably due to increased ambient noise; and coastal mainland sites recorded four to seven times more NFCs, on average, than coastal nearshore or offshore island sites. Despite some potential complications in inferring migration intensity and species composition from NFC data, the acoustic monitoring of NFCs provides a viable complement to methodologies (e.g., radar) currently used to explore the spatiotemporal patterns of songbird migration as well as evaluating the atmospheric conditions that shape these patterns.

Coastal bat acoustic activity varied with regional wind conditions indicative of cold front passage and expected to induce a more coastal flight path, but associations with other atmospheric conditions from models of songbird migration were typically weak; bat acoustic activity also associated with various aspects of temperature. Predictive models of forthcoming regional bat activity have direct conservation implications given that migration figures prominently in wind turbine-related bat fatalities and the imminent expansion of wind energy into the nearshore and offshore environments of New England and the mid-Atlantic. Predictive models were reasonably accurate in anticipating nights of the highest and lowest bat activity, particularly for low frequency bats. Thus, these predictive models may provide a regional migratory bat activity context for future site-specific applications that, in turn, inform turbine operations and reduce adverse interactions and fatalities.

I conducted the first empirical and simultaneous test of the two primary predictions of contemporary models of plant-frugivore interactions within spatially explicit networks: (1) rate of fruit removal increases as densities of conspecific 
neighborhood fruits increase, and (2) fruit removal rate varies positively with frugivore abundance. Focal arrowwood plants in neighborhoods with high conspecific fruit density sustained moderately decreased fruit removal rates (i.e., competition) relative to those in low density neighborhoods, a result that agrees with most field research to date but contrasts with theoretical expectation. I suggest the spatial contexts that favor competition are considerably more common than the relatively uniform, low aggregation fruiting landscapes that promote facilitation. Patterns of arrowwood removal by avian frugivores generally varied positively with, and apparently in response to, seasonal changes in migratory frugivore abundance, but this effect varied with the distribution of arrowwood. My results underscore the importance of considering spatial context (e.g., fruit distribution and aggregation, frugivory hubs) in plant-avian frugivore interactions. Thus, contemporary theoretical models of plant-frugivore interactions, while quite useful, may not adequately characterize most empirical work to date, particularly in temperate systems that support seasonally abundant frugivores. As such, models of plant-frugivore interactions will benefit from the exploration of alternative or additional model parameters.

Fuel stores in a migrating songbird, manipulated during stopover, directly affected stopover movement dynamics and departure decisions; however, their influence on stopover dynamic was most pronounced later in fall migration. Precipitation and wind additionally modified stopover and departure behavior. My results demonstrate the importance of placing stopover behaviors in the context of relevant intrinsic (e.g., endogenous time program) and extrinsic (e.g., resource 
distribution and abundance, topography, atmospheric conditions) factors. The effect of fuel stores on migration speed may be more pronounced along migratory barriers like the Atlantic coast, as larger fuel stores resulted in shorter stopovers and a more direct migratory route. The pervasive influence of fuel stores on migrant stopover behavior underscores the central role of fuel acquisition in the dynamics, speed, and success of migration and the importance of quality stopover sites to migratory birds. 


\section{ACKNOWLEDGMENTS}

Sincerest of thanks to my advisor, Scott McWilliams. It was not my intent to become your longest-tenured graduate student, and perhaps that honor would not be mine had I not fought so hard to avoid becoming a physiologist! Cheers, mate, and thanks for everything. I very much hope we can collaborate again down the road.

Thanks to my committee - Peter Paton, Liliana Gonzalez, Penelope Pooler, and Howie Ginsberg. Peter, it was always a pleasure to chat with you about birds, wind, or whatever, and additional thanks for the opportunity to band at the Kingston Wildlife Research Station whilst finishing writing. Liliana, you are largely responsible for the joy I find in toiling through all things quantitative, and it is often toil; thank you.

Penelope, I enjoyed our conversations about statistics, monitoring, and the craziness of parenting small children. Howie, I very much enjoyed your non-avian perspective on all matters ecological; it was a privilege to have you chair my defense.

Very special thanks to Deb Bourassa. You seemingly keep the NRS department functioning single-handedly. I can scarcely count the number of times that I would not have been paid were it not for your 'gentle' reminders. Or a field crew member not hired. Or paid. From the correct account (how many was I using?). Or an order not placed. Or waxworms not delivered to Block Island. Or a workers' compensation claim not filed (or covered). You played a vital role in the completion of this project. Thank you again, and may grandmotherdom be good to you!

Scott Comings of the Nature Conservancy graciously accommodated me and my populous field crews and provided property access and logistical support on Block Island. I'll remember my time on Block Island fondly, and you were an integral part 
of that. Thank you. Michelle Boyles toiled through close to a million acoustic files to pull out just over 42,000 actual flight calls. It's quite possible I'd still be sorting noise files without your assistance! Your help was most appreciated. Rick McKinney offered many excellent discussions and provided access to multiple (temperamental) mass spectrometers and some excellent pick-up basketball games.

Funding was provided by a variety of sources, including the Rhode Island Agricultural Experiment Station, National Science Foundation, and U.S. Department of Agriculture to Scott McWilliams, the State of Rhode Island for the Ocean Special Area Management Plan to Scott McWilliams and Peter Paton, and The Nature Conservancy. The acoustic monitoring work was funded largely via a cooperative agreement with the Rhode Island National Wildlife Refuge Complex (NWR); I enjoyed this collaboration with Charlie Vandemoer and Rhonda Smith.

It was my privilege to work with two industrious and diligent field crews, including Blake Jones, Rebecca Alan, Katie Barnes, Sara Bebus, Kathy Chmiel, Jessica Cressman, Laura Jenkins, Christina Knoll, and Elizabeth Pokrivka. To Blake, my good friend, I offer my sincerest gratitude for your outstanding work as a crew leader. Thanks for making my transition from 'father of one' to 'father of two' seamless, despite the transition's occurrence squarely in the middle of a field season. Several outstanding undergraduate assistants and researchers played important supportive roles in various aspects of the project: Joe Atwater, Sarah Donlan, Yvette Haughney, Christina Knoll, Linnea Rowse, and Jessica Takatsuki. Thank you. Thanks also to Kim Gaffett and Steve Reinert of the Block Island Banding Station and the Rhode Island NWR for their respective contribution of Block Island and southern 
Rhode Island banding data. Andrew Farnsworth, Bill Evans, and Sherwood Snyder provided useful discussions on avian acoustics. New Shoreham Town Manager Nancy Dodge facilitated access to town property for experimental manipulation.

Most importantly, thanks to my beloved family. Rhonda, what can I say? Your support is unwavering and your patience worthy of sainthood. Thanks for pulling us through. I will make this team effort worth your while. Lucas and Caleb, you make every day a 'field' day. Thanks for making it clear where my priorities lie. I love you boys! And, finally, my sincerest thanks to Mom and Dad, for your tireless support as parents, grandparents, and friends. I love you. 


\section{DEDICATION}

This dissertation is dedicated to:

Allen Kramer, an extraordinary educator (and euchre player),

and

Al Dufty, an extraordinary mentor 


\section{PREFACE}

This dissertation has been prepared in Manuscript Format according to the guidelines established by the University of Rhode Island. 


\section{TABLE OF CONTENTS}

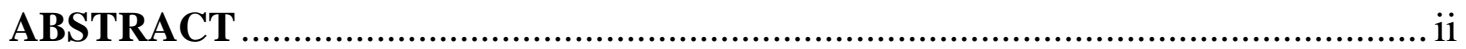

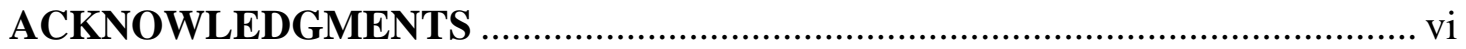

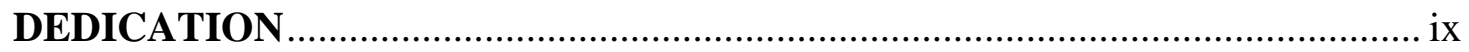

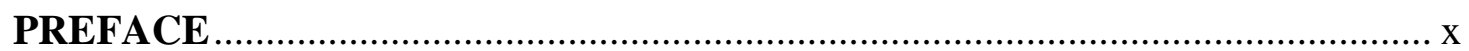

TABLE OF CONTENTS ........................................................................

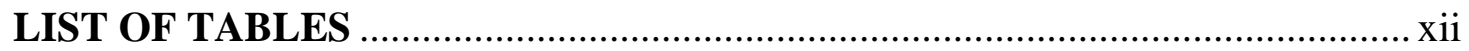

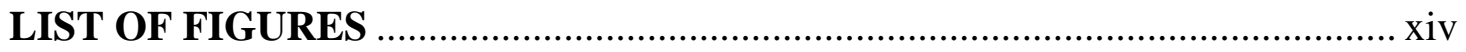

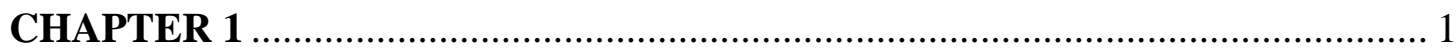

"Using Nocturnal Flight Calls to Assess the Fall Migration of Warblers and Sparrows along a Coastal Ecological Barrier" ............................................ 1

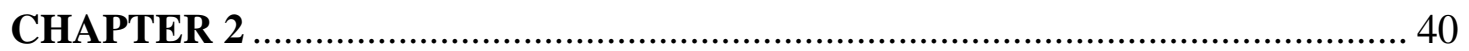

“Autumn Coastal Bat Migration Relates to Atmospheric Condtions: a Regional Context for Near-shore and Off-shore Wind Energy Development" ............. 40

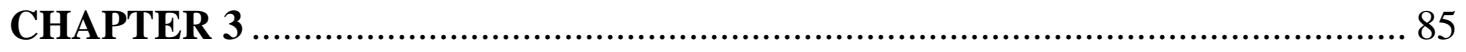

"Fruit Removal Rate Depends on Neighborhood Fruit Density, Frugivore

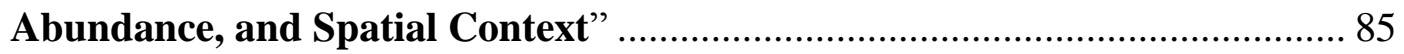

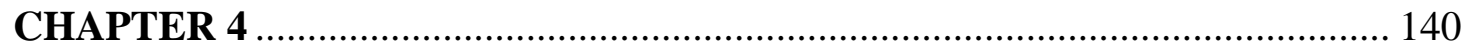

"What To Do When Stopping Over: Behavioral Decisions of a Migrating

Songbird at a Stopover Site are Dictated by Initial Change in Their Body

Condition and Mediated by Key Environmental Conditions".................... 140 


\section{LIST OF TABLES}

TABLE

PAGE

\section{CHAPTER 1}

Table 1. Operational summary of nocturnal flight call microphones at eight locations in southern Rhode Island, USA, during the 2010 - 2011 fall migrations

Table 2. Classification of nocturnal flight calls (NFCs) of migrating warblers (Parulidae) and sparrows (Emberizidae) recorded in southern Rhode Island, USA, during autumn in 2010 and 2011 26

Table 3. Relationships between nightly warbler and sparrow nocturnal flight call (NFC) detections and average regional nightly atmospheric or ambient noise conditions estimated via generalized additive models

\section{CHAPTER 2}

Table 1. Ultrasonic microphone operational summary at seven locations on the Rhode Island National Wildlife Refuge Complex in southern Rhode Island, USA, during the 2010 - 2012 fall migrations

Table 2. Classification of ultrasonic bat passes (call sequences) recorded in southern

Rhode Island, USA, during autumn 2010 - 2012

Table 3. Atmospheric variables used to explore relationships with patterns of migrating bat activity in southern Rhode Island, USA, from 2010 to 2012

Table 4. Relationships between regional nightly activity of high and low frequency bats and average regional nightly atmospheric conditions derived from a generalized additive mixed model (high frequency) or a generalized linear mixed model (low frequency) 


\section{CHAPTER 2, CONTINUED}

Table 5. Relationships between regional nightly activity of high and low frequency bats and average regional atmospheric conditions approximately 30 min prior to sunset derived from generalized linear mixed models

\section{CHAPTER 2, Appendix A}

Table A1. Sources of weather data used to derive atmospheric conditions for comparison with migratory bat acoustic activity

\section{CHAPTER 3}

Table $1.95 \%$ confidence set of zero-inflated negative binomial (ZINB) mixture models of fruit removal patterns and logistic generalized linear mixed models (GLMM) evaluating the probability of incurring fruit removal on Block Island in 2009 and 2010

CHAPTER 3, Online Resource 1

Table 1. Morphological and macronutritional characteristics $( \pm$ SD) of northern and southern arrowwood fruits (Viburnum recognitum and $V$. dentatum, respectively) collected on Block Island, Rhode Island in 2010

Table 2. Hypothetical models for patterns of fruit removal on Block Island in 2009 and 2010 


\section{LIST OF FIGURES}

FIGURE

PAGE

\section{CHAPTER 1}

FIG. 1. Locations of microphones and National Weather Service ASOS stations used to examine the relationship between atmospheric conditions and the nocturnal flight call activity of migrating songbirds in southern Rhode Island (RI), USA, from September to November, 2010-2011

FIG. 2. Seasonal variation in the mean number of nocturnal flight calls (NFCs) detected for warblers and sparrows during fall migration in (A) 2010 and (B) 2011 at

eight coastal sites in southern Rhode Island, USA 35

FIG. 3. Seasonal variation in warbler and sparrow nocturnal flight call (NFC) detections during fall in 2010 and 2011 at eight coastal sites in southern Rhode Island, USA: (A-B) two sites on the mainland coast, (C) one on Aquidneck Island, and (D-H) five on Block Island

FIG. 4. Diel variation in warbler and sparrow nocturnal flight call (NFC) detections in 2010 and 2011 at (A) two coastal locations (sites N and T, see Figure 1) on mainland Rhode Island, (B) a single location on a nearshore island (site S), (C) three locations on northern Block Island (sites K, W, and L), and (D) two locations on southern Block Island (sites $\mathrm{P}$ and $\mathrm{C}$ )

FIG. 5. Changes in warbler and sparrow nocturnal flight call (NFC) detections during the 2010 and 2011 fall migrations as a function of (A-E) average regional atmospheric conditions and (F) ambient noise; associations were estimated with generalized additive models 


\section{CHAPTER 2}

Fig. 1. Locations of ultrasonic microphones and National Weather Service ASOS stations used to examine relationships between atmospheric conditions and migrating bat activity in southern Rhode Island (RI), USA, from August through October, 2010-

Fig. 2. Comparison of nightly regional activity among high (A) and low frequency (B) bats recorded by ultrasonic recorders in southern Rhode Island, USA, during 2010-

Fig. 3. Changes in regional high frequency bat activity over the course of autumn (day of year) and as a function of nightly averages of regional atmospheric conditions; associations were estimated with a generalized additive mixed model

Fig. 4. Changes in regional low frequency bat activity over the course of autumn (day of year) and as a function of nightly average of regional atmospheric conditions; associations were estimated with a generalized linear mixed model

Fig. 5. Changes in regional high frequency bat activity over the course of autumn and as a function of regional averages of atmospheric conditions collected approximately 30 min prior to sunset; associations were estimated with a generalized linear mixed model.

Fig. 6. Changes in regional low frequency bat activity over the course of autumn and as a function of regional averages of atmospheric conditions collected approximately 30 min prior to sunset; associations were estimated with a generalized linear mixed model. 


\section{CHAPTER 2, CONTINUED}

Fig. 7. Regional high (HF) and low (LF) frequency bat activity and corresponding predictions based on regional atmospheric conditions collected approximately $30 \mathrm{~min}$

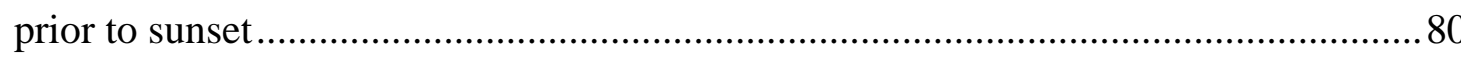

\section{CHAPTER 3}

Fig. 1. Theoretical changes in fruit removal rate from focal arrowwood (Viburnum sp.) plants under various neighborhood fruit density and frugivore activity scenarios ..... 121

Fig. 2. (a) Schematic of an experimental arrowwood plot on Block Island in autumn 2009. (b) Schematic of a typical arrowwood pair on Block Island in autumn 2010, comprising a northern arrowwood shrub (Viburnum recognitum; unshaded shrubs) adjacent to and within $5 \mathrm{~m}$ of a southern arrowwood plant ( $V$. dentatum; shaded shrubs)

Fig 3. Median percentage $(\%)$ of fruit lost since the previous fruit count (interquartile range shown in shading) from enclosed (solid line) and unenclosed (dashed line) arrowwood infructescences in (a) low and (b) high density neighborhoods on northern Block Island and from (c) low and (d) high density neighborhoods on southern Block Island during autumn 2009. 123

Fig. 4. Median percentage (\%) of fruit lost since the previous fruit count (interquartile range shown in shading) from enclosed (solid line) and unenclosed (dashed line) cymes of northern arrowwood (Viburnum recognitum) on (a) northern and (b) southern Block Island and from southern arrowwood (V. dentatum) on (c) northern and (d) southern Block Island during autumn 2010 


\section{CHAPTER 3, CONTINUED}

Fig. 5. Seasonal patterns in arrowwood fruit removal by avian frugivores and migrant activity based on concurrent marine radar monitoring during fall migration on Block Island. (a) In 2009, low density neighborhoods incurred moderately increased fruit removal relative to high density neighborhoods. (b) In 2010, arrowwood on northern Block Island incurred increased fruit removal relative to arrowwood on southern

Block Island, regardless of arrowwood species

CHAPTER 3, Online Resource 1

Fig. 1. Marine (X-band) radar data collected between 16 Sep and 2 Nov 2009 on

Block Island

Fig. 2. Marine (X-band) radar data and high-frequency nocturnal flight call (NFC) recordings collected between 16 Sep and 7 Nov 2010 on Block Island exhibit good agreement in their patterns of migratory activity (and presumably arrival to Block

Island)......

\section{CHAPTER 4}

Figure 1. Geographical context of Block Island, Rhode Island (RI), USA, where we experimentally investigated the role of fuel stores on stopover movements and departure decisions in Hermit Thrushes during the fall migrations of 2009 and 2010

Figure 2. Hermit Thrush fuel stores were modified by feeding regime (maintenance vs. ad libitum) provided to short-term captive birds over, on average, 3 - 4 days during the fall migrations of 2009 and 2019 on Block Island, Rhode Island, USA ... 187 


\section{CHAPTER 4, CONTINUED}

Figure 3. Relationships between body mass and (A) wing chord, (B) subcutaneous fat score, and (C) breast musculature score from 484 observations on 294 Hermit Thrushes captured on Block Island, Rhode Island, USA during the fall migrations of 2009 and 2010 188

Figure 4. Relationships between body mass and (A) wing chord, (B) subcutaneous fat score, and (C) breast musculature score from 484 observations on 294 Hermit Thrushes captured on Block Island, Rhode Island, USA during the fall migrations of 2009 and 2010

Figure 5. Relationships between body mass and (A) wing chord, (B) subcutaneous fat score, and (C) breast musculature score from 484 observations on 294 Hermit Thrushes captured on Block Island, Rhode Island, USA during the fall migrations of 2009 and 2010 190

Figure 6. Relationships between body mass and (A) wing chord, (B) subcutaneous fat score, and (C) breast musculature score from 484 observations on 294 Hermit Thrushes captured on Block Island, Rhode Island, USA during the fall migrations of 


\title{
CHAPTER 1
}

"Using Nocturnal Flight Calls to Assess the Fall Migration of Warblers and Sparrows along a Coastal Ecological Barrier"

by

\author{
Adam D. Smith ${ }^{1,2}$, Peter W. C. Paton ${ }^{1}$, and Scott R. McWilliams ${ }^{1}$
}

is submitted to $P L O S O N E$

${ }^{1}$ Department of Natural Resources Science, University of Rhode Island, 1 Greenhouse Road, Kingston, RI 02881, USA

${ }^{2}$ E-mail: adam.smith@my.uri.edu 


\begin{abstract}
Atmospheric conditions fundamentally influence the timing, intensity, energetics, and geography of avian migration. While the influence of weather on the magnitude and spatiotemporal patterns of nocturnal bird migration has been inferred typically using radar, the flight calls produced by many bird species during nocturnal migration provides additional information regarding the species composition of nocturnal migration. We used nocturnal flight call (NFC) recordings of at least 22 migratory songbirds (14 warbler and 8 sparrow species) during fall migration from eight sites along the mainland and island coasts of Rhode Island to evaluate five hypotheses regarding NFC detections. Patterns of warbler and sparrow NFC detections largely supported our expectations in that (1) NFC detections associated positively and strongly with wind conditions that influence the intensity of coastal bird migration and negatively with regional precipitation; (2) NFCs increased during conditions with reduced visibility (e.g., high cloud cover); (3) NFCs decreased with higher wind speeds, presumably due to increased ambient noise; and (4) coastal mainland sites recorded four to seven times more NFCs, on average, than coastal nearshore or offshore island sites. However, we found little evidence that (5) nightly or intra-night patterns of NFCs reflected the well-documented latitudinal patterns of migrant abundance on an offshore island. Despite some potential complications in inferring migration intensity and species composition from NFC data, the acoustic monitoring of NFCs provides a viable and complementary methodology for exploring the spatiotemporal patterns of songbird migration as well as evaluating the atmospheric conditions that shape these patterns.
\end{abstract}




\section{Introduction}

Atmospheric dynamics fundamentally influence the timing, intensity, energetics, and geography of avian migration [1-3]. Wind conditions (i.e., direction and speed)

around low and high pressure systems and associated frontal boundaries are particularly influential [4]. During fall migration in the northern hemisphere, many birds migrate preferentially when winds provide some tailwind component after the passage of a cold front [2,4,5; but see 6$]$. However, wind conditions during migratory flight can concentrate migrants at topographic barriers [7-9]. The increased densities of migrants at stopover sites along these 'leading lines' [10] can reduce energy replenishment rates via competition as well as increase the risk of predation [11-14]. These potential density-dependent consequences substantiate the need to identify the environmental factors that direct the movements and distribution of songbirds during migration, particularly along ecological barriers that may experience disproportionate migrant densities.

In the northeastern United States during southbound fall migration, many nocturnal passerine migrants concentrate along the Atlantic Coast and on offshore land masses under specific weather conditions [15-17]. In particular, hatching-year migrants often fail to compensate for prevailing winds and are displaced to the coast or offshore (the so-called "coastal effect"; [18]), with offshore birds typically reorienting towards or along the nearest land mass near dawn [17,19-21]. Although reverse migration and reorientation are common phenomena along the Atlantic Coast (e.g., $[16,17,19,22])$, their occurrence and extent depend on a complex interplay between wind, topography, 'on-the-ground' distribution of resources and risk, and 
individual histories (e.g., [23-27]). The context- and weather-dependent response of nocturnal passerine migrants to coastlines, as well as their subsequent redistributional movements, implies that spatiotemporal variation in the geographic distribution of migrants aloft occurs at multiple scales along the Atlantic Coast.

The influence of weather on the magnitude and spatiotemporal patterns of nocturnal bird migration has been inferred primarily using radar (e.g., $[2,4,28]$ ), although the use of nocturnal flight calls (NFCs) provides an interesting alternative approach. Many bird species produce distinct vocalizations during sustained flight, particularly nocturnal migration, potentially enabling the simultaneous evaluation of the magnitude, spatiotemporal patterns, and species composition of nocturnal migration [29-31]. In general, the temporal patterns of NFC detections associate positively with the migration intensity inferred from radar [32-34]. However, certain atmospheric conditions complicate the relationship between NFC detections and the number of birds aloft - NFC detections increase when visual communication is limited (e.g., low visibility and cloud ceiling, high cloud cover; summarized in [35]), but decrease with increasing ambient noise $[32,36]$. Understanding these influences on the spatiotemporal patterns of NFCs will improve our ability to infer the spatial distribution and abundance of songbirds along their migration routes and ecological barriers.

We evaluated five hypotheses regarding the detection of migrant songbird NFCs along the Atlantic Coast of southern New England in relation to atmospheric and ambient conditions, as well as coastal context: (1) NFC detections vary strongly with the atmospheric conditions that influence the intensity of bird migration in 
general and coastal migration in particular (e.g., front passage, wind conditions, and precipitation; [2,4]); (2) NFC detections increase under conditions expected to hinder visual communication (i.e., cloudy skies with low ceilings and reduced visibility); (3) NFC detections decrease when weather conditions that increase ambient noise, particularly high winds, as well as other non-wind sources of ambient noise. Finally, we expected NFC detections to vary with geographic context (i.e., relative coastal position) among sites in coastal Rhode Island. Specifically, we expected (4) more NFC detections at mainland sites relative to offshore sites, and that (5) total NFC detections and intra-night patterns of NFC detections on an offshore island would vary according to well-documented latitudinal patterns of migrant abundance on the island (i.e., migrants concentrate at the northern end of the island; [20,37]).

\section{Materials and Methods}

During fall 2010 - 2011, we monitored NFC of songbirds at eight sites in southern Rhode Island, USA: two along the mainland coast (Figure 1; sites $\mathrm{N}$ and T), one along the southern coast of Aquidneck Island, a large $\left(98 \mathrm{~km}^{2}\right)$ nearshore island at the southern end of Narragansett Bay (Figure 1; site S), and five sites along the periphery of Block Island $\left(25 \mathrm{~km}^{2}\right)$, which is located approximately $15 \mathrm{~km}$ south of mainland Rhode Island (Figure 1; sites C, K, L, P and W). We placed six microphones (Figure 1 ; sites $\mathrm{K}, \mathrm{L}, \mathrm{N}, \mathrm{S}, \mathrm{T}$, and $\mathrm{W}$ ) on protected, public lands with the authorization of the property manager; we placed the remaining two microphones (Figure 1; sites $\mathrm{C}$ and $\mathrm{P}$ ) were placed on private property with the authorization of the property owners. At each site, we recorded NFCs with a microphone (SMX-NFC; Wildlife Acoustics, Inc., 
Concord, MA) attached to a passive recorder (SM2BAT, $24 \mathrm{kHz}$ sampling rate;

Wildlife Acoustics, Inc., Concord, MA) set to maximum gain (+60 dB). The SMXNFC possessed a relatively flat frequency response from $2-12 \mathrm{kHz}$, and its placement near a horizontal, acrylic glass plate $(22.9 \mathrm{~cm}$ x $22.9 \mathrm{~cm})$ created a pressure zone for sounds originating above the plate, effectively increasing signal gain by up to $6 \mathrm{~dB}$ [29] while attenuating sounds from below the plate. We mounted each microphone approximately $5-5.5 \mathrm{~m}$ above the ground, which was above the height of prevailing coastal shrub vegetation. The precise detection range of this microphone is unclear, but similar pressure-zone microphones suggest vertical detections are possible up to approximately $300 \mathrm{~m}$ above ground level and maximum horizontal detections of approximately $125 \mathrm{~m}$ [29]. We located monitoring sites far from artificial lighting (e.g., residences), which can disorient and concentrate nocturnal songbird migrants (reviewed in [38]). We recorded NFCs from evening civil twilight to morning civil twilight (i.e., sun elevation approximately $6^{\circ}$ below the horizon), from 8 September to 8 November in 2010 and from 8 September to 10 November in 2011. However, we truncated the recordings 15 min prior to morning civil twilight (about 45 min prior to sunrise) due to frequent vocalizations from birds on the ground near the microphone; the resulting nightly recordings varied in length $(10.3-13.0 \mathrm{~h})$ over the course of the recording seasons. Coverage was not complete during these periods due to various equipment malfunctions, nor were we able to record at all sites in each year (Table 1).

We filtered potential flight calls from nightly recordings using a band-limited energy detector algorithm in Raven Pro 1.3 (Build 32, Cornell Lab of Ornithology, Ithaca, NY). We specified the algorithm to extract high frequency band flight calls 
(i.e., within the frequency range of $6-11 \mathrm{kHz}$ ), which included most migratory species of warblers (Parulidae) and sparrows (Emberizidae) in eastern North America $[29,30]$. Our analysis was restricted to high frequency flight calls because ambient noise in the $1-5 \mathrm{kHz}$ frequency range (e.g., wind, insects, amphibians, or machines) consistently precluded the extraction of flight calls from species producing low- and mid-frequency vocalizations (e.g., thrushes, grosbeaks, tanagers). Within this $6-11$ $\mathrm{kHz}$ frequency range, we configured the algorithm to extract potential calls $23-398$ $\mathrm{ms}$ in duration and separated by at least $98 \mathrm{~ms}$, with a signal-to-noise threshold of 3.5 $\mathrm{dB}$ and $30 \%$ minimum signal occupancy. We estimated the background noise against which the signal of potential calls was compared as the $50^{\text {th }}$ percentile energy value within a $1200 \mathrm{~ms}$ block with a hop size of $243 \mathrm{~ms}$. We exported potential calls to individual time-stamped audio (*.wav) files, and then generated a spectrogram of each audio file using GlassOFire (www.oldbird.org) from which we manually classified calls and discarded false detections (e.g., wind, rain drops, non-flight call vocalizations). To assess the effects of varying ambient noise on the detection of high frequency flight calls, we used Raven Pro to calculate the average power (dB) in the 6 $-11 \mathrm{kHz}$ frequency range during the first hour of each night at each microphone.

We assigned NFCs to species when possible, but more commonly into a complex of similar species [30]. We further aggregated these species complexes into two families for analysis: warblers and sparrows (Table 2). While some species complexes initially contained NFCs from both families, we carefully separated presumed sparrow from warbler NFCs, typically by call length. Approximately $10 \%$ of detected flight calls were too weak to assign confidently to the level of family (9\%) 
or belonged to other bird families (e.g., Indigo Buntings, Passerina cyanea; $1 \%$ ); we excluded these calls from further analyses.

Regional atmospheric conditions

We derived atmospheric conditions based primarily on weather data from observations at five National Weather Service Automated Surface Observing System (ASOS) stations occurring within $50 \mathrm{~km}$ of the centroid of microphone locations (Figure 1). ASOS reports wind speed and direction, as well as precipitation amount, every minute, although the data are derived from accumulations over the previous 1 or $2 \mathrm{~min}$; visibility, cloud cover, and cloud ceiling data were reported every $5 \mathrm{~min}$. We calculated wind profit from wind direction and wind speed [39]; wind profit represents the distance a bird is drifted toward a specified target direction in a fixed time interval through only the effect of wind. Typically, the target direction is the migratory goal, but we specified due southeast $\left(135^{\circ}\right)$ as the target direction to better capture those combinations of wind direction and speed that indicate recent cold front passage but also more likely to induce a coastal flight path in migrating birds, and perhaps the coastal effect [18] in inexperienced migrants. We calculated nightly averages for weather variables from evening to morning civil twilight, thus encompassing the period of active monitoring. We also calculated the proportion of hours during a given night with at least one ASOS station reporting precipitation. Additional details of weather data acquisition and manipulation are available from the authors.

Analysis 
We used generalized additive models $[40,41]$ to explore the association between regional atmospheric conditions on NFC detections and differences in NFC rates among sites. GAMs accommodate potential nonlinear changes in calling activity with predictor variables while allowing us to incorporate serial correlation [41]; we implemented them using the gamm function of the mgcv package [42] in R, version 2.15.2 [43]. We used negative binomial GAMs to accommodate overdispersion in NFC detections. The gamm function requires an estimate for the negative binomial dispersion parameter which we estimated for each GAM with a similarly-structured generalized linear model that used a third-order polynomial for seasonal (i.e., day of year) effects.

We estimated GAMs separately for warblers and sparrows. We allowed for potential nonlinear seasonal (i.e., day of year) effects using the default thin plate regression spline; we allowed this seasonal effect to vary among sites. A first-order autoregressive (AR-1) error structure reasonably accounted for serial correlation in residuals. We grouped the correlation structure within each site and year combination to expedite GAM estimation [41]. We centered and scaled by one standard deviation all continuous model input variables to improve estimation and facilitate the assessment of the relative importance of atmospheric conditions to NFC detections [44]; we did not modify the categorical variables for year and recording site. We omitted cloud ceiling from the analysis due to its high collinearity with cloud cover (i.e., variance inflation factor $>10$ ). To avoid biased parameter estimates and standard errors when evaluating hypotheses, we did not eliminate any terms from the models [45]. Finally, we estimated the average seasonal discrepancy in NFC detections 
between mainland sites and island sites with two additional GAMs (i.e., warblers and sparrows) that dichotomized recording sites according to this geographic context.

\section{Results}

We recorded 27,452 warbler and 14,876 sparrow flight calls in 638 microphone nights ( 7,250 h of recordings) during the fall migrations of 2010 - 2011 (Table 2). Most warbler NFCs (62\%) were classified into a single complex ('ZEEPs'; Table 2) dominated presumably by four species with similar flight calls; several additional species likely are represented in this complex, but to a much lesser extent. Four sparrow species were presumed responsible for nearly all ( 97\%) sparrow NFCs ('SPARs’; Table 2), although a few other species likely are represented (Table 2). Warblers and sparrows exhibited similar general patterns of NFC detections, but slightly different phenologies (Figures 2 and 3). Generally, NFC detections peaked in late September/early October (warblers) or mid-October (sparrows) and declined through the end of the season (Figure 3), regardless of site, although the data did not justify a curvilinear fit for a few sites (i.e., Figure 3D, F, G). Averaged over the entire migration period, mainland sites (Figure 3A-B) detected more than four times the warbler NFC detections and seven times the sparrow NFC detections relative to island sites (Figure 3C-H); warbler and sparrow NFC detections were similar between the single nearshore island location (Figure 3C) and Block Island locations (Figure 3D-H).

Warblers exhibited similar intra-night NFC detection patterns regardless of geographic context (Figure 4). Specifically, warbler NFC detections increased sharply 
in the first few hours after civil sunset and peaked before the middle of the night, then decreased more slowly through civil sunrise. The primary discrepancy among locations was the relatively reduced warbler NFC detections in the last quarter of the night prior to civil sunrise at southern Block Island sites (Figure 4D). Additionally, the non-zero density of NFC detections at civil sunset suggests warbler migration was underway by this time (Figure 4). Compared to warblers, sparrow NFC detections increased more slowly after civil sunset and exhibited a more protracted period of peak activity centered around the middle of the night, roughly $2330 \mathrm{~h}$ EST (Figure 4). Again southern Block Island sites were the exception to this general pattern, as sparrow NFC detections was distinctly reduced near civil sunset and sunrise, producing a more pronounced peak of activity near the middle of the night (Figure $4 \mathrm{D})$.

Warbler and sparrow NFC detections increased substantially with wind conditions indicative of recent cold front passage and favorable for coastal migration (Table 3, Figure 5A). Additionally, warbler and sparrow NFC detections decreased with an increasing regional presence of rain (Table 3, Figure 5D). Warbler and sparrow NFC detections increased under cloudier skies (and lower cloud ceilings; Table 3, Figure 5C), but decreased visibility was associated with increased detections only in warblers (Table 3, Figure 5E). NFC detections decreased considerably with increasing wind speeds (Table 3, Figure 5B). Independent of wind speed, ambient noise (e.g., insects, machines) only marginally decreased the detection of warbler flight calls and was not associated with the detection of sparrow NFCs (Table 3, Figure 5F). 


\section{Discussion}

We used NFC recordings of at least 22 migratory songbirds (14 warbler and 8 sparrow species) during fall migration from multiple sites along mainland and island coasts of Rhode Island to evaluate hypotheses regarding NFC detections. Patterns of warbler and sparrow NFC detections largely supported our expectations that (1) NFC detections were associated positively and strongly with wind profit and negatively with regional precipitation; (2) NFCs increased with reduced visibility for migrants (e.g., high cloud cover); (3) NFCs decreased with higher wind speeds, presumably due to increased ambient noise; and (4) coastal mainland sites recorded four to seven times more NFCs, on average, than coastal nearshore or offshore island sites. However, we found little evidence that (5) nightly or intra-night patterns of NFCs reflected the welldocumented latitudinal patterns of migrant abundance on Block Island.

Associations of NFC detectability with atmospheric conditions

Atmospheric and ambient conditions can influence the detection of NFCs directly by inducing a change in the rate at which migrants call, or indirectly by influencing the number of birds aloft or NFC detectability. Certain atmospheric conditions commonly are associated with increased numbers of birds aloft in north temperate areas (e.g., front passage, wind conditions, and precipitation; [1,2,4]) and increase the likelihood of migrant concentrations along the Atlantic Coast of North America [22,28]. We formulated wind profit to reflect wind conditions favorable for migration in general (i.e., the northerly component that typically follows cold front passage and building 
high pressure) but also to favor a westerly component that would likely induce a flight path towards the coast and offshore displacement. While northeast and east winds may provide favorable tailwinds to migrating songbirds in our region $[2,4]$, we expected winds from these directions to diminish the concentrating influence of the Atlantic Coast on southbound migrant activity. Consequently, our formulation of wind profit ascribed reduced or negative values to these wind conditions. We suggest the strong association of warbler and sparrow NFC detections with wind profit supports the idea that NFC detections generally reflect the number of birds aloft. We note that in addition to wind profit, there exist several alternatives for capturing the multivariate problem of wind assistance, each making different assumptions regarding the behavior of the organism of interest [46].

Unlike wind profit, the extent to which other atmospheric conditions influence NFC detections directly or indirectly is less clear and not likely to be mutually exclusive. Therefore, atmospheric conditions likely complicate the relationship between vocal birds aloft and NFC detections. For example, precipitation is thought to suppress migration $[1,2,4]$, which concurs with the negative association of regional precipitation with NFC detections we documented in this study. However, heavy precipitation could make it more difficult to detect NFCs by increasing the background noise (see below). In contrast, light to moderate precipitation could decrease visibility without hindering migration and thus induce increased calling rates $[35,47]$ or lower flight altitudes [8], thereby increasing detections.

Cloud cover and visibility describe additional conditions under which the influence on NFC detections may be direct or indirect. NFC detections are known to 
be positively related to increasing cloud cover (or decreasing cloud ceiling, which correlated very strongly with cloud cover in this study) or decreasing visibility (reviewed in [35]; see also [47]). Farnsworth [35] suggested that increased calling rates by individuals under conditions of poor visibility may be adaptive for maintaining contact, avoiding collisions, and coordinating migratory behavior, particularly in inexperienced migrants [48]; this hypothesis implies a behaviormodifying influence on calling rates. Its potential pertinence to inexperienced migrants is particularly relevant to this study, as the vast majority of autumnal songbird migrants along the coast are young birds executing their first migration [4953]. But indirect effects seem equally plausible; poor visibility, cloud cover, and low cloud ceiling may reasonably decrease flight altitudes relative to clearer nights, placing more migrants within NFC detection range. Although we documented the expected increase in NFC detections with increasing cloud cover (warblers and sparrows) and decreasing visibility (warblers only), we were unable to distinguish between such direct and indirect influences.

We further expected certain atmospheric and biological conditions to increase background noise and decrease our ability to detect NFCs, and thus associate negatively to NFC detections. The primary sources of noise in this study were wind (i.e., noise produced by air passing through microphone wind screens) and insects. For warblers and sparrows, wind speed was strongly negatively associated with NFC detections. Higher wind speeds might also decrease the number of migrants aloft, particularly when opposing the direction of travel [4,54], but high wind conditions may also result in lower flight altitudes [54-56] and thus possibly increased 
detectability. We suggest that the negative effect of wind speed reflected primarily an increase in background noise and an associated decrease in the detectability of NFCs more so than a decrease in warbler and sparrow abundance aloft [34]; the correlation of background noise measurements with wind speed at each site $(\mathrm{r}=0.59, \mathrm{P}<0.001$, df =622; 'within-site' correlation sensu [57]) supports this conclusion. Wind noise generally spanned the entire frequency range of NFCs (i.e., $6-11 \mathrm{kHz}$ ), and while high noise levels effectively precluded detections of most species, intermediate noise levels may have non-uniformly discriminated against species that produce less powerful calls or fly at higher altitudes. We found little evidence that non-wind noise appreciably decreased the detection of NFCs. Insect noise was the most frequent, albeit irregular, non-wind source of background noise; insect noise rarely exceeded 6.5 $\mathrm{kHz}$ and became less common as the season progressed. The irregularity and typical frequency range of insect noise may explain the weak influence of insect noise on warbler NFC detection and the apparent lack of such an influence for sparrows. The warbler NFCs relevant to this study occur at lower frequencies, on average, than the relevant sparrow NFCs [30]. And, while the large part of most warbler NFCs occur above $6.5 \mathrm{kHz}$, a few species produce lower frequency flight calls that occur mostly below $6.5 \mathrm{kHz}$ and thus may have been disproportionately concealed by insect noise (Table 2); the NFCs of all sparrow species in this study occur completely or predominantly above $6.5 \mathrm{kHz}[30]$.

NFC detections and coastal context 
We recorded warbler and sparrow NFCs in multiple coastal contexts along the Atlantic Coast of the northeastern United States, an important migratory corridor during autumn migration. NFC detections occurred episodically over the fall migration season, similar to migration intensity in the region (e.g., $[9,15,17,58])$, presumably the result of most migrants coinciding movements with ephemerally favorable conditions $[2,4,28,39,59]$. Although offshore islands often offer excellent opportunities to observe high densities of migrants [20,37], we expected that most migrants would move over land or near the coast, rather than offshore, and thus would detect more NFCs at mainland sites compared to offshore sites. Indeed, warbler and sparrow NFC detections were considerably higher at our two mainland sites. Radar studies suggest the difference in NFC detections between coastal contexts along the Atlantic Coast reflects migrant abundance rather than a difference in the calling behavior or flight altitudes of birds, as the bulk of migration intensity occurs along the coast and inland, not over ocean, excluding water crossings from Nova Scotia over the Gulf of Maine [15-17,60]. Furthermore, if patterns of NFC detections reflected changes in calling behavior more so than abundance, we might reasonably expect the opposite pattern (i.e., birds displaced offshore increase calling rates). Flight altitude might play some role in the observed pattern, but the data are scarce and mixed and often complicated by radar peculiarities (see, e.g., [8,21,25]).

There exists a well-documented pattern in 'on-the-ground' migrant densities on Block Island: migrants occur in higher densities on the northern half of the island, where they prepare for reoriented flights to the mainland or subsequent migratory flights $[20,37]$. Indeed, the two migration banding operations on the island ([52]; 
USFWS unpubl. data) are located in the northern quarter of the island and so exploit the phenomenon, as have multiple previous studies [61-64]. We thus expected a similar latitudinal pattern in NFC detections among Block Island sites; however, we found little evidence for this pattern (or differences among sites in general), suggesting that concentrations of migrants on the northern half of Block Island result primarily from redistribution after landfall (e.g., [22,24,65,66]). Indeed, regular observation of significant diurnal, northerly movements of migrants on offshore islands following nights of active southerly migration provide evidence of such a redistribution ([20,37]; A. D. Smith pers. obs.).

Migration activity along the Atlantic Coast, as assessed by radar, generally peaks in the few hours following sunset and declines steadily thereafter $[9,33,58,60,67]$. Comparisons of NFC detections with radar are few but suggest that NFC detections follow a similar pattern ([34]; but see the New York data in [33]) or peaks up to a few hours later, usually near or just after the middle of the night $[33,68]$. Seasonal patterns of intra-night NFC detections in this study (Figure 4) support an apparent delay in peak NFC detections relative to expectations from previous radar work; the patterns also suggest that sparrows migrate, or at least call, slightly later in the night on average than warblers (Figure 4). The intra-night patterns of warbler and sparrow NFC detections were generally consistent for the larger coastal context (i.e., mainland vs. island) and among latitudinal contexts on Block Island, with the possible exception of sparrow NFC detections at southern Block Island sites (Figure 4D). For reasons that remain unclear, the reduced activity near sunrise and sunset at these sites suggests that fewer sparrows are landing and settling on southern Block Island. 
Finally, rather than comparing seasonal averages of intra-night activity, more detailed work will be necessary to evaluate the variability of the relationship between migrant density and concurrent NFC detections (e.g., [34]).

\section{NFC species composition}

Acoustic monitoring is relatively inexpensive compared to radar, the equipment can be automated, and it provides information not readily obtained from other methodologies, including species composition and phenology information for vocal species and the ability to detect secretive, rare, or otherwise difficult to survey species $[69,70]$. However, inferring the relative abundances of calling species using patterns of NFCs is complicated because several common species do not regularly vocalize during migration (e.g., flycatchers, vireos, mimids; $[30,35,36])$ whereas other species regularly vocalize during migration and so may be over-represented in NFC recordings (e.g., Savannah Sparrows; [70]). For example, a comparison of NFC detections and capture rates at four of our microphone locations where there was an active and close $(<500 \mathrm{~m})$ banding operation suggests that Savannah and Chipping Sparrows were likely over-represented in NFC recordings whereas Yellow-rumped Warblers were likely under-represented in NFC recordings. Clearly, inferring the relative abundances of calling species using patterns of NFCs requires more knowledge of calling rates among species [36] and a means to correct for speciesspecific differences in detection. Despite these potential complications in interpreting NFC data and inferring migration intensity, the acoustic monitoring of NFCs provides a viable and complementary methodology for exploring the spatiotemporal patterns of 
songbird migration (e.g., [29,70]; see also oldbird.org), as well as evaluating the atmospheric conditions that shape these patterns.

\section{Acknowledgments}

B. Jones assisted in the installation and maintenance of microphones. M. Boyles separated possible flight calls from noise files. A. Farnsworth, B. Evans, and S. Snyder provided useful discussions on avian acoustics during the initial phases of the project. S. Comings and The Nature Conservancy provided accommodations and logistical support on Block Island. Very special thanks to S. Comings and the Pyne family for granting access to their properties for microphone installation. Special thanks to K. Gaffett and S. Reinert of the Block Island Banding Station the Rhode Island National Wildlife Refuge Complex for their contributions of Block Island and southern Rhode Island banding data, respectively.

\section{References}

1. Alerstam T (1990) Bird migration. Cambridge, United Kingdom: Cambridge University Press. 432 p.

2. Richardson WJ (1990) Timing of bird migration in relation to weather: updated review. In: Gwinner E, editor. Bird Migration. Berlin: Springer-Verlag. pp. 78-101.

3. Liechti F (2006) Birds: blowin' by the wind? J Ornithol 147: 202-211.

4. Richardson WJ (1978) Timing and amount of bird migration in relation to weather: a review. Oikos 30: 224-272.

5. Able KP (1973) The role of weather variables and flight direction in determining the magnitude of nocturnal bird migration. Ecology 54: 10311041. 
6. Karlsson H, Nilsson C, Bäckman J, Alerstam T (2011) Nocturnal passerine migration without tailwind assistance. Ibis 153: 485-493.

7. Åkesson S (1993) Coastal migration and wind drift compensation in nocturnal passerine migrants. Ornis Scand 24: 87-94.

8. Hüppop O, Dierschke J, Exo K-M, Fredrich E, Hill R (2006) Bird migration studies and potential collision risk with offshore wind turbines. Ibis 148: 90109.

9. Gagnon F, Ibarzabal J, Savard JL, Bélisle M, Vaillancourt P (2011) Autumnal patterns of nocturnal passerine migration in the St. Lawrence estuary region, Quebec, Canada: a weather radar study. Can J Zool 89: 31-46.

10. Geyr von Schweppenburg HF (1963) Zur terminologie und theorie der leitlinie. J Für Ornithol 104: 191-204.

11. Alerstam T (1978) Reoriented bird migration in coastal areas: dispersal to suitable resting grounds? Oikos 30: 405-408.

12. Moore FR, Yong W (1991) Evidence of food-based competition among passerine migrants during stopover. Behav Ecol Sociobiol 28: 85-90.

13. Åkesson S (1999) Do passerine migrants captured at an inland site perform temporary reverse migration in autumn? Ardea 87: 129-137.

14. Kelly JF, DeLay LS, Finch DM, Blem C (2002) Density-dependent mass gain by Wilson's Warblers during stopover. Auk 119: 210-213.

15. Drury WH, Keith JA (1962) Radar studies of songbird migration in coastal New England. Ibis 104: 449-489.

16. Drury WH, Nisbet ICT (1964) Radar studies of orientation of songbird migrants in southeastern New England. Bird-Band 35: 69-119.

17. Richardson WJ (1972) Autumn migration and weather in eastern Canada: a radar study. Am Birds 26: 10-16.

18. Ralph CJ (1978) Disorientation and possible fate of young passerine coastal migrants. Bird-Band 49: 237-247.

19. Richardson WJ (1978) Reorientation of nocturnal landbird migrants over the Atlantic Ocean near Nova Scotia in autumn. Auk 95: 717-732.

20. Able KP (1977) The orientation of passerine nocturnal migrants following offshore drift. Auk 94: 320-330. 
21. Diehl RH, Larkin RP, Black JE, Moore FR (2003) Radar observations of bird migration over the Great Lakes. Auk 120: 278-290.

22. Wiedner DS, Kerlinger P, Sibley DA, Holt P, Hough J, et al. (1992) Visible morning flight of Neotropical landbird migrants at Cape May, New Jersey. Auk 109: 500-510.

23. Dunn EH, Nol E (1980) Age-related migratory behavior of warblers. J Field Ornithol 51: 254-269.

24. Åkesson S, Karlsson L, Walinder G, Alerstam T (1996) Bimodal orientation and the occurrence of temporary reverse bird migration during autumn in south Scandinavia. Behav Ecol Sociobiol 38: 293-302.

25. Bruderer B, Liechti F (1998) Flight behaviour of nocturnally migrating birds in coastal areas: crossing or coasting. J Avian Biol 29: 499-507.

26. Fortin D, Liechti F, Bruderer B (1999) Variation in the nocturnal flight behaviour of migratory birds along the northwest coast of the Mediterranean Sea. Ibis 141: 480-488.

27. Fitzgerald TM, Taylor PD (2008) Migratory orientation of juvenile yellowrumped warblers (Dendroica coronata) following stopover: sources of variation and the importance of geographic origins. Behav Ecol Sociobiol 62: 1499-1508.

28. Gagnon F, Ibarzabal J, Savard J-PL, Vaillancourt P, Bélisle M, et al. (2011) Weather effects on autumn nocturnal migration of passerines on opposite shores of the St. Lawrence estuary. Auk 128: 99-112.

29. Evans WR, Mellinger DK (1999) Monitoring grassland birds in nocturnal migration. Stud Avian Biol 19: 219-229.

30. Evans WR, O’Brien M (2002) Flight calls of migratory birds: eastern North American landbirds (CD-ROM).

31. La VT (2012) Diurnal and nocturnal birds vocalize at night: a review. Condor 114: 245-257.

32. Larkin RP, Evans WR, Diehl RH (2002) Nocturnal flight calls of Dickcissels and doppler radar echoes over south Texas in spring. J Field Ornithol 73: 2-8.

33. Farnsworth A, Gauthreaux, Jr. SA, Blaricom D van (2004) A comparison of nocturnal call counts of migrating birds and reflectivity measurements on Doppler radar. J Avian Biol 35: 365-369. 
34. Gagnon F, Bélisle M, Ibarzabal J, Vaillancourt P, Savard J-PL (2010) A comparison between nocturnal aural counts of passerines and radar reflectivity from a Canadian weather surveillance radar. Auk 127: 119-128.

35. Farnsworth A (2005) Flight calls and their value for future ornithological studies and conservation research. Auk 122: 733-746.

36. Farnsworth A, Russell RW (2007) Monitoring flight calls of migrating birds from an oil platform in the northern Gulf of Mexico. J Field Ornithol 78: 279289.

37. Baird J, Nisbet ICT (1960) Northward fall migration on the Atlantic coast and its relation to offshore drift. Auk 77: 119-149.

38. Gauthreaux SA, Belser CG (2006) Effects of artificial night lighting on migrating birds. In: Rich C, Longcore T, editors. Ecological consequences of artificial night lighting. Washington, D.C., USA: Island Press. pp. 67-93.

39. Erni B, Liechti F, Underhill LG, Bruderer B (2002) Wind and rain govern the intensity of nocturnal bird migration in Central Europe - a log-linear regression analysis. Ardea 90: 155-166.

40. Hastie TJ, Tibshirani RJ (1990) Generalized additive models. CRC Press. 356 p.

41. Wood SN (2006) Generalized additive models: an introduction with R. Boca Raton, FL, USA: Chapman and Hall/CRC.

42. Wood SN (2011) Fast stable restricted maximum likelihood and marginal likelihood estimation of semiparametric generalized linear models. J R Stat Soc Ser B Stat Methodol 73: 3-36.

43. R Development Core Team (2011) R: a language and environment for statistical computing. Vienna, Austria: R Foundation for Statistical Computing. Available: http://www.R-project.org/.

44. Schielzeth H (2010) Simple means to improve the interpretability of regression coefficients. Methods Ecol Evol 1: 103-113.

45. Harrell FE (2001) Regression modeling strategies: with applications to linear models, logistic regression, and survival analysis. New York: Springer.

46. Kemp MU, Shamoun-Baranes J, van Loon EE, McLaren JD, Dokter AM, et al. (2012) Quantifying flow-assistance and implications for movement research. J Theor Biol 308: 56-67. 
47. Hüppop O, Hilgerloh G (2012) Flight call rates of migrating thrushes: effects of wind conditions, humidity and time of day at an illuminated offshore platform. J Avian Biol 43: 85-90.

48. Simons AM (2004) Many wrongs: the advantage of group navigation. Trends Ecol Evol 19: 453-455.

49. Baird J, Bagg AM, Nisbet ICT, Robbins CS (1959) Operation Recovery: report on mist-netting along the Atlantic Coast in 1958. Bird-Band 30: 143-171.

50. Ralph CJ (1981) Age ratios and their possible use in determining autumn routes of passerine migrants. Wilson Bull 93: 164-188.

51. Morris SR, Holmes DW, Richmond ME (1996) A ten-year study of the stopover patterns of migratory passerines during fall migration on Appledore Island, Maine. Condor 98: 395-409.

52. Reinert SE, Lapham E, Gaffett K (2002) Landbird migration on Block Island: community composition and conservation implications for an island stopover habitat. In: Paton PW, Gould LL, August PV, Frost AO, editors. The Ecology of Block Island. Kingston, Rhode Island, USA: The Rhode Island Natural History Survey. pp. 151-168.

53. Rimmer C, Faccio S, Lloyd-Evans T, Hagan, III J (2004) A comparison of constant-effort mist netting results at a coastal and inland New England site during migration. Stud Avian Biol 29: 123-134.

54. Able KP (1970) A radar study of the altitude of nocturnal passerine migration. Bird-Band 41: 282-290.

55. Kerlinger P, Moore FR (1989) Atmospheric structure and avian migration. In: Power DM, editor. Current Ornithology, Volume 6. New York, New York, USA: Plenum Press. pp. 109-142.

56. Dokter AM, Shamoun-Baranes J, Kemp MU, Tijm S, Holleman I (2013) High altitude bird migration at temperate latitudes: a synoptic perspective on wind assistance. PLoS ONE 8: e52300.

57. Bland JM, Altman DG (1995) Statistics notes: calculating correlation coefficients with repeated observations. Part 1--correlation within subjects. BMJ 310: 446-446.

58. Mizrahi D, Fogg R, Magarian T, Elia V, Hodgetts P, et al. (2010) Radar monitoring of bird and bat movement patterns on Block Island and its coastal waters. In: McCann J, 28 others, editors. Ocean Special Area Management Plan. Narragansett, Rhode Island, USA: University of Rhode Island, Vol. 2. p. Technical Report 11, Appendix K. Available: 
http://seagrant.gso.uri.edu/oceansamp/pdf/appendix/full_volume2_osamp.pdf. Accessed 1 June 2012.

59. Gauthreaux SA, Michi JE, Belser CG (2005) The temporal and spatial structure of the atmosphere and its influence on bird migration strategies. In: Greenberg R, Marra PP, editors. Birds of two worlds: the ecology and evolution of migration. Baltimore, Maryland, USA: The Johns Hopkins University Press. p. 488.

60. Geo-Marine, Inc. (2010) Ocean/wind power ecological baseline studies, Volume II: avian studies. Final report submited to the New Jersey Department of Environmental Protection. Plano, Texas, USA: Geo-Marine, Inc. 2109 p.

61. Parrish JD (1997) Patterns of frugivory and energetic condition in Nearctic landbirds during autumn migration. Condor 99: 681-697.

62. Smith SB, McPherson KH, Backer JM, Pierce BJ, Podlesak DW, et al. (2007) Fruit quality and consumption by songbirds during autumn migration. Wilson $\mathrm{J}$ Ornithol 119: 419-428.

63. Smith SB, McWilliams SR (2010) Patterns of fuel use and storage in migrating passerines in relation to fruit resources at autumn stopover sites. Auk 127: $108-118$.

64. Bolser JA, Alan RA, Smith AD, Li L, Seeram NP, et al. (2013) Birds select fruits with more anthocyanins and phenolic compounds during autumn migration. Wilson J Ornithol 125: 97-108.

65. Bingman VP (1980) Inland morning flight behavior of nocturnal passerine migrants in eastern New York. Auk 97: 465-472.

66. Hall G, Bell R (1981) The diurnal migration of passerines along and Appalachian ridge. Am Birds 35: 135-138.

67. Peckford ML, Taylor PD (2008) Within night correlations between radar and ground counts of migrating songbirds. J Field Ornithol 79: 207-214.

68. Graber RR (1968) Nocturnal migration in Illinois: different points of view. Wilson Bull 80: 36-71.

69. Evans WR (1994) Nocturnal flight call of Bicknell's Thrush. Wilson Bull 106: $55-61$.

70. Evans WR, Rosenberg KV (2000) Acoustic monitoring of night-migrating birds - a progress report. In: Bonney R, Pashley DN, Cooper RJ, Niles L, editors. Strategies for bird conservation: The Partners in Flight planning process; Proceedings of the 3rd Partners in Flight Workshop; 1995 October 1- 
5; Cape May, NJ. Proceedings RMRS-P-16. Ogden, UT: U.S. Department of Agriculture Forest Service, Rocky Mountain Research Station. pp. 151-159. 
Table 1. Operational summary of nocturnal flight call microphones at eight locations in southern Rhode Island, USA, during the 2010 - 2011 fall migrations.

\begin{tabular}{|c|c|c|c|c|c|c|c|c|c|}
\hline \multirow[b]{2}{*}{ Year } & & \multicolumn{3}{|l|}{ Mainland } & \multicolumn{5}{|c|}{ Block Island } \\
\hline & & Ninigret & Trustom & Sachuest & Kurz & Wash & Lapham & Pyne & Comings \\
\hline 2010 & Start night & - & - & 14 Sep & $8 \mathrm{Sep}$ & 11 Sep & 8 Sep & 9 Sep & 12 Sep \\
\hline & \# nights operated/recorded & - & - & $56 / 45^{1}$ & $62 / 52$ & $59 / 51$ & $62 / 24$ & $61 / 61$ & $58 / 58^{1}$ \\
\hline 2011 & Start night & 8 Sep & $8 \mathrm{Sep}$ & $8 \mathrm{Sep}$ & 9 Sep & 9 Sep & 9 Sep & - & 9 Sep \\
\hline & \# nights operated/recorded & $64 / 63$ & $64 / 58$ & $64 / 58$ & $63 / 57$ & $63 / 31$ & $63 / 51$ & - & $63 / 29$ \\
\hline
\end{tabular}

Discrepancies between the number of nights operated and number of nights recorded indicate that an equipment malfunction precluded recording. Monitoring ended on 8 November in 2010 and 10 November in 2011. 
Table 2. Classification of nocturnal flight calls (NFCs) of migrating warblers (Parulidae) and sparrows (Emberizidae) recorded in southern Rhode Island, USA, during autumn in 2010 and 2011.

\begin{tabular}{llll}
\multicolumn{2}{c}{ Classification } & \multicolumn{2}{c}{ Number of NFCs } \\
Group & Complex & 2010 & 2011 \\
Warbers & ZEEP & 2,424 & 14,712
\end{tabular}

$\begin{array}{llll} & \text { 1BUP } & 2,776 & 2,415 \\ & & & \\ \text { 1BDN } & 295 & 1,337 \\ & & \\ \text { NOPA } & 218 & 576 \\ \text { AMRE } & 282 & 394 \\ \text { COYE } & 119 & 421 \\ \text { 2BUP } & 112 & 383 \\ & & & \\ \text { BAWW } & 92 & 198 \\ \text { OVEN } & 95 & 137 \\ & \text { PAWA } & 96 & 134 \\ \text { BTBW } & 17 & 47 \\ \text { CSWA } & 20 & 41 \\ \text { NOWA } & 13 & 38 \\ \text { MOWA } & 17 & 18 \\ \text { Sparrows } & \text { CAWA } & 9 & 6 \\ & \text { WIWA } & 0 & 10 \\ & \text { SPAR } & 2,396 & 5,501\end{array}$

Dominant constituent species ${ }^{\mathrm{b}}$

Blackpoll Warbler, Northern Waterthrush, Common Yellowthroat*, Magnolia Warbler; minor: Bay-breasted Warbler, Yellow Warbler, Connecticut Warbler, Chestnut-sided Warbler*, Black-and-white Warbler, Cape May Warbler; rare: Hooded Warbler, Blackburnian Warbler, Worm-eating Warbler

Yellow-rumped Warbler*; minor: Ovenbird, American Redstart, Black-throated Blue Warbler; rare: Blue-winged Warbler, Golden-winged Warbler

Northern Parula, Palm Warbler*; minor: Cape May Warbler, Pine Warbler*; rare:

Prairie Warbler*

Northern Parula*

American Redstart

Common Yellowthroat*

Yellow-rumped Warbler*, Nashville Warbler, Tennessee Warbler; minor: Blackthroated Green Warbler, Mourning Warbler; rare: Orange-crowned Warbler Black-and-white Warbler

Ovenbird

Palm Warbler*

Black-throated Blue Warbler

Chestnut-sided Warbler*

Northern Waterthrush

Mourning Warbler

Canada Warbler

Wilson's Warbler

Chipping Sparrow, White-throated Sparrow, Song Sparrow, Savannah Sparrow; minor: Swamp Sparrow, Lincoln's Sparrow, White-crowned Sparrow; rare: Field Sparrow, 


$\begin{array}{llll} & & & \text { Vesper Sparrow, Grasshopper Sparrow } \\ \text { SAVS } & 716 & 3,111 & \text { Savannah Sparrow } \\ \text { WTSP } & 360 & 1,170 & \text { White-throated Sparrow } \\ \text { CHSP } & 351 & 760 & \text { Chipping Sparrow } \\ \text { LISW } & 34 & 220 & \text { Swamp Sparrow; also Lincoln's Sparrow } \\ \text { DEJU } & 94 & 128 & \text { Dark-eyed Junco } \\ \text { FISP } & 3 & 18 & \text { Field Sparrow } \\ \text { GRSP } & 1 & 13 & \text { Grasshopper Sparrow }\end{array}$

${ }^{a}$ Classification complexes comprised of species with similar call notes, based on and modified slightly from (Evans and O'Brien 2002): ZEEP - "zeep" complex plus warbler members of the "buzz calls" complex and Cape May Warbler; 1BUP - warbler species producing single-banded calls in the "short rising seep" complex; 1BDN - warblers producing single-banded calls in the "descending seep" complex, plus Cape May Warbler; 2BUP - warbler species producing double-banded calls in the "short rising seep" complex; SPAR - sparrow members of the "descending seep," "short rising seep," and "buzz calls" complexes, plus long single- or doublebanded sparrow calls (Chipping Sparrow, Song Sparrow, White-throated Sparrow, and Grasshopper Sparrow); LISW - sparrow members of the "buzz calls" complex

${ }^{\mathrm{b}}$ Scientific names: Warblers - American Redstart (Setophaga ruticilla), Bay-breasted Warbler (S. castanea), Black-and-white Warbler (Mniotilta varia), Blackburnian Warbler (S. fusca), Blackpoll Warbler (S. striata), Black-throated Blue Warbler (S. caerulescens), Black-throated Green Warbler (S. virens), Blue-winged Warbler (Vermivora cyanoptera), Canada Warbler (Cardellina 
canadensis), Cape May Warbler (S. tigrina), Chestnut-sided Warbler (S. pensylvanica), Common Yellowthroat (Geothlypis trichas), Connecticut Warbler (Oporornis agilis), Golden-winged Warbler (V. chrysoptera), Hooded Warbler (S. citrina), Magnolia Warbler (S. magnolia), Mourning Warbler (G. philadelphia), Nashville Warbler (Oreothlypis ruficapilla), Northern Parula (S. americana),

Northern Waterthrush (Parkesia noveboracensis), Orange-crowned Warbler (O. celata), Ovenbird (Seiurus aurocapilla), Palm Warbler (S. palmarum), Pine Warbler (S. pinus), Prairie Warbler (S. discolor), Tennessee Warbler (O. peregrina), Wilson's Warbler (C. pusilla), Worm-eating Warbler (Helmitheros vermivorum), Yellow Warbler (S. petechia), Yellow-rumped Warbler (S. coronata); Sparrows - Chipping Sparrow (Spizella passerina), Dark-eyed Junco (Junco hyemalis), Field Sparrow (Spizella pusilla), Grasshopper Sparrow (Ammodramus savannarum), Lincoln's Sparrow (Melospiza lincolnii), Savannah Sparrow (Passerculus sandwichensis), Song Sparrow (Melospiza melodia), Swamp Sparrow (M. georgiana), Vesper Sparrow (Pooecetes gramineus), White-crowned Sparrow (Zonotrichia leucophrys), and White-throated Sparrow (Z. albicollis)

Dominant constituent species are grouped according to their expected contribution based on general impression of authors (i.e., some calls left unidentified to species were suggestive of a given species), knowledge of occurrence and migratory phenology in the region, and 5,526 banding records of relevant species from approximately 8 September to 10 November from five fall migration banding operations in southern Rhode Island in 2010-2011 (A. D. Smith unpubl. data; USFWS unpubl. data; K. Gaffett and S. Reinert unpubl. data; P. W. C. Paton unpubl. data). Species listed first are presumed to be the most common contributors; species following 'minor' 
are presumed to make minor contributions; species following 'rare' are presumed rare contributors. Species marked with an asterisk possess flight calls that occur completely, or to a significant extent, below $6.5 \mathrm{kHz}$ (see text for details). 
Table 3. Relationships between nightly warbler and sparrow nocturnal flight call (NFC) detections and average regional nightly atmospheric or ambient noise conditions estimated via generalized additive models.

\begin{tabular}{llllllll}
\multicolumn{3}{c}{ Warblers } & \multicolumn{5}{c}{ Sparrows } \\
Variable & $\begin{array}{l}\text { Expected } \\
\text { association }\end{array}$ & Estimate (SE) & $t^{\mathrm{b}}$ & $P^{\mathrm{c}}$ & Estimate (SE) & $t^{\mathrm{b}}$ & $P^{\mathrm{c}}$ \\
Wind profit & + & $1.13(0.08)$ & 14.99 & $<0.001$ & $1.01(0.09)$ & 11.31 & $<0.001$ \\
Wind speed & - & $-0.91(0.09)$ & -10.24 & $<0.001$ & $-1.37(0.10)$ & -13.57 & $<0.001$ \\
Rain & - & $-0.37(0.09)$ & -4.08 & $<0.001$ & $-0.47(0.10)$ & -4.63 & $<0.001$ \\
Cloud cover & + & $0.40(0.08)$ & 4.77 & $<0.001$ & $0.24(0.09)$ & 2.78 & 0.006 \\
Visibility & - & $-0.19(0.07)$ & -2.66 & 0.008 & $0.00(0.08)$ & 0.03 & 0.97 \\
Noise & - & $-0.16(0.08)$ & -2.11 & 0.035 & $-0.07(0.08)$ & -0.81 & 0.42
\end{tabular}

a Input variables were centered and scaled; thus, exponentiation of parameter estimates provides the average change in NFC detections per standard deviation change of the input variable. Standard deviations of input variables: wind profit (1.91 m/s), wind speed $(1.53 \mathrm{~m} / \mathrm{s})$, rain $(22.57 \%)$, cloud cover (35.27\%), visibility (1.70 mi), noise (8.28 dB).

b 603 residual degrees of freedom

${ }^{c}$ Although the expected associations are one-directional, we report $P$ from the two-sided test to avoid missing large differences in the unexpected direction (Ruxton and Neuhäuser 2010) 
Figure 1. Microphone and weather station locations used to assess nocturnal flight call activity of migrating songbirds. Locations of microphones (circles) and National Weather Service ASOS stations (flags) used to examine the relationship between atmospheric conditions and the nocturnal flight call activity of migrating songbirds in southern Rhode Island (RI), USA, from September to November, 20102011. Microphone locations: N - Ninigret, T - Trustom, S - Sachuest, K - Kurz, W Wash, L - Lapham, P - Pyne, and C - Comings. ASOS stations: 1 - Providence/T. F. Green State Airport, 2 - Newport State Airport, 3 - Westerly State Airport, 4 - GrotonNew London Airport, and 5 - Montauk Airport. See text for more details.

Figure 2. Seasonal variation in warbler and sparrow nocturnal flight call rates. Seasonal variation in the number of nocturnal flight calls (NFCs) detected per active microphone for warblers (white fill) and sparrows (gray fill) during fall migration in (A) 2010 and (B) 2011 at eight coastal sites in southern Rhode Island, USA.

Figure 3. Geographic variation in the seasonal patterns of warbler and sparrow flight calls. Average seasonal pattern in warbler (solid line) and sparrow (dashed line) nocturnal flight call (NFC) detections during fall in 2010 and 2011 at eight coastal sites in southern Rhode Island, USA (see Figure 1): (A-B) two sites on the mainland coast, (C) one on Aquidneck Island, and (D-H) five on Block Island. Seasonal patterns were estimated with generalized additive models; the seasonal trend of the linear predictor (and 95\% confidence interval) is illustrated with other variables held at their mean value. All plots share the same vertical scale to facilitate comparisons of 
NFC detections among locations. Note that each unit change in the linear predictor represents nearly a tripling of NFC detections.

Figure 4. Intranight variation in warbler and sparrow nocturnal flight calls. Intranight variation in warbler (solid line) and sparrow (dashed line) nocturnal flight call (NFC) detections in 2010 and 2011 at (A) two coastal locations (sites N and T; see Figure 1) on mainland Rhode Island, (B) a single location on a nearshore island (site S), (C) three locations on northern Block Island (sites K, W, and L), and (D) two locations on southern Block Island (sites P and C). The horizontal axis uses a percentage scale to account for increasing night length throughout the study period, with 50\% corresponding to approximately $2330 \mathrm{~h}$ EST. The vertical axis (NFC density) is identical among panels to facilitate comparisons of NFC detections; actual density values are omitted for clarity.

Figure 5. Warbler and sparrow flight call relationships with atmospheric and ambient conditions. Changes in warbler (solid line) and sparrow (dashed line) nocturnal flight call (NFC) detections during the 2010 and 2011 fall migrations as a function of average regional atmospheric conditions (A-E) and ambient noise (F); associations were estimated with generalized additive models. We illustrate each variable's association (and 95\% confidence interval) with the linear predictor of NFC detections when all other variables are at their mean value; we excluded the intercept and site-specific effects from the linear predictor to facilitate the comparison of effect magnitudes among variables. Note that each unit change in the linear predictor 
represents nearly a tripling of NFC detections. Rug plots illustrate the distribution of the input variables 


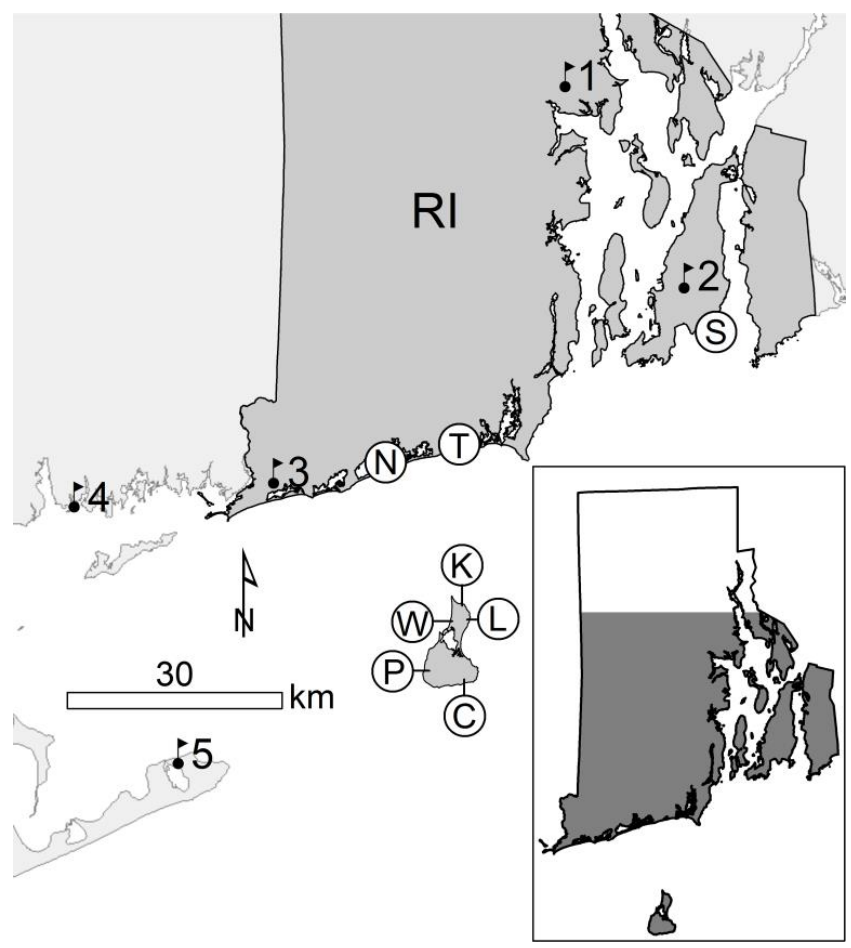

Figure 1. 


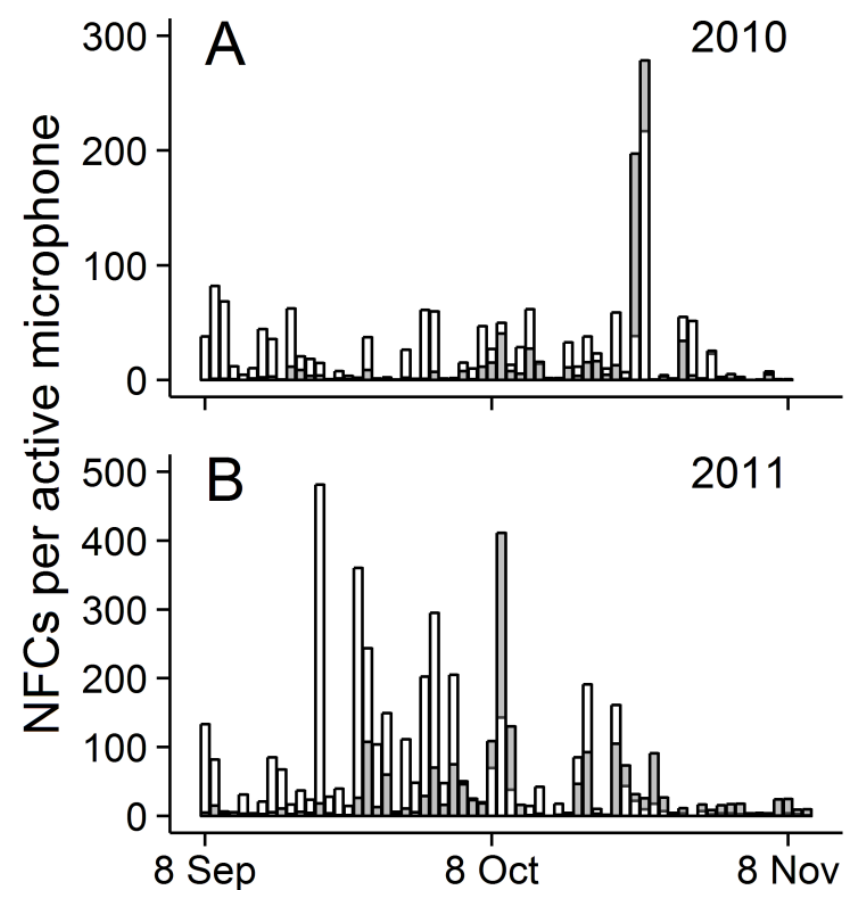

Figure 2. 

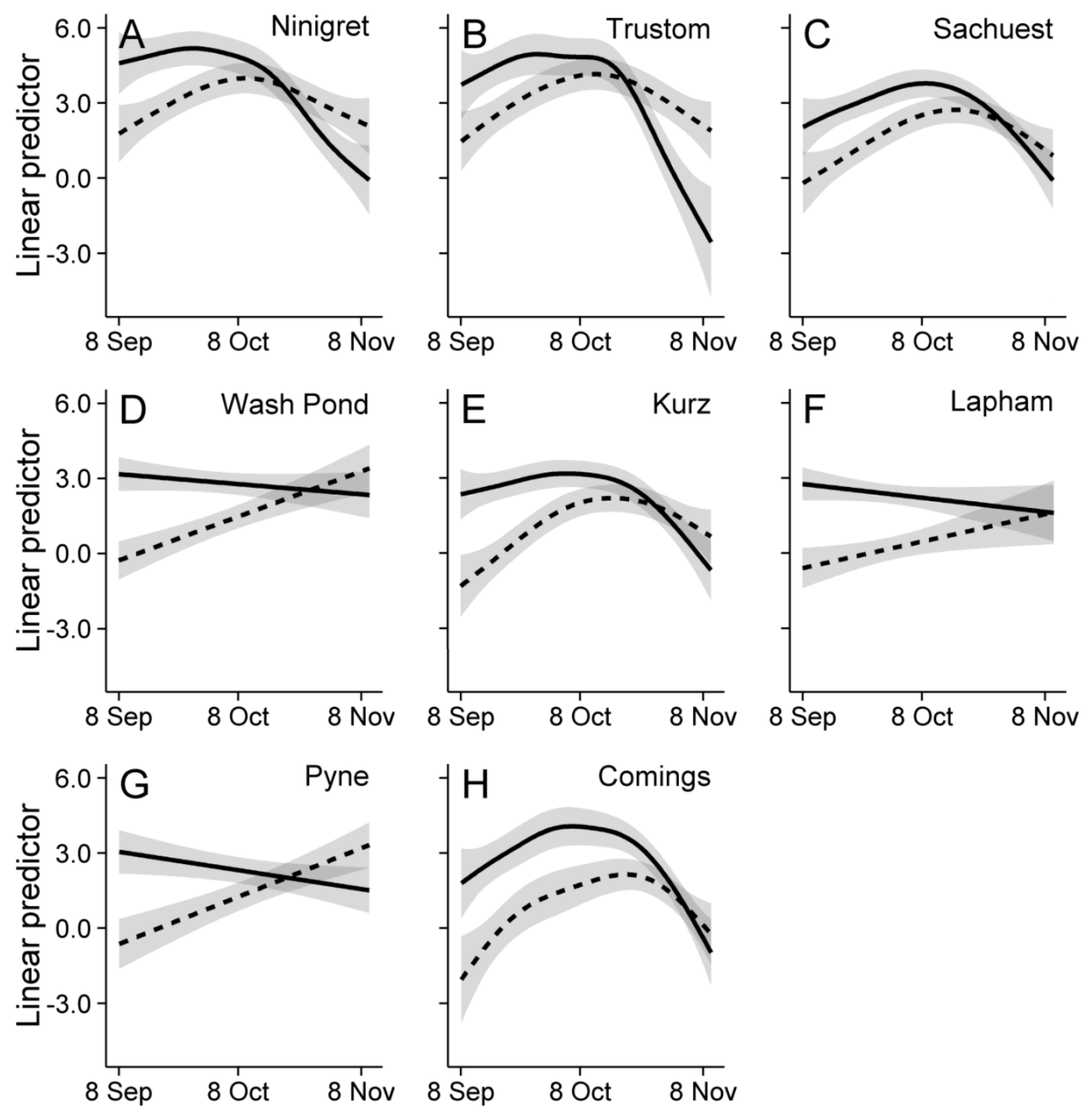

Figure 3. 


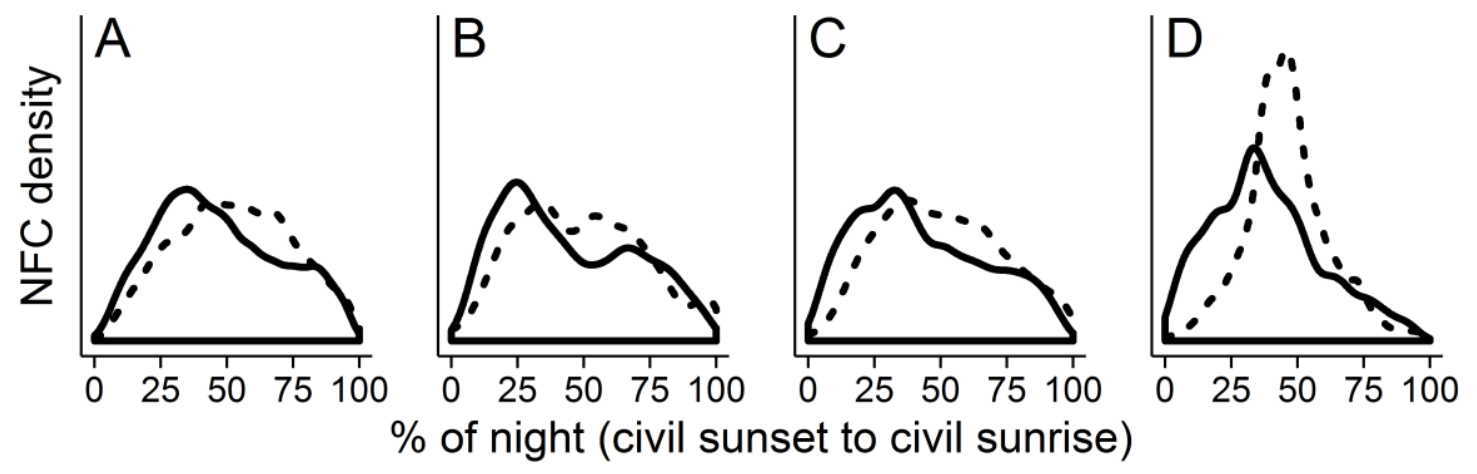

Figure 4 . 

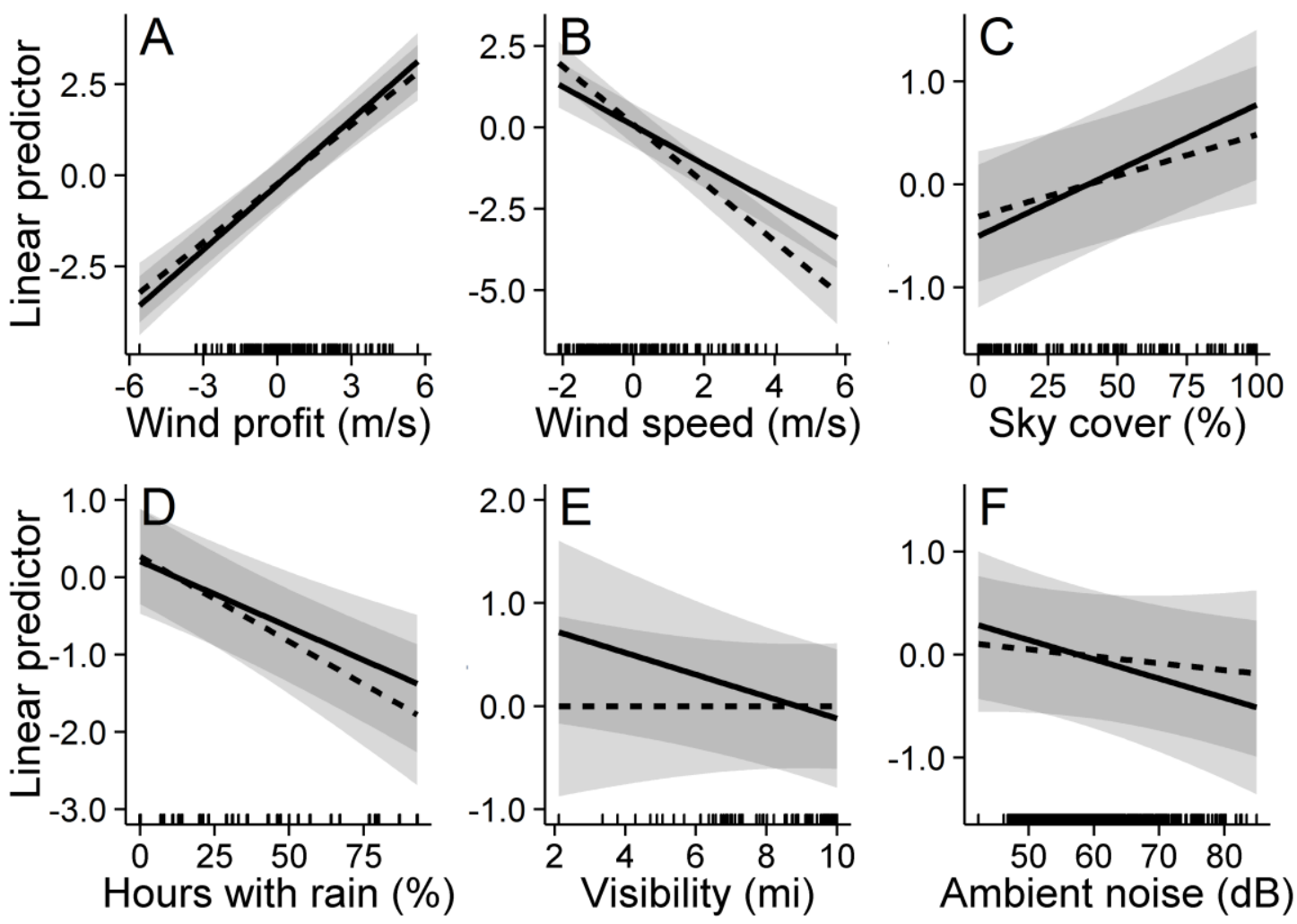

Figure 5. 


\section{CHAPTER 2}

"Autumn Coastal Bat Migration Relates to Atmospheric Condtions: a Regional Context for Near-shore and Off-shore Wind Energy Development"

by

Adam D. Smith ${ }^{1,2}$ and Scott R. McWilliams ${ }^{1}$

is submitted to Biological Conservation

${ }^{1}$ Department of Natural Resources Science, University of Rhode Island, 1 Greenhouse Road, Kingston, RI 02881, USA

${ }^{2}$ E-mail: adam.smith@my.uri.edu 


\begin{abstract}
The cryptic behavior of migrating bats leaves us largely uninformed of their seasonal distribution and abundance, important movement corridors, and migration behaviors. However, models of avian migration in relation to meteorological variables may prove useful in describing seasonal patterns of coastal bat activity and for assessing the risk of wind turbine-related bat fatalities in proposed nearshore and offshore sites. We pursued two primary objectives regarding regional migratory bat activity along the Atlantic Coast of southern New England, USA, inferred from continuous acoustic monitoring: (1) to evaluate hypotheses regarding the association of coastal bat activity with regional atmospheric conditions and thus the applicability of aspects of avian migration models to bats, and (2) to construct and evaluate models that predict forthcoming regional nightly bat activity based on accessible meteorological data. Acoustic bat activity was attributable primarily to long-distance migratory red and silver-haired bats but also the short-distance migrant tri-colored bat and sedentary big brown bat; myotids and hoary bat detections were relatively uncommon. Coastal bat activity varied with regional wind conditions indicative of cold front passage and expected to induce a more coastal flight path, but associations with other atmospheric conditions from models of songbird migration were typically weak; bat acoustic activity also associated with various aspects of temperature. Predictive models of regional nightly bat activity were reasonably accurate in anticipating nights of the highest and lowest bat activity, particularly for low frequency bats. These predictive models may provide a regional migratory bat activity context for future site-specific applications that, in turn, inform turbine operations and reduce adverse interactions and fatalities.
\end{abstract}

\title{
Key words
}

acoustic monitoring, bats, migration, New England, Rhode Island, weather, wind energy 


\section{Introduction}

As predators of flying insects, most North American bats occupying temperate and cold climates (sensu Peel et al. 2007) exhibit seasonal movements to avoid food scarcity and poor environmental conditions. The scale and termini of these movements vary among species and individuals. For example, bats may move tens to hundreds of kilometers to regional hibernacula or many hundreds of kilometers to warmer climates (Fleming and Eby 2003, Cryan 2011). Unlike most migratory songbirds which forage during the day and migrate at night, bats forage and migrate nocturnally, typically remaining inactive and inconspicuous during the day. These cryptic habits leave us almost completely uninformed of the details of their seasonal distribution and abundance, important movement corridors, and migration behaviors (Cryan 2003, Cryan and Barclay 2009). Nonetheless, migratory bats likely experience similar challenges and selection pressures to migrating birds, providing some justification for applying models of avian migration to bat migration (Larkin 2006, Holland 2007, McGuire and Guglielmo 2009, Willis et al. 2010). Certainly, regional similarities in patterns of bat activity during migration (Kerns et al. 2005, Lott 2008, Johnson et al. 2011b) and the consistent association between bat activity and cold front passage evoke the comparison to bird migration (Erickson and West 2002, Cryan and Brown 2007, Arnett et al. 2008, Johnson et al. 2011a, Weller and Baldwin 2012).

Migrating birds often converge along topographic leading lines (e.g., coastlines, mountain ridges, river valleys; Williamson 1962, Mueller and Berger 1967); similar patterns have been noted in bats (Barclay 1984, Timm 1989, Ahlén et al. 2009, Baerwald and Barclay 2009, Dzal et al. 2009, Furmankiewicz and Kucharska 2009, McGuire et al. 2012) and their potential insect prey (Drake and Farrow 1988, Pedgley 1990, Rydell et al. 2010). In the northeastern United States, the Atlantic Coast represents an obvious topographic barrier to and concentrator of animal movements. Indeed, many southbound avian migrants orient and concentrate along the Atlantic Coast and on offshore land masses under specific weather conditions (Drury and Keith 1962, Drury and Nisbet 1964, Richardson 1972). Additionally, numerous hatching year (juvenile) avian migrants are displaced to the coast and offshore (the so-called "coastal effect"; Ralph 1978) having failed to compensate for prevailing winds, a phenomenon that may likewise affect migrating juvenile bats (Holland 2007, Johnson et al. 2011a). Moreover, the long-distant migrants among North American bats - the so-called "tree bats", specifically eastern red bats (hereafter, red bats; Lasiurus borealis), hoary bats (Lasiurus cinereus), and silverhaired bats (Lasionycteris noctivagans) - possibly employ coastal navigation during fall migration (Cryan 2003, Johnson et al. 2011a, with anecdotal support reviewed in Cryan and Veilleux 2007). It remains unclear, however, whether the Atlantic Coast represents an important migratory corridor for bats (especially tree bats) and if its use by migratory bats depends strongly on atmospheric conditions (e.g., front passage, westerly winds, and the coastal effect), as it does for birds.

Understanding the seasonal use of the Atlantic Coast by migrating bats has direct conservation implications given that migration may figure prominently in wind turbine-related bat fatalities (Cryan 2003, Johnson 2005, Kunz et al. 2007b, Arnett et al. 2008, Cryan et al. 2012) and the expansion of wind energy into the nearshore and 
offshore environments of New England and the mid-Atlantic appears imminent (Mahan et al. 2010, U.S. Department of Energy 2011). Whether migratory activity per se causes turbine-related fatalities or simply concentrates bats in proximity to turbines (and other factors subsequently facilitate the bat-turbine interaction) warrants evaluation (Cryan and Barclay 2009), but bat activity clearly increases during the autumn migratory season and fatalities often correspond with bat activity (Johnson et al. 2004, Kunz et al. 2007a, Baerwald and Barclay 2011, Johnson et al. 2011b, Jain et al. 2011, Young et al. 2011, Weller and Baldwin 2012). Identifying periods of high bat activity and associated atmospheric and meteorological conditions can assist the development of predictive tools to guide the operation of wind turbines, perhaps preempting bat fatalities, and thus represents a potentially valuable conservation tool (Reynolds 2006, Horn et al. 2008, Loew et al. 2013). We pursued two primary objectives regarding regional bat activity along the Atlantic Coast of southern New England: first, to evaluate hypotheses regarding the association of regional atmospheric conditions with coastal bat activity and thus the applicability of aspects of avian migration models to bats, and second to construct and evaluate predictive models of regional nightly bat activity based on accessible meteorological data. We discuss the use of this model as a tool for informing mitigation strategies to reduce the potential risks to migrating bats at future near-shore and off-shore wind facilities.

\section{Methods}

\subsection{Study area and acoustic monitoring}

During fall 2010 - 2012, we recorded the nocturnal acoustic activity of bats at seven locations on the Rhode Island National Wildlife Refuge Complex in southern Rhode Island: Sachuest Point, Ninigret Pond, Watchaug Pond, two locations near Trustom Pond and two locations on Block Island (Fig. 1). The Sachuest Point location occurred at the interface of maritime shrubland and herbaceous old field (Enser and Lundgren 2006). The Ninigret Pond location occurred in mixed herbaceous and shrub old field, but within $25 \mathrm{~m}$ of a saltwater coastal lagoon and its thin $(15 \mathrm{~m})$ maritime shrub border. The Watchaug Pond location occurred along the shrubby interface of a large $\left(2.3 \mathrm{~km}^{2}\right)$ kettle pond and a small $\left(250-\mathrm{m}^{2}\right)$ lawn in the larger context of deciduous secondary forest. One Trustom Pond location occurred at the three-way interface of a small stand $\left(\sim 350 \mathrm{~m}^{2}\right)$ of mixed shrubs and second-growth trees, a freshwater coastal lagoon, and herbaceous old field (T; Fig. 1), whereas the second occurred along a tall mixed species grassland and pasture interface. The two Block Island locations occurred in dense maritime shrubland, although one (H; Fig. 1) was within $15 \mathrm{~m}$ from a coastal wetland invaded heavily by common reed (Phragmites australis).

At each location, we recorded bat activity (i.e., number of bat passes; see below) with an ultrasonic microphone (SMX-US; Wildlife Acoustics, Inc., Concord, MA) attached to a passive full-spectrum ultrasonic recorder (SM2BAT, 192 or 384 kHz sampling rate; Wildlife Acoustics, Inc., Concord, MA). We installed each microphone at a specific site that allowed us to sample above the canopy with limited obstructions within $50 \mathrm{~m}$ of the microphone and where we expected foraging bat 
activity (e.g., near water or the interface of multiple habitats). We mounted each microphone horizontally on U-channel posts approximately $5-5.5 \mathrm{~m}$ above ground level, oriented northward, and above the canopy of prevailing vegetation. We recorded from evening civil twilight to morning civil twilight (i.e., sun elevation approximately $6^{\circ}$ below the horizon), from 8 September to 31 October in 2010 and 2011 and from 2 August to 31 October in 2012. Coverage was not complete during these periods due to equipment malfunctions and poor weather, nor did we record at all sites in each year (Table 1). We changed our ultrasonic recorder settings during the study according to the manufacturer's suggestions. In 2010, we recorded at maximum gain $(+60 \mathrm{~dB})$ and the recorder logged potential bat passes when a signal exceeded by $6 \mathrm{~dB}$ the $0.5 \mathrm{~s}$ rolling average power spectrum in the target frequency band; recording ceased when no trigger was detected for 1 s. In 2011 and 2012, we recorded at a slightly reduced gain setting $(+48 \mathrm{~dB})$ and the recorder logged potential bat passes when a signal exceeded by $18 \mathrm{~dB}$ the $0.5 \mathrm{~s}$ rolling average power spectrum in the frequency band; recording ceased when no trigger was detected for $2 \mathrm{~s}$. The sensitivity and detection range of microphones varies with call frequency, but based on controlled tests using lower gain settings (+ $36 \mathrm{~dB}$; Adams et al. 2012) we expect that our microphones sampled high- and low-frequency bats within a threedimensional airspace of ca. $30 \mathrm{~m}$ and $50 \mathrm{~m}$ radius around the microphone, respectively, although sampling efficiency likely decreased with distance from the microphone.

We decompressed recorded audio using the freely available WAC2WAV software (Version 3.2.7; Wildlife Acoustics, Inc., Concord, MA). We directed the software to create separate files ('Split Trigger' option) for each distinct ultrasonic event, to adjust the SMX-US microphone frequency response ('SMX-US Comp' filter), and to remove files containing only noise ('Skip Noise'). Recorded files were truncated to a maximum length of $8 \mathrm{~s}$, the longest file the classification software could process (see below). We defined bat passes as $\geq 2$ call pulses of at least 2 ms duration or a single call pulse of at least $5 \mathrm{~ms}$ (Weller and Baldwin 2012) in each file. We considered each file to have only one pass of a given species (i.e., we did not distinguish possible multiple individuals of the same species). Occasionally, multiple species were recorded in a single file, in which case a single pass was counted for each of the represented species or frequency groups (see below).

\subsection{Bat Classification}

Nine bat species inhabit or potentially migrate through Rhode Island in autumn; most make at least regional movements from or through the state (Table 2). The three species of tree bats are long distance migrants (red, hoary, and silver-haired bats). Tri-colored bats (Perimyotis subflavus) make shorter regional movements (Fujita and Kunz 1984, Fleming and Eby 2003), and some individuals may also engage in more extensive seasonal movements (sensu tree bats; Fraser et al. 2012). Four myotids - the little brown myotis (M. lucifugus), northern myotis ( $M$. septentrionalis), eastern small-footed myotis (M. leibii), and Indiana bat (M. sodalis) also make shorter, regional movements from maternity colonies to hibernacula (e.g., Davis and Hitchcock 1965, Kurta and Murray 2002). Big brown bats (Eptesicus 
fuscus) are the most sedentary, rarely moving more than $80 \mathrm{~km}$ between summer colonies and winter hibernacula (Beer 1955, Mills et al. 1975, Neubaum et al. 2006). Migratory phenology in the region is poorly understood, but is estimated to occur primarily in August - October in migratory tree bats and July - September in shortdistance hibernators (Table 2).

We used the commercially available sound analysis software SonoBat ${ }^{\mathrm{TM}}$ (Version 3.02, NNE suite; SonoBat, Arcata, CA) to classify recorded bat passes. SonoBat classifies bat passes using hierarchical decision algorithms (Parsons and Szewczak 2009, Redgwell et al. 2009) and returns a single species identification if the discriminant probability exceeds a user-defined threshold at each step in the decision hierarchy; the discriminant probability indicates how closely the data approach the centroid of the multivariate decision space of a species and not the probability of a correct identification. We used all recorded bat passes in our analyses (see below), but we report the species classification only of those bat passes comprising at least two call pulses (median $=4$, range 2 - 12) that met the software's default quality threshold (0.80) and achieved a 0.90 consensus discriminant probability. In general, pulses meeting the quality threshold were easily distinguished from noise, contained useful time-frequency and time-amplitude information, and in many cases the presence of harmonics indicated relatively close proximity to the microphone (see, e.g., Szewczak 2004). We visually inspected classified calls to affirm software classifications. Due to acoustic similarities among Myotis species we placed all myotids into a collective species group. We categorized all non-classified bat passes according to the characteristic frequency of their vocalizations (Table 2). Six species (i.e., red bat, tri-colored bat, and the four myotids) typically emit high frequency ultrasonic calls $>35 \mathrm{kHz}$ and three species (i.e., silver-haired bat, hoary bat, and big brown bat) give low frequency ultrasonic $<35 \mathrm{kHz}$.

\subsection{Regional atmospheric conditions}

We herein evaluate whether regional atmospheric conditions influence temporal variation in bat activity along the Atlantic Coast in a manner consistent with bird migration. Our two primary objectives evaluated similar atmospheric conditions (Table 3), although on different time frames (see below). We derived atmospheric conditions based primarily on weather data from observations at five National Weather Service Automated Surface Observing System (ASOS) stations occurring within $50 \mathrm{~km}$ of the centroid of microphone locations (Fig. 1). ASOS stations report weather conditions within $10 \mathrm{~m}$ of ground level (i.e., similar to microphone height). We used ASOS data reported every minute and derived from data accumulations over the previous 1 or 2 minutes (1-min ASOS), although visibility data were reported every 5 minutes (5-min ASOS). ASOS data were collected The 1-min and 5-min ASOS data is available freely through the National Climatic Data Center. Rarely, we supplemented missing ASOS data with approximately hourly Quality Controlled Local Climatological Data from the same 5 stations. Additionally, we obtained daily maximum temperature data from a single station (Providence, Rhode Island; KPVD; 725070); we used this data to evaluate whether the high temperature for a given day was warmer or cooler than the 30-year (1982-2012) daily average high temperature. 
All data are archived and available from the National Climatic Data Center (Appendix A, Table A1).

We calculated nightly averages for weather variables from evening civil twilight to morning civil twilight, thus encompassing the period of active monitoring (Table 3). For average nightly temperature, relative humidity, and atmospheric pressure, we additionally calculated their increment from the previous night. We also calculated the proportion of hours during a given night with at least one ASOS station reporting precipitation. Finally, we calculated the deviation of the daily high temperature from the 30-yr average high temperature.

Our attempt to anticipate regional nightly bat activity ahead of its occurrence required the use of atmospheric conditions prior to, or very early into, the night of interest. Thus, we calculated the regional average of pertinent weather variables from single observations reported approximately 30 minutes prior to sunset at each station. Finally, we incorporated weather surveillance (NEXRAD) radar data, which can provide information on the presence and magnitude of migratory animal activity in the atmosphere (Gauthreaux and Belser 1998). We collected NEXRAD Level II base reflectivity (230 $\mathrm{km}$ range, $0.5^{\circ}$ elevation) images from Boston, Massachusetts (KBOX) via the HDSS Access System (Table A1). We selected radar scans approximately 1 hour after sunset, at which time nocturnal migration should be well underway (Gauthreaux 1971). We excluded radar data more than $150 \mathrm{~km}$ from the radar; beyond this distance the radar beam scans above the altitude at which most animals are likely to be flying (Ruth et al. 2008). When no precipitation was present with $150 \mathrm{~km}$ of the radar, we filtered radar reflectivity factors (dBZ) values above 32.5 $\mathrm{dBZ}$, which is near the maximum value expected for flying animals (Gauthreaux and Belser 1998, Gauthreaux et al. 2008); we did not filter reflectivity factors in the presence of precipitation. We converted reflectivity factors into linear units $(\mathrm{Z})$ to better quantify aerial bioscatter (Chilson et al. 2012); we used the sum of these converted factors within $150 \mathrm{~km}$ of the radar as our final reflectivity value. Additional details of weather and radar data acquisition and manipulation are provided in Appendix A.

\subsection{Analysis}

We used generalized additive mixed models (GAMMs; Wood 2006, Zuur et al. 2009) to explore the association between regional atmospheric conditions on migratory bat activity (i.e., aggregated bat passes; see below). GAMMs accommodate potential nonlinear changes in bat activity with predictor variables (e.g., over time) while allowing us to incorporate random effects and serial correlation (Wood 2006); we implemented them using the gamm function of the mgcv package (version 1.7-22, CRAN.R-project.org/package $=$ mgcv, accessed 20 Nov 2012). We used negative binomial GAMMs to accommodate overdispersion in bat activity. The gamm function requires an a priori estimate for the negative binomial dispersion parameter; we estimated this parameter for each GAMM by fitting a similarly-structured generalized linear mixed model (GLMM) with the glmmADMB package (version 0.7.3, glmmadmb.r-forge.r-project.org, accessed 20 Nov 2012) which could not, however, accommodate serial autocorrelation. 
We evaluated potential bias in the association between atmospheric conditions and bat activity due to incomplete sampling or the delayed start of monitoring in 2010 and 2011, as well as potential bias from our use of penalized quasi-likelihood (PQL) to estimate generalized linear mixed models and GAMMs (Bolker et al. 2009). We simulated 1,000 complete data sets (i.e., from 2 Aug to 31 Oct of each year at all stations) and then filtered each data set to match the sampling structure of our data. This evaluation revealed essentially no bias in the estimated associations between atmospheric conditions and bat activity.

We approached the GAMMs for each objective differently, given their intended purpose and the model selection constraints imposed by PQL, which precludes standard likelihood-based approaches to model selection (e.g., Akaike's Information Criterion). To improve estimation and facilitate the assessment of the relative importance of atmospheric conditions to bat activity, we centered and scaled by one standard deviation all continuous model input variables (Gelman 2008, Schielzeth 2010). We also recoded (to -1/1) and then centered binary indicator variables to correspond to scaled continuous variables with the exception of the categorical year variable, which we included as a random effect (see below). We included a binary indicator to capture the change in detector settings after 2010.

We evaluated hypotheses regarding the association between bat activity and atmospheric conditions using nightly averaged variables; day of year, daily temperature deviation from normal, and the proportion of the night with precipitation were the exceptions (Table 3 ). We omitted temperature and relative humidity due to collinearity (i.e., variance inflation factors $>3$ ). We allowed for potential nonlinear seasonal (i.e., day of year) effects using the default thin plate regression spline. We evaluated interactions only between the linear specification of day of year and two temperature variables. Specifically, we anticipated that bat activity might respond more strongly to temperature departures from normal and changes in nightly temperature (relative to the previous night) later in the season (Table 3 ). We also expected variation in bat activity among sites and years due, for example, to habitat or topographical differences (Johnson et al. 2011a) and the vagaries of animal migration, respectively. As we were trying to generalize to patterns of regional bat activity, we included year as a random effect. Despite only three levels, we did not experience any difficulties in the estimation of random effect variances.

We evaluated associations between average nightly regional atmospheric conditions and aggregated regional bat activity (i.e., we summed the number of bat passes across active microphones for each night of monitoring). We used only those nights with at least three operational microphones (162 of 197 nights) and included an offset term in the GAMMs for the number of active microphones on a given night. We estimated GAMMs separately for high- and low-frequency bats to allow for potential differences between activity and atmospheric conditions; recall that all highfrequency bats were expected to move on at least a regional scale, whereas the lowfrequency bats included long-distance migrants and a sedentary species. We found a first-order autoregressive error structure satisfactory based on exploratory analysis of serial correlation in residuals. We grouped the correlation structure within the random effect to expedite estimation (Wood 2006). To avoid biased parameter estimates and 
standard errors when evaluating hypotheses, we did not eliminate any terms from the models (Harrell 2001).

We predicted regional nightly bat activity prior to its occurrence using atmospheric conditions obtained about 30 min prior to sunset; again, day of year and daily temperature deviation were exceptions, along with radar-related variables (i.e., linear reflectivity and the presence of regional precipitation). We again constructed GAMMs separately for bats in high and low characteristic frequencies. We evaluated in turn each variable with a shrinkage-penalized spline while specifying all other variables in parametric form, as model complexity precluded the simultaneous fitting of multiple splines. We considered the interactions between temperature variables (i.e., deviation from normal and temperature increment) and the day of year spline; this allowed the coefficients for the temperature variables to vary smoothly throughout the season. We also allowed separate smooths for radar reflectivity depending on the presence or absence of precipitation within $150 \mathrm{~km}$ of the radar. We used and estimated the autoregressive error structure as in the nightly models (see above). We excluded from the final models all variables with splines resulting in zero effective degrees of freedom. Penalized splines suggested linear specifications for all retained variables, reducing the GAMMs to GLMMs with serially correlated errors.

We evaluated the predictive ability of the GLMMs using cross-validation. We sequentially omitted data from a single night, refit the model, and compared the predicted bat activity on the omitted night to actual bat activity. To facilitate the evaluation of the predictive success of the GLMMs, we categorized at their quartiles the continuous predictions of bat pass rate from each model; this generated four ordered classes of predicted bat activity, containing roughly equal numbers of observations, to compare with the corresponding classes of observed pass rates. For simplicity, we refer to the activity classes (with their associated percentiles) as follows: low ( $\leq 25 \%)$, low-medium (26-50\%), medium-high $(51-75 \%)$, and high (> $75 \%)$. We managed and processed atmospheric and bat pass data and conducted all statistical analyses in R (R Version 2.15.2, www.r-project.org, accessed 12 Nov 2012; see Appendix A).

\section{Results}

\subsection{Acoustic summary}

We recorded 47611 bat passes during the 775 detector nights of the three autumns of this study. Although 15368 passes (32.2\% of all passes) contained at least two pulses of sufficient quality to facilitate classification to species, SonoBat reached a consensus classification on only 8005 (16.8\% of all passes). Most classified passes were consistent with migratory tree bats (Table 2), in particular red and silver-haired bats; hoary bats were detected relatively infrequently. We also detected significant acoustic activity from sedentary big brown bats and short-distance migrant tri-colored bats. We recorded myotids (mostly little brown myotis; A. Smith, unpublished data) infrequently (Table 2). Bat passes classified with high confidence suggest seasonal differences in the activity of certain species (Fig. 2). For example, big brown bat and tri-colored bat acoustic activity was highest prior to September, 
after which silver-haired bat acoustic activity increased. We detected most red bat activity prior to the middle of September, but it was present to some extent throughout the season (Fig. 2). Relaxing the quality (0.70) and consensus discriminant probability (from 0.90 to 0.75 ) thresholds required for classification increased the number of classified calls (from $16.8 \%$ to $20.3 \%$ of all passes) and the estimated contribution of red bats, hoary bats and myotids (ca. 14\%, on average) to the acoustic data, but did not substantively change the seasonal phenology (A. Smith, unpublished data).

\subsection{Nightly bat activity and concurrent regional atmospheric conditions}

High and low frequency bat models indicated some degree of support for most of the expected associations between bat activity and atmospheric conditions (Table 3 ), although the magnitude of this support varied (Table 4). Exponentiation of model parameter estimates (Table 4) provides an average change in bat activity for each standard deviation change in the input variable, but we present average changes in bat activity on a per unit change in the input variable to facilitate interpretation. High and low frequency bat activity exhibited similar associations with atmospheric conditions, although the associations were typically much stronger in low frequency bats (Figures 3 and 4). Bat activity declined approximately $2-3 \%$ per day over the course of the season (Figures 3A and 4A); in high frequency bats, this decrease was most pronounced after 1 October (Fig. 3A). Wind profit exhibited the strongest association with bat activity among atmospheric conditions; high and low frequency bat activity varied positively by approximately $18 \%$ and $45 \%$ for each $\mathrm{m} / \mathrm{s}$ change, respectively (Figures $3 \mathrm{~B}$ and 4B, Table 4). The relative change in average nightly temperature from the prior night varied positively with bat activity (Figures $3 \mathrm{C}$ and $4 \mathrm{C}$ ). Each ${ }^{\circ} \mathrm{C}$ change associated with an approximately $6 \%$ and $13 \%$ change in high and low frequency bat activity, respectively. Separately from night to night temperature changes, bat activity also associated positively with increasing temperatures relative to normal, changing about $5 \%$ and $10 \%$ per ${ }^{\circ} \mathrm{C}$ in high and low frequency bat activity (Figures 3E and 4D). This association changed strongly in low frequency bats over the course of the season, with below average temperatures suppressing activity more strongly as the season progressed (Fig. 4E). High frequency bat activity also varied positively with pressure changes from the prior night (about 3\% per mb; Fig. 3D), but this effect was only weakly apparent in low frequency bats (Table 4).

Despite strong relationships with wind profit and temperature-related variables, the high and low frequency models had some difficulty accounting for relatively high bat activity. Specifically, all considerable deviations from the model fit (i.e., |normalized residuals $\mid>3$ ) were underestimations of bat activity on nights of relatively high bat activity. Both deviations in the high frequency GAMM occurred on nights with bat activity above the $95 \%$ percentile. A similar pattern was evident in the low frequency GLMM, as two of three deviations occurred on nights with bat activity above the $95 \%$ percentile and the third on a night with activity above the $85 \%$ percentile. The models did not share any nights with poorly fit observations.

\subsection{Predicting regional nightly bat activity}


Five input variables and one interaction were retained in the high and low frequency pre-sunset GAMMs, although not all were identified as important in the final GLMMs (Figures 5 and 6, Table 5). High and low frequency bat activity exhibited similar associations with atmospheric conditions, although as with nightly atmospheric conditions, the associations were typically much stronger in low frequency bats. Expected bat activity declined approximately 2-3\% per day over the course of the season (Figures 5A and 6A). Wind profit varied positively with forthcoming regional bat activity (Figures $5 \mathrm{C}$ and $6 \mathrm{~B}$ ), with expected high and low frequency bat activity changing $9 \%$ and $16 \%$ per $\mathrm{m} / \mathrm{s}$, respectively. Pre-sunset temperature change in the previous $24 \mathrm{~h}$ associated positively with approaching low frequency bat activity ( $9 \%$ change in activity per ${ }^{\circ} \mathrm{C}$; Fig. $6 \mathrm{C}$ ). Changes in atmospheric pressure in the 6 hours prior to sunset associated positively with upcoming high frequency bat activity (11\% change in activity per mb; Fig. 5B). Increasing temperatures relative to normal associated positively with low frequency bat activity (7\% change in activity per ${ }^{\circ} \mathrm{C}$; Fig. 6D), although its influence changed as the season progressed for all bats, with below average temperatures suppressing activity more strongly as the season progressed (Figures 5D and 6E); given the centered input variables, it was appropriate to interpret this interaction in the high frequency model independently of the main (and weakly positive; Table 5) effect of temperatures relative to normal. Visibility just prior to sunset related modestly to forthcoming low frequency bat activity (11\% change in activity per mi of visibility; Fig. 6F); given typically good visibility, this effect likely reflected inclement conditions at low visibilities.

GLMMs performed best when anticipating the extremes of relative bat activity and, in general, predictions from the low frequency bat model were more accurate (Fig. 7). Using low frequency bats as an example, when the GLMM predicted the highest bat activity class for a given night, activity occurred in the highest class about $65 \%$ of the time and in the highest two activity classes about $90 \%$ of the time. Similar levels of accuracy occurred when anticipating the nights of lowest bat activity. Predictions for the middle classes of high frequency bat activity were marginally better than random, although predictions favored the correct end of the activity spectrum.

\section{Discussion}

We monitored the acoustic activity of bats along the Atlantic Coast of southern New England during their presumed autumn migratory period. Most detected bat activity was attributable to long-distance migratory tree bats, with significant contributions from sedentary big brown bats and short-distance migrant tri-colored bats. High and, in particular, low frequency bat activity varied with regional atmospheric conditions expected to induce a more coastal flight path and exhibited various associations with temperature. Bat activity associated with other atmospheric conditions in general agreement with expectations based on models of songbird migration or previous work with bats, although these associations typically were weak. Predictive models of regional nightly bat activity based on pre-sunset meteorological data reasonably anticipated nights of the high and low bat activity. 
4.1. Patterns of bat migration along the northeastern Atlantic Coast of North America: migration flyway?

Evaluating the importance of the northeastern Atlantic Coast as a concentrator of and flyway for migrating bats is complicated. While we necessarily assume the number of bat passes and associated pass rates correlate with abundance, the strength of this correlation is uncertain and likely variably. As such, acoustic activity is most appropriately considered an index of absolute bat activity (Miller 2001). Furthermore, differences among ultrasonic detectors (Adams et al. 2012), monitoring context (Cryan and Barclay 2009), and analysis methods (e.g., bat pass definition, filtering, manual vs. automatic classification; Britzke et al. 2013) complicate comparisons with activity levels in other acoustic studies in the eastern United States (e.g., Arnett et al. 2006, 2007; Hein et al. 2011; Johnson et al. 2011a; Johnson et al. 2011b; Young et al. 2011). We nonetheless suggest that the northeastern Atlantic Coast is an important route for migrating bats based on two primary lines of evidence: (1) we detected considerable acoustic activity at locations generally lacking suitable roosting habitat within $1-2 \mathrm{~km}$, and (2) there was a tendency for bat activity to vary with certain atmospheric conditions that concentrate migrating songbirds along the northeastern Atlantic Coast. Long-term, cross-seasonal acoustic monitoring of bats in coastal as well as inland sites would further clarify the relative importance of certain areas for migrating bats, and whether bats like birds are more concentrated along ecological barriers such as the Atlantic Ocean.

\subsection{Classification and species composition of bat acoustic activity}

Despite the relatively low classification rate, classified bat passes accurately characterized the composition of unclassified calls assuming two conditions were fulfilled: (1) the classification software correctly (and with equal probability) classified quality calls for all species and (2) bat species produced similar proportions of high quality calls. For the species encountered in this study, SonoBat classifies quality sequences with similar success (see the classification assessment in the SonoBat documentation). However, some species or species groups may produce a higher proportion of unusable, fragmented sequences (Barclay 1999). Indeed, the same assessment of high quality reference calls suggests that red bat and, to a lesser extent, myotid call sequences are more likely to be of insufficient quality for automated identification compared to other northeastern species (see footnote 5 in Table 2). Thus, red bats and myotids were likely underrepresented in the unidentified calls (see, e.g., the last column of Table 2), a notion corroborated by the increased frequency of these species in the acoustic data when we relaxed SonoBat's quality and classification thresholds. Finally, while low frequency bats tend to be detected more frequently with increasing detector height (Arnett et al. 2006, 2007, Weller and Baldwin 2012), this tendency is not ubiquitous and is much less pronounced or absent in open or shrubby habitats (Arnett et al. 2006, Redell et al. 2006, Baerwald and Barclay 2009, Hein et al. 2011, but see Weller and Baldwin 2012). We thus suggest 
our microphones sampled low frequency and high frequency bats with equal effectiveness.

\subsection{Bat activity and atmospheric conditions}

Temperature is perhaps the foremost modifier of bat activity and this study proved no exception. The influence of temperature on bat activity is often mediated by changes in prey availability (Taylor 1963, Taylor and O'Neill 1988, Hickey and Fenton 1996). Indeed, the expected and steady seasonal decrease in bat activity from August through October likely reflects the general pattern of decreasing temperatures (with which day of year was very strongly correlated) and related changes in prey availability. But additional variables captured context (departure from normal temperature) or dynamic (24-hr temperature increment) aspects of temperature on a nightly basis and, perhaps with them, the relative likelihood of encountering insect prey. For instance, departures from normal temperature mattered little early in the season when average nightly temperatures remained relatively warm (i.e., always above $15^{\circ} \mathrm{C}$ ), but later in the season, particularly late in September and through October, below average temperatures increasingly inhibited bat activity. However, none of these temperature variables implies that bat activity was due necessarily to migratory activity, unless the decision to migrate is based in part on the ability to forage concurrently with migration (e.g., Šuba et al. 2012, Voigt et al. 2012).

The strong positive association between bat activity and wind profit suggests, however, that actively migrating individuals represent an important component of our bat activity data. We formulated wind profit in this study to give positive values for wind directions (approximately WSW to NNE) that (1) indicated the recent passage of cold fronts, (2) forced a more coastal migratory course, or (3) possibly induced the coastal effect (Ralph 1978) in migrating bats. The first condition is valid by our definition of wind profit given typical wind conditions behind cold fronts in the northeast (e.g., Richardson 1990), although we could not evaluate the applicability of the second or third conditions in this study. Note however that positive wind profit values are not a necessary condition for significant migratory activity along the Atlantic Coast. For example, northeast and east winds also provide favorable tailwinds to migrating songbirds (and presumably bats; Richardson 1990), but we expect they diminish the concentrating influence of the Atlantic Coast on migrant activity. We consider it appropriate, then, that these wind conditions produced mostly negative wind profits by our definition given the stated purpose of evaluating the conditions associated with coastal migratory activity.

The absence of an association between bat activity and wind speed in this study contrasts notably with the nearly universal negative association between wind speed and migrating bat activity reported elsewhere (Fiedler 2004, Arnett et al. 2006, Redell et al. 2006, Reynolds 2006, Horn et al. 2008, Baerwald and Barclay 2011, Weller and Baldwin 2012). This discrepancy may relate to our use of regional rather than site-specific wind speed measurements, although regional nightly average wind speeds correlated strongly with the corresponding nightly measurements near the two Block Island microphones ( $R=0.86, n=102$; A. Smith, unpublished data). Given the low canopy of our sites, we used wind speeds measured at approximately $10 \mathrm{~m}$ above 
ground level (AGL), resulting in consistently slower average nightly wind speeds that than those measured $30-50 \mathrm{~m}$ AGL in other studies. Negative associations between bat activity and wind speed seem disproportionately influenced by high average wind speeds ( $\geq 6 \mathrm{~m} / \mathrm{s}$ ), which represented ca. $4 \%$ of nights in our study (compared to $20 \%$ to over $50 \%$ in other studies). Thus, we perhaps monitored activity at heights and wind speeds below which the influence on bat behavior was reduced.

Low frequency bats associated strongly with wind profit despite the considerable presence of presumably local, non-migratory big brown bats (Table 2). But the observed sharp seasonal decrease in big brown bat abundance and their relative absence after the middle of September (Fig. 2B) contrasts sharply with their more consistent acoustic presence throughout autumn farther south along the Atlantic Coast (Johnson et al. 2011a). Technical issues seem unlikely as we can think of no reason why big brown bat calls would become more difficult to classify as the season progressed, or represent systematically misidentified silver-haired bats early in the season. Nor do we expect many big brown bats were entering hibernacula in early September (Kurta and Baker 1990); average nightly temperatures in September remained well above freezing $\left(17.7 \pm 3.1^{\circ} \mathrm{C}\right)$. Rather, we offer three non-mutually exclusive speculations: we documented (1) a seasonal shift in habitat use away from coastal habitats, (2) use of coastal habitats by newly-independent juveniles, or (3) transients moving from summer roosts to regional winter hibernacula. Only the systematic misidentification of silver-haired bats and the presence of transient big brown bats suggest the possibility of a strong association with wind profit. Transient big brown bats is conceivable, as the sedentary life of big brown bats may be a relatively recent adaptation to human-influence environments (Mills et al. 1975).

\subsection{Predictive models of bat activity}

Wind profit and temperature (including its seasonality, context, and dynamics) best predicted forthcoming bat activity, particularly for low frequency bats; this is not surprising given their importance in the nightly activity models and the strong autocorrelation of atmospheric conditions on short time scales. High-frequency bats apparently responded to short-term $(6 \mathrm{hr})$ changes in atmospheric pressure as well. Rising pressure typically indicates the recent passage of a cold front and increasingly favorable weather for flying (Richardson 1990). Its lack of importance in the nightly models may have to do with the change in increment; we switched from a $24 \mathrm{hr}$ increment to a $6 \mathrm{hr}$ increment to better capture short-term pressure trends associated with passing cold fronts (Richardson 1990). That radar reflectivity was not associated with bat activity was disappointing, but perhaps not surprising. Reflectivity must be used with radial velocity and wind conditions to distinguish vertebrate from invertebrate activity (Gauthreaux and Belser 1998, Buler and Diehl 2009); radar contamination (e.g., anomalous propagation, sea breeze clutter) must also be considered (Buler and Diehl 2009). We expect that an assessment of vertebrate migratory activity based on expert review would increase the utility of radar data in predictive models.

Predictive models for both frequencies of bat calls performed best when anticipating nights of the highest and lowest bat activity. But how good are the 
predictions? Adverse interactions between bats and wind facilities are perhaps best mitigated by anticipating the nights of highest bat activity (Reynolds 2006, Horn et al. 2008). Consider, then, an example application using the predictive model for low frequency bats in which a hypothetical coastal wind facility's protocol is to curtail turbine operation on autumn nights when the model anticipates high regional bat activity. For the sake of illustration, our example ignores (likely important) sitespecific variation in activity (see below). Such a protocol might avoid substantial negative interactions on about $90 \%$ of those nights, when bat activity occurs at a medium-high or high level. On $10 \%$ of these nights, however, energy production is curtailed on nights of relatively low bat activity. Additionally, this protocol does not prescribe turbine curtailment on $34 \%$ of the nights with high regional bat activity. For high frequency bats, the numbers are less favorable: bats are active at a medium-high or high level on $78 \%$ of nights but relatively inactive on $22 \%$ of nights with curtailed production, and turbines are not curtailed on $56 \%$ of the nights with the highest regional bat activity. While there is certainly a benefit to knowing with some probability that bats will be very active (or inactive) on a given night, room for model improvement remains; the predictive models explained only about $9 \%$ and $36 \%$ of the variation in high frequency and low frequency bat activity, respectively.

Atmospheric dynamics influence migration in complex ways and on different temporal and spatial scales (Shamoun-Baranes et al. 2010). We generated predictions at a regional scale, but bat activity also varies on local scales, often considerably, and conditions important at any given location may differ from those at the regional level (Erickson and West 2002). Our predictive models used atmospheric variables that were readily accessible at the regional level and with clear expectations for their influence on bat activity. While the importance of these variables may fluctuate in informative ways at any given location (wind speed seems a reasonable candidate, as does wind profit for offshore locations), other variables may also prove useful and more accessible on a site-by-site basis (e.g., prey availability or habitat types; Horn et al. 2008, Santos et al. 2013).

\subsection{Conservation implications}

Recent work emphasizes that effective landscape planning of wind power development and a comprehensive assessment of its risk depend fundamentally on high quality baseline data concerning the behavior, habitat associations, distribution, and regional and continental activity trends of migratory animals (Johnson et al. 2011b, Strickland et al. 2011, Carrete et al. 2012, Santos et al. 2013). We thus attempted to understand the atmospheric conditions that presumably influence the distribution and activity of migrating bats along the north Atlantic Coast during fall migration in advance of increased offshore and nearshore wind development. Additionally, we suggest that our predictive models for the Atlantic Coast provide a regional migratory bat activity context within which site-specific (i.e., wind generation facility) applications will be important to explore agreement with or, more informatively, departures from these regional expectations. Modeling migratory bat activity at multiple scales improves our ability to anticipate nights or periods of high bat activity, thus informing turbine operations and reducing adverse interactions and 
fatalities considerably with potentially modest reductions in power production. Similarly, anticipating nights of low activity could prevent unnecessary turbine curtailment, further reducing lost power generation (Weller and Baldwin 2012). Finally, the efficacy of predictive models will undoubtedly benefit from an understanding of the ultimate causes of fatalities at wind turbines (Cryan and Barclay 2009, Loew et al. 2013).

\section{Acknowledgments}

We thank the Rhode Island National Wildlife Refuge Complex for largely funding this study via Cooperative Agreement 50181-9-J111. Additional funding was provided by the State of Rhode Island for the Ocean Special Area Management Plan to SRM and P. Paton, Rhode Island Agricultural Experiment Station (Contribution No. XXXX) to SRM, and a Nature Conservancy grant to ADS. R. Smith, B. Jones, and USFWS interns assisted in the installation and maintenance of microphones. S. Comings and The Nature Conservancy provided accommodations and logistical support on Block Island.

\section{Appendix A. Supplementary material}

Supplementary methodological descriptions associated with this article can be found, in the online version, at XXX.

\section{References}

Adams, A. M., M. K. Jantzen, R. M. Hamilton, and M. B. Fenton. 2012. Do you hear what I hear? Implications of detector selection for acoustic monitoring of bats. Methods in Ecology and Evolution 3:992-998.

Agosta, S. J. 2002. Habitat use, diet and roost selection by the big brown bat (Eptesicus fuscus) in North America: a case for conserving an abundant species. Mammal Review 32:179-198.

Ahlén, I., H. J. Baagøe, and L. Bach. 2009. Behavior of Scandinavian bats during migration and foraging at sea. Journal of Mammalogy 90:1318-1323.

Arnett, E. B., W. Brown, W. P. Erickson, J. K. Fiedler, B. L. Hamilton, T. H. Henry, A. Jain, G. D. Johnson, J. Kerns, R. R. Koford, C. P. Nicholson, T. J. O'Connell, M. D. Piorkowski, and R. D. Tankersely, Jr. 2008. Patterns of bat fatalities at wind energy facilities in North America. Journal of Wildlife Management 72:61-78.

Arnett, E. B., J. P. Hayes, and M. M. Huso. 2006. Patterns of pre-construction bat activity at a proposed wind facility in south-central Pennsylvania. An annual report submitted to the Bats and Wind Energy Cooperative. Bat Conservation International, Austin, Texas, USA.

Arnett, E. B., M. M. Huso, D. S. Reynolds, and M. R. Schirmacher. 2007. Patterns of pre-construction bat activity at a proposed wind facility in northwest Massachusetts. An annual report submitted to the Bats and Wind Energy Cooperative. Bat Conservation International, Austin, Texas, USA. 
Baerwald, E. F., and R. M. R. Barclay. 2009. Geographic variation in activity and fatality of migratory bats at wind energy facilities. Journal of Mammalogy 90:1341-1349.

Baerwald, E. F., and R. M. R. Barclay. 2011. Patterns of activity and fatality of migratory bats at a wind energy facility in Alberta, Canada. Journal of Wildlife Management 75:1103-1114.

Barclay, R. M. R. 1984. Observations on the migration, ecology, and behavior of bats at Delta Marsh, Manitoba. Canadian Field-Naturalist 98:331-336.

Barclay, R. M. R. 1999. Bats are not birds - a cautionary note on using echolocation calls to identify bats: a comment. Journal of Mammalogy 80:290-296.

Beer, J. R. 1955. Survival and movements of banded big brown bats. Journal of Mammalogy 36:242-248.

Bolker, B. M., M. E. Brooks, C. J. Clark, S. W. Geange, J. R. Poulsen, M. H. H. Stevens, and J. S. White. 2009. Generalized linear mixed models: a practical guide for ecology and evolution. Trends in Ecology \& Evolution 24:127-135.

Britke, E. R., E. H. Gillam, and K. L. Murray. 2013. Current state of understanding of ultrasonic detectors for the study of bat ecology. Acta Theriologica 58:109117.

Buler, J. J., and R. H. Diehl. 2009. Quantifying bird density during migratory stopover using weather surveillance radar. IEEE Transactions on Geoscience and Remote Sensing 47:2741 -2751.

Carrete, M., J. A. Sánchez-Zapata, J. R. Benítez, M. Lobón, F. Montoya, and J. A. Donázar. 2012. Mortality at wind-farms is positively related to large-scale distribution and aggregation in griffon vultures. Biological Conservation 145:102-108.

Chilson, P. B., W. F. Frick, P. M. Stepanian, J. R. Shipley, T. H. Kunz, and J. F. Kelly. 2012. Estimating animal densities in the aerosphere using weather radar: to $Z$ or not to $Z$ ? Ecosphere 3:72.

Cryan, P. M. 2003. Seasonal distribution of migratory tree bats (Lasiurus and Lasionycteris) in North America. Journal of Mammalogy 84:579-593.

Cryan, P. M. 2011. Wind turbines as landscape impediments to the migratory connectivity of bats. Environmental Law 355-370.

Cryan, P. M., and R. M. R. Barclay. 2009. Causes of bat fatalities at wind turbines: hypotheses and predictions. Journal of Mammalogy 90:1330-1340.

Cryan, P. M., and A. C. Brown. 2007. Migration of bats past a remote island offers clues toward the problem of bat fatalities at wind turbines. Biological Conservation 139:1-11.

Cryan, P. M., J. W. Jameson, E. F. Baerwald, C. K. R. Willis, R. M. R. Barclay, E. A. Snider, and E. G. Crichton. 2012. Evidence of late-summer mating readiness and early sexual maturation in migratory tree-roosting bats found dead at wind turbines. PLoS ONE 7:e47586.

Cryan, P. M., and J. P. Veilleux. 2007. Migration and use of autumn, winter, and spring roosts by tree bats. Pages 153-176 in M. J. Lacki, J. P. Hayes, and A. Kurta, editors. Bats in forests: conservation and management. Johns Hopkins University Press, Baltimore, Maryland, USA. 
Davis, W. H., and H. B. Hitchcock. 1965. Biology and migration of the bat, Myotis lucifugus, in New England. Journal of Mammalogy 296-313.

Drake, V. A., and R. A. Farrow. 1988. The influence of atmospheric structure and motions on insect migration. Annual Review of Entomology 33:183-210.

Drury, W. H., and J. A. Keith. 1962. Radar studies of songbird migration in coastal New England. Ibis 104:449-489.

Drury, W. H., and I. C. T. Nisbet. 1964. Radar studies of orientation of songbird migrants in southeastern New England. Bird-Banding 35:69-119.

Dzal, Y., L. A. Hooton, E. L. Clare, and M. B. Fenton. 2009. Bat activity and genetic diversity at Long Point, Ontario, an important bird stopover site. Acta Chiropterologica 11:307-315.

Enser, R. W., and J. A. Lundgren. 2006. Natural communities of Rhode Island. Rhode Island Natural History Survey, Kingston, Rhode Island, USA. <http://www.rinhs.org/wp-content/uploads/ricommclass.pdf>. Accessed 20 Apr 2012.

Erickson, J. L., and S. D. West. 2002. The influence of regional climate and nightly weather conditions on activity patterns of insectivorous bats. Acta Chiropterologica 4:17-24.

Erni, B., F. Liechti, L. G. Underhill, and B. Bruderer. 2002. Wind and rain govern the intensity of nocturnal bird migration in Central Europe-a log-linear regression analysis. Ardea 90:155-166.

Fiedler, J. K. 2004. Assessment of bat mortality and activity at Buffalo Mountain Windfarm, eastern Tennessee. Thesis, Department of Forestry, Wildlife and Fisheries, University of Tennessee, Knoxville, Tennessee, USA.

Fleming, T. H., and P. Eby. 2003. Ecology of bat migration. Pages 156-208 in T. H. Kunz and M. B. Fenton, editors. Bat ecology. The University of Chicago Press, Chicago, Illinois, USA.

Fraser, E. E., L. P. McGuire, J. L. Eger, F. J. Longstaffe, and M. B. Fenton. 2012. Evidence of latitudinal migration in tri-colored bats, Perimyotis subflavus. PLoS ONE 7:e31419.

Frick, W. F., P. M. Stepanian, J. F. Kelly, K. W. Howard, C. M. Kuster, T. H. Kunz, and P. B. Chilson. 2012. Climate and weather impact timing of emergence of bats. PLoS ONE 7:e42737.

Fujita, M. S., and T. H. Kunz. 1984. Pipistrellus subflavus. Mammalian Species 228:1-6.

Furmankiewicz, J., and M. Kucharska. 2009. Migration of bats along a large river valley in southwestern Poland. Journal of Mammalogy 90:1310-1317.

Gauthreaux, S. A. 1971. A radar and direct visual study of passerine spring migration in southern Louisiana. Auk 88:343-365.

Gauthreaux, S. A., and C. G. Belser. 1998. Displays of bird movements on the WSR88D: patterns and quantification. Weather and Forecasting 13:453-464.

Gauthreaux, S. A., J. W. Livingston, and C. G. Belser. 2008. Detection and discrimination of fauna in the aerosphere using Doppler weather surveillance radar. Integrative and Comparative Biology 48:12-23.

Gelman, A. 2008. Scaling regression inputs by dividing by two standard deviations. Statistics in Medicine 27:2865-2873. 
Griffin, D. R. 1971. The importance of atmospheric attenuation for the echolocation of bats (Chiroptera). Animal Behaviour 19:55-61.

Harrell, F. E. 2001. Regression modeling strategies: with applications to linear models, logistic regression, and survival analysis. Springer, New York.

Hein, C. D., M. R. Schirmacher, E. B. Arnett, and M. M. Huso. 2011. Patterns of preconstruction bat activity at the proposed Resolute Wind Energy Project, Wyoming, 2009-2010. A final report submitted to the Bats and Wind Energy Cooperative. Bat Conservation International, Austin, Texas, USA.

Hickey, B., and M. B. Fenton. 1996. Behavioural and thermoregulatory responses of female hoary bats, Lasiurus cinereus (Chiroptera: Vespertilionidae), to variations in prey availability. Ecoscience 3:414-422.

Holland, R. 2007. Orientation and navigation in bats: known unknowns or unknown unknowns? Behavioral Ecology and Sociobiology 61:653-660.

Horn, J. W., E. B. Arnett, and T. H. Kunz. 2008. Behavioral responses of bats to operating wind turbines. Journal of Wildlife Management 72:123-132.

Jain, A. A., R. R. Koford, A. W. Hancock, and G. G. Zenner. 2011. Bat mortality and activity at a northern Iowa wind resource area. American Midland Naturalist 165:185-200.

Johnson, G. D., M. K. Perlik, W. P. Erickson, and M. D. Strickland. 2004. Bat activity, composition, and collision mortality at a large wind plant in Minnesota. Wildlife Society Bulletin 32:1278-1288.

Johnson, G. D. 2005. A review of bat mortality at wind-energy developments in the United States. Bat Research News 46:45-49.

Johnson, J. B., J. E. Gates, and N. P. Zegre. 2011a. Monitoring seasonal bat activity on a coastal barrier island in Maryland, USA. Environmental Monitoring and Assessment 173:685-699.

Johnson, J. S., K. S. Watrous, G. J. Giumarro, T. S. Peterson, S. A. Boyden, and M. J. Lacki. 2011b. Seasonal and geographic trends in acoustic detection of treeroosting bats. Acta Chiropterologica 13:157-168.

Kerns, J., W. P. Erickson, and E. B. Arnett. 2005. Bat and bird fatality at wind energy facilities in Pennslylvania and West Virginia. Pages 24-95 in E. B. Arnett, editor. Relationships between bats and wind turbines in Pennsylvania and West Virginia: an assessment of bat fatality search protocols, patterns of fatality, and behavioral interactions with wind turbines. A final report submitted to the Bats and Wind Energy Cooperative. Bat Conservation International, Austin, Texas, USA.

Kunz, T. H., E. B. Arnett, B. M. Cooper, W. P. Erickson, R. P. Larkin, T. Mabee, M. L. Morrison, M. D. Strickland, and J. M. Szewczak. 2007a. Assessing impacts of wind-energy development on nocturnally active birds and bats: a guidance document. Journal of Wildlife Management 71:2449-2486.

Kunz, T. H., E. B. Arnett, W. P. Erickson, A. R. Hoar, G. D. Johnson, R. P. Larkin, M. D. Strickland, R. W. Thresher, and M. D. Tuttle. 2007b. Ecological impacts of wind energy development on bats: questions, research needs and hypotheses. Frontiers in Ecology and the Environment 5:315-324.

Kurta, A., and R. H. Baker. 1990. Eptesicus fuscus. Mammalian Species 386:1-10. 
Kurta, A., and S. W. Murray. 2002. Philopatry and migration of banded Indiana bats (Myotis sodalis) and effects of radio transmitters. Journal of Mammalogy 83:585-589.

Larkin, R. P. 2006. Migrating bats interacting with wind turbines - what birds can tell us. Bat Research News 47:23-32.

Lawrence, M. G. 2005. The relationship between relative humidity and the dewpoint temperature in moist air: a simple conversion and applications. Bulletin of the American Meteorological Society 86:225-233.

Limpert, D. L., D. L. Birch, M. S. Scott, M. Andre, and E. Gillam. 2007. Tree selection and landscape analysis of eastern red bat day roosts. Journal of Wildlife Management 71:478-486.

Loew, S. S., K. E. Rollins, D. K. Meyerholz, and A. P. Capparella. 2013. Reevaluation of collision risk at wind farms. Biological Conservation 157:432.

Lott, K. D. 2008. Daily and seasonal patterns of bat activity along central Appalachian riges. Master thesis, Department of Biology, Frostburg State University, Frostburg, Maryland, USA.

Mager, K. J., and T. A. Nelson. 2001. Roost-site selection by eastern red bats (Lasiurus borealis). American Midland Naturalist 145:120-126.

Mahan, S., I. Pearlman, and J. Savitz. 2010. Untapped wealth: offshore wind can deliver cleaner, more affordable energy and more jobs than offshore oil. Oceana, Washington, D.C., USA.

McGuire, L. P., and C. G. Guglielmo. 2009. What can birds tell us about the migration physiology of bats? Journal of Mammalogy 90:1290-1297.

McGuire, L. P., C. G. Guglielmo, S. A. Mackenzie, and P. D. Taylor. 2012. Migratory stopover in the long-distance migrant silver-haired bat, Lasionycteris noctivagans. Journal of Animal Ecology.

Miller, B. 2001. A method for determining relative activity of free flying bats using a new activity index for acoustic monitoring. Acta Chiropterologica 3:93-105.

Mills, R. S., G. W. Barrett, and M. P. Farrell. 1975. Population dynamics of the big brown bat (Eptesicus fuscus) in southwestern Ohio. Journal of Mammalogy 56:591-604.

Mueller, H. C., and D. D. Berger. 1967. Wind drift, leading lines, and diurnal migration. Wilson Bulletin 79:50-63.

Neubaum, D. J., T. J. O'Shea, and K. R. Wilson. 2006. Autumn migration and selection of rock crevices as hibernacula by big brown bats in Colorado. Journal of Mammalogy 87:470-479.

O’Keefe, J. M., S. C. Loeb, J. D. Lanham, and H. S. Hill Jr. 2009 . Macrohabitat factors affect day roost selection by eastern red bats and eastern pipistrelles in the southern Appalachian Mountains, USA. Forest Ecology and Management 257:1757-1763.

Parsons, K. N., G. Jones, and F. Greenaway. 2003. Swarming activity of temperate zone microchiropteran bats: effects of season, time of night and weather conditions. Journal of Zoology 261:257-264.

Parsons, S., and J. M. Szewczak. 2009. Detecting, recording, and analyzing the vocalizations of bats. Pages 91-111 in T. H. Kunz and S. Parsons, editors. 
Ecological and Behavioral Methods for the Study of Bats. 2nd edition. Johns Hopkins University Press, Baltimore, Maryland, USA.

Pedgley, D. E. 1990. Concentration of flying insects by the wind. Philosophical Transactions of the Royal Society of London. B, Biological Sciences 328:631653.

Peel, M. C., B. L. Finlayson, and T. A. Mcmahon. 2007. Updated world map of the Köppen-Geiger climate classification. Hydrology and Earth System Sciences $11: 1633-1644$.

Perry, R. W., and R. E. Thill. 2007. Tree roosting by male and female eastern pipistrelles in a forested landscape. Journal of Mammalogy 88:974-981.

Ralph, C. J. 1978. Disorientation and possible fate of young passerine coastal migrants. Bird-Banding 49:237-247.

Redell, D., E. B. Arnett, J. P. Hayes, and M. M. Huso. 2006. Patterns of preconstruction bat activity determined using acoustic monitoring at a proposed wind facility in south-central Wisconsin. A final report submitted to the Bats and Wind Energy Cooperative. Bat Conservation International, Austin, Texas, USA.

Redgwell, R. D., J. M. Szewczak, G. Jones, and S. Parsons. 2009. Classification of echolocation calls from 14 species of bat by support vector machines and ensembles of neural networks. Algorithms 2:907-924.

Reynolds, D. S. 2006. Monitoring the potential impact of a wind development site on bats in the northeast. Journal of Wildlife Management 70:1219-1227.

Richardson, W. J. 1972. Autumn migration and weather in eastern Canada: a radar study. American Birds 26:10-16.

Richardson, W. J. 1990. Timing of bird migration in relation to weather: updated review. Pages 78-101 in E. Gwinner, editor. Bird Migration. Springer-Verlag, Berlin.

Ruth, J. M., J. J. Buler, R. H. Diehl, and R. S. Sojda. 2008. Management and research applications of long-range surveillance radar data for birds, bats, and flying insects: U.S. Geological Survey Fact Sheet 2008-3095. U. S. Geological Survey. <http://www.fort.usgs.gov/products/publications/pub_abstract.asp?PubID=223 $59>$.

Rydell, J., L. Bach, M.-J. Dubourg-Savage, M. Green, L. Rodrigues, and A. Hedenström. 2010. Mortality of bats at wind turbines links to nocturnal insect migration? European Journal of Wildlife Research 56:823-827.

Santos, H., L. Rodrigues, G. Jones, and H. Rebelo. 2013. Using species distribution modelling to predict bat fatality risk at wind farms. Biological Conservation 157:178-186.

Schielzeth, H. 2010. Simple means to improve the interpretability of regression coefficients. Methods in Ecology and Evolution 1:103-113.

Shamoun-Baranes, J., W. Bouten, and E. E. van Loon. 2010. Integrating meteorology into research on migration. Integrative and Comparative Biology 50:280-292.

Strickland, M. D., E. B. Arnett, W. P. Erickson, D. H. Johnson, M. L. Morrison, J. A. Shaffer, and W. Warren-Hicks. 2011. Comprehensive guide to studying wind 
energy/wildlife interactions. National Wind Coordinating Collaborative, Washington, D.C., USA.

Šuba, J., G. Petersons, and J. Rydell. 2012. Fly-and-forage strategy in the bat

Pipistrellus nathusii during autumn migration. Acta Chiropterologica 14:379385.

Szewczak, J. M. 2004. Advanced analysis techniques for identifying bat species.

Pages 121-126 in R. M. Brigham, E. K. V. Kalko, G. Jones, S. Parsons, and H. J. G. A. Limpens, editors. Bat Echolocation Research: Tools, Techniques and Analysis. Bat Conservation International. Austin, Texas, USA.

Taylor, L. R. 1963. Analysis of the effect of temperature on insects in flight. Journal of Animal Ecology 32:99-117.

Taylor, R., and M. O'Neill. 1988. Summer activity patterns of insectivorous bats and their prey in Tasmania. Wildlife Research 15:533-539.

Timm, R. M. 1989. Migration and molt patterns of red bats, Lasiurus borealis (Chiroptera: Vespertilionidae), in Illinois. Bulletin of the Chicago Academy of Sciences 14:1-7.

U.S. Department of Energy. 2011. A national offshore wind strategy: creating an offshore energy industry in the United States. U.S. Department of Energy.

Voigt, C. C., K. Sörgel, J. Šuba, O. Keišs, and G. Pētersons. 2012. The insectivorous bat Pipistrellus nathusii uses a mixed-fuel strategy to power autumn migration. Proceedings of the Royal Society B: Biological Sciences 279:3772-3778.

Weller, T. J., and J. A. Baldwin. 2012. Using echolocation monitoring to model bat occupancy and inform mitigations at wind energy facilities. Journal of Wildlife Management 76:619-631.

Weller, T. J., and J. A. Baldwin. 2012. Using echolocation monitoring to model bat occupancy and inform mitigations at wind energy facilities. Journal of Wildlife Management 76:619-631.

Williamson, K. 1962. The nature of "leading line" behaviour. Bird Migration 2:176182.

Willis, C. K. R., R. M. R. Barclay, J. G. Boyles, R. Mark Brigham, V. Brack Jr., D. L. Waldien, and J. Reichard. 2010. Bats are not birds and other problems with Sovacool's (2009) analysis of animal fatalities due to electricity generation. Energy Policy 38:2067-2069.

Winchell, J. M., and T. H. Kunz. 1996. Day-roosting activity budgets of the eastern pipistrelle bat, Pipistrellus subflavus (Chiroptera: Vespertilionidae). Canadian Journal of Zoology 74:431-441.

Wood, S. N. 2006. Generalized additive models: an introduction with R. Chapman and Hall/CRC, Boca Raton, FL, USA.

Young, D. P., Jr., S. Nomani, W. L. Tidhar, and K. Bay. 2011. NedPower Mount Storm wind energy facility post-construction avian and bat monitoring. <http://www.batsandwind.org/pdf/WV 20- Young et al. 2011 - Mount Storm Fall 2010 Report( 2-10-11).pdf $>$.

Zuur, A. F., E. N. Ieno, N. J. Walker, A. A. Savaliev, and G. M. Smith. 2009. Mixed effects models and extensions in ecology with R. Springer, New York, New York, USA. 
Fig. 1. Locations of ultrasonic microphones (circles) and National Weather Service ASOS stations used to examine relationships between atmospheric conditions and migrating bat activity in southern Rhode Island (RI), USA, from August through October, 2010-2012. Microphone location abbreviations: S - Sachuest, T - Trustom (pond site), U - Trustom (upland site), N - Ninigret, W - Watchaug, K - Kurz, and H Wash. ASOS stations: 1 - Providence/T. F. Green State Airport, 2 - Newport State Airport, 3 - Westerly State Airport, 4 - Groton-New London Airport, and 5 - Montauk Airport. See text for more details.

Fig. 2. Comparison of nightly regional activity among high (A) and low frequency (B) bats recorded by ultrasonic recorders in southern Rhode Island, USA, during 2010-2012. Patterns of activity over time are of primary concern; comparisons of relative activity among species depend on perhaps untenable assumptions. Only classified bat calls are presented; passes were classified using SonoBat 3.02. We adjusted the number of bat passes to compensate for differences in detector sensitivity between 2010 and 2011-2012. High frequency bats: LABO (eastern red bat; Lasiurus borealis), PESU (tri-colored bat; Perimyotis subflavus), and MYSP (Myotis sp.); low frequency bats: EPFU (big brown bat; Eptesicus fuscus), LACI (hoary bat; Lasiurus cinereus), and LANO (silver-haired bat; Lasionycteris noctivigans).

Fig. 3. Changes in regional high frequency bat activity over the course of autumn (day of year) and as a function of nightly averages of regional atmospheric conditions; associations were estimated with a generalized additive mixed model. We illustrate each variable's association (and 95\% confidence interval) with the linear predictor of bat activity when all other variables are at their mean value unless the variable interacted with day of year, in which case we illustrate the effect for early (15 Aug), middle (15 Sep), and late (15 Oct) in the season; we excluded the intercept from the linear predictor to facilitate the comparison of effect magnitudes among variables. Rug plots illustrate the distribution of the input variables.

Fig. 4. Changes in regional low frequency bat activity over the course of autumn (day of year) and as a function of nightly average of regional atmospheric conditions; associations were estimated with a generalized linear mixed model. We illustrate each variable's association (and 95\% confidence interval) with the linear predictor of bat activity when all other variables are at their mean value unless the variable interacted with day of year, in which case we illustrate the effect for early (15 Aug), middle (15 Sep), and late (15 Oct) in the season; we excluded the intercept from the linear predictor to facilitate the comparison of effect magnitudes among variables. Rug plots illustrate the distribution of the input variables.

Fig. 5. Changes in regional high frequency bat activity over the course of autumn (day of year) and as a function of regional averages of atmospheric conditions collected approximately $30 \mathrm{~min}$ prior to sunset; associations were estimated with a generalized linear mixed model. We illustrate each variable's association (and 95\% confidence interval) with the linear predictor of bat activity when all other variables are at their mean value unless the variable interacted with day of year, in which case we illustrate 
the effect for early (15 Aug), middle (15 Sep), and late (15 Oct) in the season; we excluded the intercept from the linear predictor to facilitate the comparison of effect magnitudes among variables. Rug plots illustrate the distribution of the input variables.

Fig. 6. Changes in regional low frequency bat activity over the course of autumn (day of year) and as a function of regional averages of atmospheric conditions collected approximately $30 \mathrm{~min}$ prior to sunset; associations were estimated with a generalized linear mixed model. The relationships between atmospheric conditions and bat activity agree generally with expectations. We illustrate each variable's association (and 95\% confidence interval) with the linear predictor of bat activity when all other variables are at their mean value unless the variable interacted with day of year, in which case we illustrate the effect for early (15 Aug), middle (15 Sep), and late (15 Oct) in the season; we excluded the intercept from the linear predictor to facilitate the comparison of effect magnitudes among variables. Rug plots illustrate the distribution of the input variables.

Fig. 7. Regional high (HF) and low (LF) frequency bat activity and corresponding predictions based on regional atmospheric conditions collected approximately $30 \mathrm{~min}$ prior to sunset. Four ordered classes of bat activity were created by categorizing predicted and actual bat pass rates at their quartiles; we refer to these activity classes (with their associated percentiles) as follows: low ( $\leq 25 \%)$, low-medium (26 - 50\%), medium-high (51-75\%), and high (>75\%). The generalized linear mixed model (GLMM) performed reasonably well at the extremes of bat activity. Predictions for the middle classes of bat activity were modestly better than random, with predictions favoring the correct end of the activity spectrum. 
Table 1. Ultrasonic microphone operational summary at seven locations on the Rhode Island National Wildlife Refuge Complex in southern Rhode Island, USA, during the 2010 - 2012 fall migrations. Discrepancies between the number of nights operated and number of nights recorded indicate that some form of equipment malfunction or extreme weather event precluded recording. Monitoring ended on 31 October in each year.

Mainland Block Island

Sachuest (S) Ninigret (N) Trustom (P) Trustom (U) Watchaug (W) Kurz (K) Wash (H)

2010

Start night

10 Sep

\# nights operated/recorded $\quad 52 / 27$

-

Wash (H) 2011

ف

\# nights ope

$8 \mathrm{Sep}$

8 Sep

$-$

$\sqrt{2}$

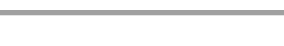

$54 / 52$

$54 / 54$

8 Sep

$54 / 50$

$-$

2 Aug

4 Oct

Start night

$91 / 80$

$28 / 22$

2 Aug

$91 / 65$

$91 / 85$

$91 / 91$

9 Sep

$11 \mathrm{Sep}$

$51 / 48$

\# nights operated/recorded 
Table 2. Classification of ultrasonic bat passes (call sequences) recorded in southern Rhode Island, USA, during autumn 2010 - 2012. We report the classification of those bat passes using SonoBat 3.02 comprising at least two calls that met the software's default quality threshold and a 0.90 consensus discriminant probability threshold. We did not distinguish among Myotis species. We categorized unclassified bat passes by their characteristic frequency (high: typically $>35 \mathrm{kHz}$; low: $<35 \mathrm{kHz}$ ). See text for details.

\begin{tabular}{|c|c|c|c|c|c|c|c|}
\hline Classification $^{1}$ & $\begin{array}{l}\text { Migratory } \\
\text { status }^{2}\end{array}$ & $\begin{array}{l}\text { Migratory } \\
\text { period }^{3}\end{array}$ & \# passes & $\begin{array}{c}\% \text { of identified } \\
\text { passes }\end{array}$ & $\begin{array}{c}\% \text { of frequency } \\
\text { activity }^{4}\end{array}$ & $\begin{array}{l}\% \text { of all } \\
\text { activity }^{4}\end{array}$ & $\begin{array}{l}\text { Adjusted \% of } \\
\text { all activity }\end{array}$ \\
\hline \multicolumn{8}{|l|}{ High frequency } \\
\hline Eastern red bat & $\mathrm{L}$ & Aug - Oct & 2677 & 33.4 & 66.6 & 48.6 & 59.4 \\
\hline Tri-colored bat & $\mathrm{S}$ & Jul - Aug & 1098 & 13.7 & 27.3 & 19.9 & 9.9 \\
\hline Myotids & $\mathrm{S}$ & Jul - Sep & 246 & 3.1 & 6.1 & 4.5 & 3.8 \\
\hline Unknown & & & 30757 & & & & \\
\hline \multicolumn{8}{|l|}{ Low frequency } \\
\hline Silver-haired bat & $\mathrm{L}$ & Aug - Oct & 1905 & 23.8 & 47.8 & 12.9 & 12.5 \\
\hline Big brown bat & $\mathrm{N}$ & & 1829 & 22.8 & 45.9 & 12.4 & 12.9 \\
\hline Hoary bat & $\mathrm{L}$ & Jul - Sep & 250 & 3.1 & 6.3 & 1.7 & 1.6 \\
\hline Unknown & & & 8849 & & & & \\
\hline
\end{tabular}

\footnotetext{
${ }^{1}$ Scientific names: eastern red bat (Lasiurus borealis), tri-colored bat (Perimyotis subflavus), myotids (little brown myotis, Myotis lucifugus; northern myotis, M. septentrionalis; eastern small-footed myotis, M. leibii; and Indiana bat, M. sodalis), silver-haired bat (Lasionycteris noctivigans), big brown bat (Eptesicus fuscus), and hoary bat (Lasiurus cinereus)

${ }^{2}$ Migratory status (L: long-distance; S: short-distance; N: non-migratory) based on Fleming and Eby (2003). Tri-colored bats (Perimyotis subflavus) may also exhibit long-distance movements (Fraser et al. 2012). The myotids may include some non-migratory species, but the predominant myotid (little brown bat; Myotis lucifugus) in our identified calls is a short-distance migrant (A. Smith, unpublished data). See text for additional discussion.

${ }^{3}$ Expected migratory period through southern New England is not well-established in any species. Estimated periods are based on: Cryan 2003, Johnson et al. 2011a, Johnson et al. 2011b (red, hoary, and silver-haired bat); McGuire et al. 2012 (silver-haired bat; Dzal et al. 2009 (hoary bat); Fujita and Kunz 1984, Winchell and Kunz 1996 (tri-colored bat); Davis and Hitchcock 1965, Arnett et al. 2007 (myotids)
} 
${ }^{4}$ Estimated assuming that the composition of identified passes is representative of species prevalence in unidentified passes of the same characteristic frequency. This percentage thus represents the sum of identified passes for each species and the estimated number of passes of each species present in the unidentified passes of the corresponding characteristic frequency, divided by the total number of passes of the corresponding characteristic frequency (frequency activity) or all frequencies (all activity).

${ }^{5}$ Adjusted for different acceptance rates of calls when making species identification of SonoBat's reference bat passes ( $\geq 2$ pulses) using default quality threshold (0.80) and achieving a 0.90 consensus discriminant probability (see SonoBat help files for the assessment). Acceptance rates for species in this study: eastern red bat (39.4\%), tri-colored bat (96.8\%), myotids (56.7\%; averaged across species), silver-haired bat $(89.1 \%)$, big brown bat $(82.8 \%)$, and hoary bat $(90.9 \%)$. 
Table 3. Atmospheric variables used to explore relationships with patterns of migrating bat activity in southern Rhode Island, USA, from 2010 to 2012. For most variables, we calculated the regional average over two time frames: (1) the nightly average from evening civil twilight to morning civil twilight, and (2) based on single observations occurring approximately 30 min prior to local sunset. Expected associations apply only to the migratory season as defined by the period of monitoring in this study, 2 August to 31 October.

\begin{tabular}{|c|c|c|c|}
\hline Variable & Units & Description & Expected association with bat activity \\
\hline Day of year & day & seasonality; day of the year & $\begin{array}{l}\text { Negative; the expected decrease in bat } \\
\text { activity through the season, however, is } \\
\text { likely driven by other climatic and } \\
\text { ecological variables (e.g., temperature and } \\
\text { prey abundance, respectively) that decrease } \\
\text { as migration progresses }\end{array}$ \\
\hline
\end{tabular}

dry bulb surface temperature; centered by weather station to account for systematic differences among station

Temperature deviation

${ }^{\circ} \mathrm{C}$

deviation of daily high temperature from the 30-yr (1982-2012) average high temperature

$\Delta$ Temperature

${ }^{\circ} \mathrm{C}$
Positive; bats tend to be more active at warmer temperatures within a given season (Weller and Baldwin 2012, and citations therein); not evaluated due to high collinearity, particularly with date

Positive; we suggest that above/below average temperatures may stimulate/suppress bat activity, particularly later in the migration season, suggesting a positive interaction with day of year

Mostly positive; we suggest that an increase/decrease in nightly temperature relative to the prior night may 
Wind speed

$\mathrm{m} / \mathrm{s}$

wind speed measured approximately $10 \mathrm{~m}$ above ground level; centered by weather station to account for systematic differences among stations

Wind profit

$\mathrm{m} / \mathrm{s}$

a variable combining wind direction and wind speed (Erni et al. 2002). The distance a bat is drifted toward a specified destination (in the present case, due southeast), in a fixed time interval, only through the effect of wind; calculated prior to centering wind speed

Barometric pressure

$\mathrm{mb}$

station barometric pressure; centered by weather station to account for systematic differences among stations

$\mathrm{mb}$ stimulate/suppress bat activity, particularly later in the migration season, suggesting a positive interaction with day of year

Negative; high wind speeds consistently associated with decreased migratory bat activity (Reynolds 2006, Baerwald and Barclay 2011, Weller and Baldwin 2012)

Positive; we expect positive wind profits as calculated to indicate combinations of wind speeds and directions that induce a more coastal flight path for migrating bats and perhaps the coastal effect (Ralph 1978) in inexperienced migrants

Positive or negative; higher pressure is typically associated with improved conditions for flying (e.g., clear skies and calmer winds), but relatively low pressure is also associated with the passage of cold fronts; reviewed in Richardson (1990)

Positive; an increase in average nightly pressure from the prior night may indicate the recent passage of a cold front and improving conditions for flying; reviewed in Richardson (1990), but see Baerwald and 
Barclay (2011)

Relative humidity

$\Delta$ Relative humidity

$\%$

$\infty$

Rain (night only)

$\mathrm{n} / \mathrm{a}$ least one station reporting the occurrence of

Visibility

mi

sensor-derived value of air clarity converted to the corresponding visibility of the human

Z

Radar reflectivity (pre-sunset only) 24-hr increment in relative humidity

proportion of the hours in a night with at precipitation

eye

calculated from temperature and dew point according to the August-Roche-Magnus formula (Lawrence 2005)

sum of linearized radar reflectivity factors within $150 \mathrm{~km}$ of the KBOX radar
Negative, but complicated due to correlations with other variables; in general, lower humidity is expected after the passage of cold fronts; reviewed in Richardson (1990); not evaluated due to high collinearity with several variables

Negative, but complicated; in general, falling humidity may be indicative of a recently-passed cold front; reviewed in (Richardson 1990)

Negative; precipitation is likely to limit the ability of bats to acquire prey by either discouraging insect activity or interfering with echolocation (e.g., Griffin 1971,

Parsons et al. 2003)

Positive; we expect the relationship is due largely to reduced activity during periods of low visibility, which is often indicative of inclement weather (e.g., fog, rain, high humidity) or conditions that may inhibit echolocation (e.g., high particular matter)

Positive in the absence of precipitation as increased reflectivity should reflect increased bioscatter (i.e., migrating animals; 
Rain near radar (pre-sunset only) $\mathrm{n} / \mathrm{a}$

Indicator of precipitation (1) or no precipitation (-1) within $150 \mathrm{~km}$ of the KBOX radar
Gauthreaux and Belser 1998, Frick et al.

2012); level or negative in the presence of precipitation, suggesting an interaction with rain near the radar

Negative; the presence of regional precipitation is expected to suppress migratory bat activity 
Table 4. Relationships between regional nightly activity of high and low frequency bats and average regional nightly atmospheric conditions derived from a generalized additive mixed model (high frequency) or a generalized linear mixed model (low frequency). Input variables were centered and scaled; thus, (1) exponentiation of parameter estimates provides the average change in bat activity per standard deviation change of the input variable, and (2) comparisons of parameter estimates within a model convey information about the relative magnitude of a variable's association with bat activity.

\begin{tabular}{|c|c|c|c|c|c|c|c|}
\hline \multirow[b]{2}{*}{ Variable $^{\mathrm{a}}$} & \multirow{2}{*}{$\begin{array}{l}\text { Expected } \\
\text { association }\end{array}$} & \multicolumn{3}{|c|}{ High frequency } & \multicolumn{3}{|c|}{ Low frequency } \\
\hline & & Estimate $(\mathrm{SE})^{\mathrm{b}}$ & $t^{\mathrm{c}}$ & $P$ & Estimate $(\mathrm{SE})^{\mathrm{b}}$ & $t^{\mathrm{c}}$ & $P$ \\
\hline Day of year & - & $-0.47(0.10)$ & -4.84 & $<0.001$ & $-0.72(0.12)$ & -6.17 & $<0.001$ \\
\hline Wind profit & + & $0.26(0.09)$ & 2.96 & 0.002 & $0.59(0.11)$ & 5.30 & $<0.001$ \\
\hline$\Delta$ Temperature & + & $0.17(0.08)$ & 2.03 & 0.02 & $0.37(0.10)$ & 3.63 & $<0.001$ \\
\hline Temperature deviation & + & $0.16(0.08)$ & 1.86 & 0.03 & $0.33(0.10)$ & 3.17 & $<0.001$ \\
\hline \multicolumn{7}{|l|}{ Day of year } & 0.004 \\
\hline$\Delta$ Pressure & + & $0.19(0.10)$ & 2.00 & 0.02 & $0.14(0.12)$ & 1.19 & 0.12 \\
\hline Wind speed & - & $-0.01(0.09)$ & -0.11 & 0.46 & $-0.12(0.11)$ & -1.10 & 0.14 \\
\hline $\begin{array}{c}\Delta \text { Temperature } \mathrm{x} \\
\text { Day of year }\end{array}$ & \multicolumn{6}{|c|}{ Day of year } & 0.24 \\
\hline Rain & - & $-0.04(0.08)$ & -0.47 & 0.32 & $-0.05(0.10)$ & -0.52 & 0.30 \\
\hline Pressure & $+/-$ & $0.09(0.10)$ & 0.91 & 0.36 & $0.00(0.12)$ & 0.00 & 0.50 \\
\hline Visibility & + & $0.03(0.08)$ & 0.39 & 0.35 & $0.01(0.10)$ & 0.11 & 0.46 \\
\hline$\Delta$ Relative humidity & - & $-0.00(0.08)$ & -0.02 & 0.50 & $0.11(0.09)$ & 1.21 & 0.89 \\
\hline \multicolumn{8}{|l|}{ Additional covariates } \\
\hline Detector settings ${ }^{\mathrm{d}}$ & + & $1.05(0.72)$ & 1.46 & 0.07 & $1.14(0.44)$ & 2.58 & 0.005 \\
\hline
\end{tabular}


a Standard deviations of input variables: day of year (22.45 days), wind profit $(1.58 \mathrm{~m} / \mathrm{s}), \Delta$ temperature $\left(3.10{ }^{\circ} \mathrm{C}\right)$, temperature deviation $\left(3.44{ }^{\circ} \mathrm{C}\right), \Delta$ pressure $(5.50 \mathrm{mb})$, wind speed $(1.33 \mathrm{~m} / \mathrm{s})$, rain $(0.21)$, pressure $(6.17 \mathrm{mb})$, visibility $(1.63 \mathrm{mi}), \Delta$ relative humidity (12.32\%); use the standard deviations with parameter estimates to evaluate the effect of a variable on bat activity. For example, all else being equal, high frequency bat activity on a night with an average wind profit of $1.58 \mathrm{~m} / \mathrm{s}$ was approximately $30 \%$ higher $\left(\mathrm{e}^{0.26}\right)$ than nights with an average wind profit of $0 \mathrm{~m} / \mathrm{s}$

${ }^{b}$ Day of year estimate from high frequency model using linear fit only for comparison with other variables; all other estimates for high frequency model that fitted day of year with a smooth term. In low frequency mode, day of year smooth term was penalized to a linear term, so the model was refit with a linear specification for day of year

c 148 residual degrees of freedom

d Indicator variable distinguishes between ultrasonic recorder settings in 2010 and 2011-2012. Due to standardization, the two levels should technically be separated by approximately two standard deviations. However, because of quite unequal sample sizes in the two levels, they are actually separated by 2.86 standard deviations. Thus, the decrease in recorder sensitivity from 2010 to 2011 2012 may be estimated by the exponentiation of 2.86 times the parameter estimate (e.g., $\mathrm{e}^{2.86 * 1.05}$ for high frequency bats) 
Table 5. Relationships between regional nightly activity of high and low frequency bats and average regional atmospheric conditions approximately $30 \mathrm{~min}$ prior to sunset derived from generalized linear mixed models. Input variables were centered and scaled; thus, (1) exponentiation of parameter estimates provides the average change in bat activity per standard deviation change of the input variable, and (2) comparisons of parameter estimates within a model convey information about the relative magnitude of a variable's association with bat activity.

\begin{tabular}{|c|c|c|c|c|c|c|c|}
\hline \multirow[b]{2}{*}{ Variable $^{\mathrm{a}}$} & \multirow{2}{*}{$\begin{array}{l}\text { Expected } \\
\text { association }\end{array}$} & \multicolumn{3}{|c|}{ High frequency } & \multicolumn{3}{|c|}{ Low frequency } \\
\hline & & Estimate (SE) & $t^{b}$ & $\mathrm{P}$ & Estimate (SE) & $\mathrm{t}^{\mathrm{b}}$ & $\mathrm{P}$ \\
\hline Day of year & - & $-0.46(0.10)$ & -4.62 & $<0.001$ & $-0.66(0.11)$ & -5.84 & $<0.001$ \\
\hline Wind profit & + & $0.20(0.08)$ & 2.62 & 0.005 & $0.34(0.08)$ & 4.12 & $<0.001$ \\
\hline$\Delta$ Temperature & + & & & & $0.22(0.08)$ & 2.90 & 0.002 \\
\hline Temperature deviation & + & $0.09(0.08)$ & 1.05 & 0.15 & $0.24(0.10)$ & 2.37 & 0.01 \\
\hline $\begin{array}{l}\text { Temperature deviation } \mathrm{x} \\
\text { Day of year }\end{array}$ & + & $0.21(0.09)$ & 2.29 & 0.01 & $0.31(0.12)$ & 2.66 & 0.004 \\
\hline$\Delta$ Pressure & + & $0.20(0.07)$ & 2.78 & 0.003 & & & \\
\hline Visibility & + & & & & $0.18(0.09)$ & 2.01 & 0.02 \\
\hline Wind speed & - & $0.11(0.07)$ & 1.63 & 0.95 & & & \\
\hline
\end{tabular}

Additional covariates

$\begin{array}{llllllll}\text { Detector settings }^{\mathrm{c}} & + & 1.04(0.71) & 1.46 & 0.07 & 0.84(0.47) & 1.80 & 0.04\end{array}$

a Standard deviations of input variables: day of year (22.45 days), wind profit $(2.35 \mathrm{~m} / \mathrm{s}), \Delta$ temperature $\left(2.54{ }^{\circ} \mathrm{C}\right)$, temperature deviation $\left(3.44{ }^{\circ} \mathrm{C}\right), \Delta$ pressure $(1.92 \mathrm{mb})$, visibility $(1.65 \mathrm{mi})$, wind speed $(1.43 \mathrm{~m} / \mathrm{s})$; use the standard deviations with parameter estimates to evaluate the effect of a variable on bat activity. For example, all else being equal, expected high frequency bat activity on a night with a wind profit of $2.35 \mathrm{~m} / \mathrm{s}$ at sunset will be approximately $22 \%$ higher $\left(\mathrm{e}^{0.20}\right)$ than on nights with a wind profit of 0 $\mathrm{m} / \mathrm{s}$ at sunset 
b 154 residual degrees of freedom

${ }^{c}$ Indicator variable distinguishes between ultrasonic recorder settings in 2010 and 2011-2012. Due to standardization, the two levels should technically be separated by approximately two standard deviations. However, because of quite unequal sample sizes in the two levels, they are actually separated by 2.86 standard deviations. Thus, the decrease in recorder sensitivity from 2010 to $2011-$ 2012 may be estimated by the exponentiation of 2.86 times the parameter estimate (e.g., $\mathrm{e}^{2.86 * 1.04}$ for high frequency bats) 


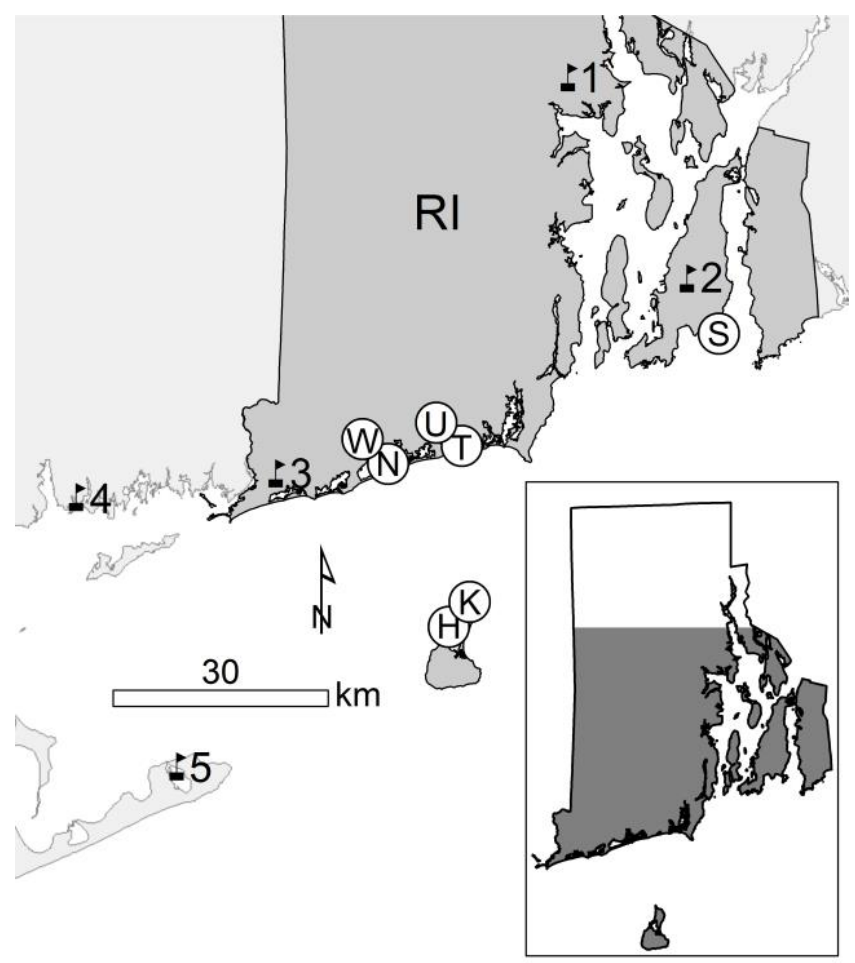

Fig. 1. 


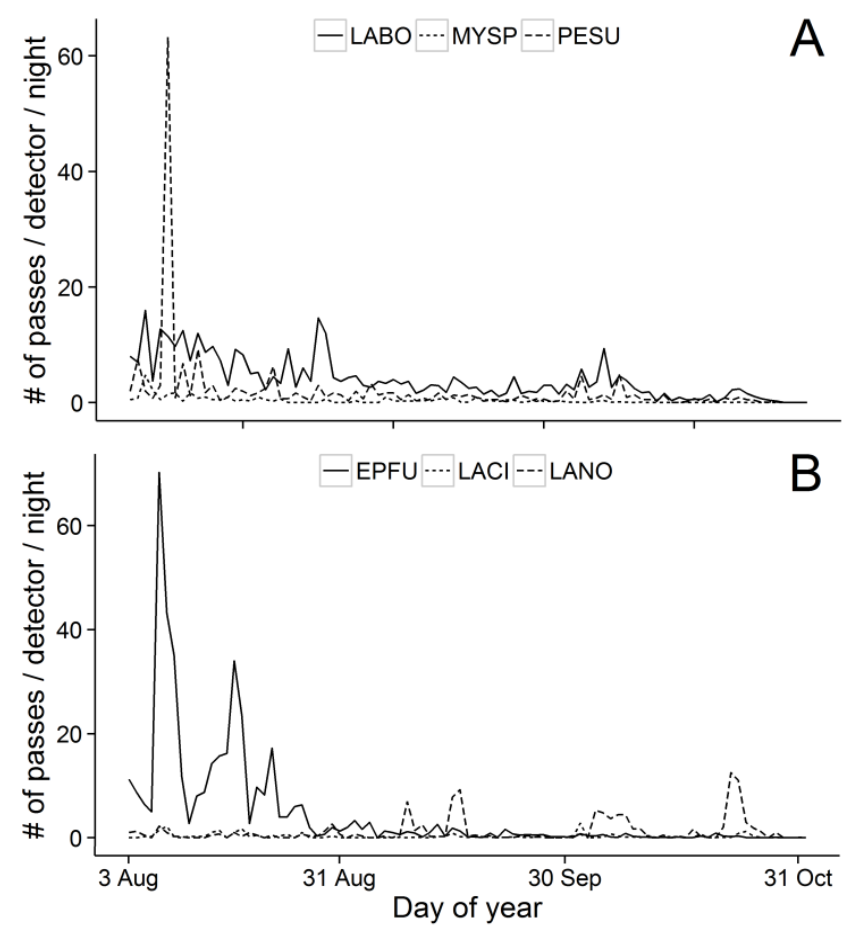

Fig. 2. 

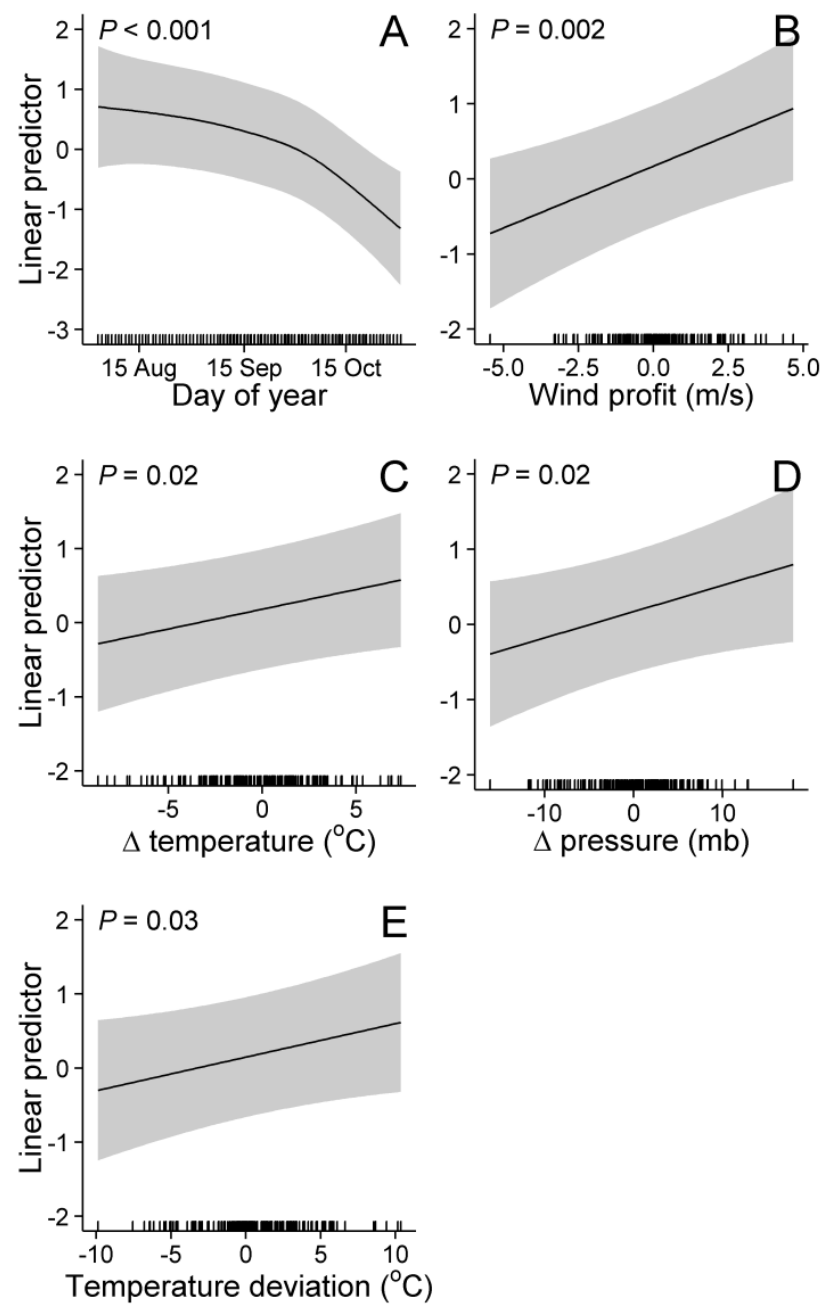

Fig. 3. 

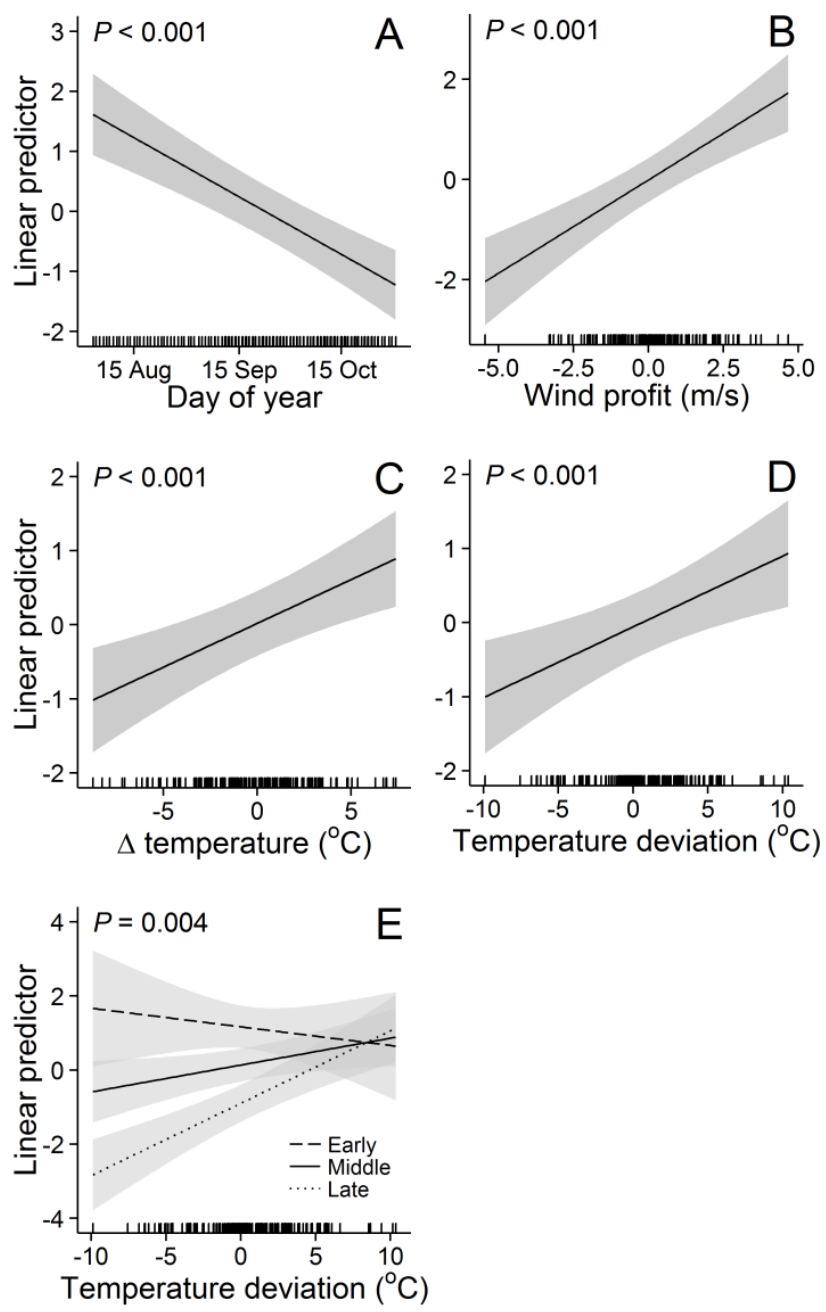

Fig. 4. 

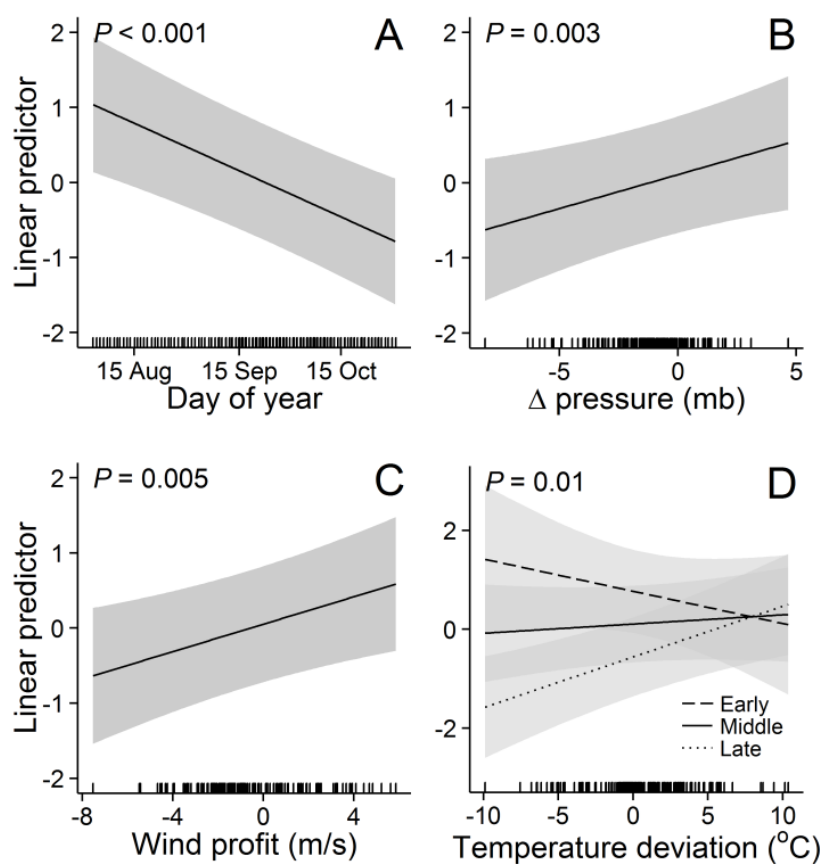

Fig. 5. 

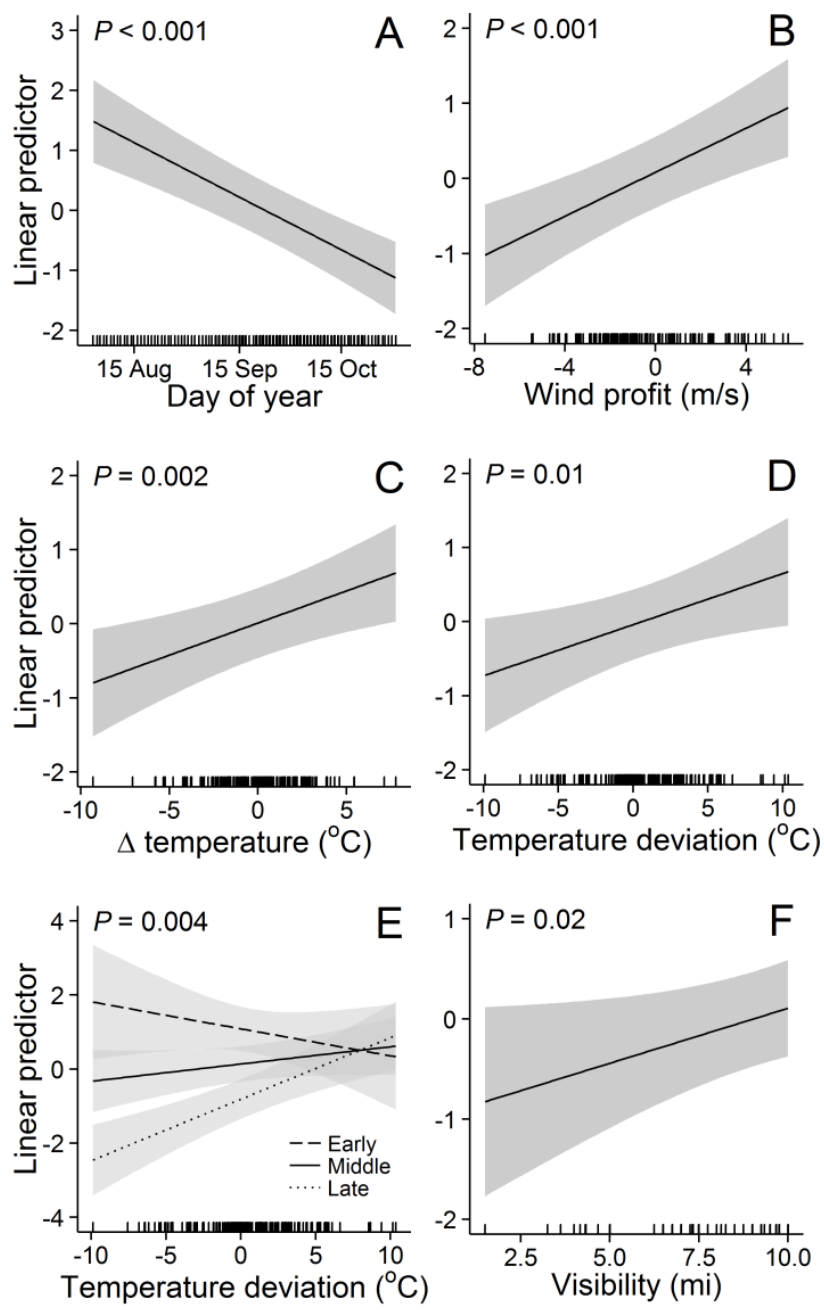

Fig. 6. 


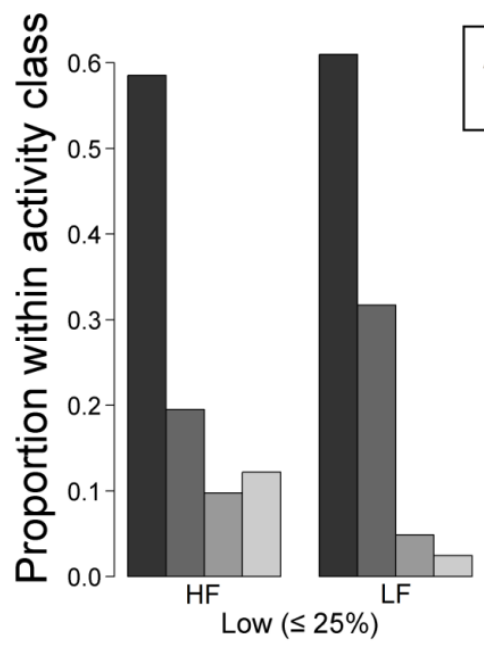

Fig. 7.

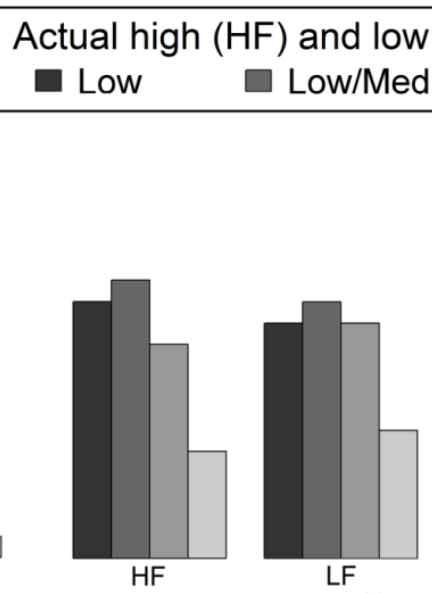

Low/Medium (26 - 50\%)

\section{Predicted bat activity (percentiles)}

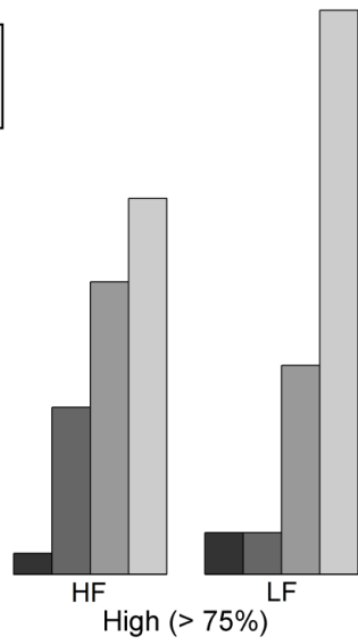

High $(>75 \%)$ 


\section{Appendix A. Supplementary material}

Supplementary material 1 . Acquisition and handling of weather data

This appendix provides information primarily on acquiring, and to some extent manipulating, weather data to create the atmospheric condition variables used in the manuscript. Nearly all of the manipulation and variable creation occurred via customized R scripts; these scripts are available from the authors but will require adaptation to the user's local system. We acquired most of the weather data from five Automated Surface Observing System (ASOS) within $50 \mathrm{~km}$ of the centroid of microphone locations (see Fig. 1 in manuscript); ASOS stations reported weather variables every minute and based on data accumulations over the previous 1 or 2 minutes (1-min ASOS), although visibility data were reported every 5 minutes (5-min ASOS). Rarely, it was necessary to supplement missing ASOS data; in these cases, we obtained approximately hourly Quality Controlled Local Climatological Data (QCLCD) from the same stations. We obtained daily maximum temperature data from the Global Summary of the Day (GSOD) for a single station (Providence, Rhode Island; 725070). We collected NEXRAD Level II base reflectivity (230 km range, $0.5^{\circ}$ elevation) images from Boston, Massachusetts (KBOX) via the HDSS Access System. All data are archived and available from the National Climatic Data Center; Table A1 provides URLs to access data and obtain additional data set information.

\section{Data sources}

One minute ASOS data were retrieved in monthly fixed width format text files split between two files. The format documentation for these files is available at http://www1.ncdc.noaa.gov/pub/data/documentlibrary/tddoc/td6405.pdf and http://www1.ncdc.noaa.gov/pub/data/documentlibrary/tddoc/td6406.pdf. Once downloaded, we used an R script to parse and assemble the text files, as well as create several derived atmospheric condition variables. The text files often required several rounds of script execution, error checking, and subsequent manual inspection of the original text files to ensure compliance with the expected format. In most cases, the format mistakes were easily resolved; in other cases, however, we had no choice but to delete the observation for a particular minute. A subsequent $\mathrm{R}$ script calculated nightly averages or other derived variables (e.g., percentage of hours with precipitation).

Five minute ASOS data were retrieved in single monthly fixed width format text files. The format documentation for these files is available at http://www1.ncdc.noaa.gov/pub/data/documentlibrary/tddoc/td6401.pdf. Once downloaded, we consolidated the monthly files into a single text file. We then created a Visual Basic for Applications macro to parse the relevant weather observations into $\mathrm{a} *$.csv file. An R script tidied up the data and calculated nightly averages.

When ASOS data were missing for a large proportion of a particular night and weather station, we manually retrieved relevant weather observations from QCLCD into *.csv files for automatic incorporation into the ASOS data within our R scripts. 
Global summary of the day data were retrieved as zipped yearly text files; after decompression, we consolidated the relevant years (1982-2012) into a single text file. We then used an R script to calculate two different measures of daily high temperature deviation from average (normal) high temperatures: deviation from the 30-year average (1982-2012) for a given date and deviation from the expected high temperature based on the previous year's temperatures. To calculate the second measure we constructed a generalized additive model (GAM) that used a moving window of temperature data spanning the previous year and terminating on the date of interest; the deviation from normal was calculated simply as the residual between the high temperature on the date of interest and expectation of this temperature from the GAM. We explored this measure because it requires the collection of less data relative to the 30-year average and may better accommodate temperature trends over time. The two measures were highly correlated for the period of interest in this study (Pearson's $r=0.98, \mathrm{t}_{496}=98.7, P<0.001$ ); we thus used the deviation from the 30 year average in our analyses.

We retrieved NEXRAD Level II base reflectivity data for Boston (KBOX) as daily consolidated Unix archive files (*.tar); each daily archive contained all the available base reflectivity files for a given day. For each night, we selected the base reflectivity file nearest to 1 hour after local sunset. Base reflectivity files were in a unique digital binary format that required special software for viewing and handling; we used the National Oceanic and Atmospheric Administration's (NOAA) Weather and Climate Toolkit (Version 3.6.4; http://www.ncdc.noaa.gov/oa/wct/; accessed 7 Dec 2012). Using the Weather and Climate Toolkit, we batch converted our single nightly base reflectivity files into ASCII grids. We then used an R script to sum reflectivity values (in linear units) within $150 \mathrm{~km}$ of the KBOX radar; this required creating a custom ASCII grid that masked reflectivity value beyond $150 \mathrm{~km}$. We also manually inspected reflectivity scans and noted the presence of presence within 150 $\mathrm{km}$ of the radar.

Data consolidation

A final R script generated the final dataset: it first merged the separate nightly weather data sets, then identified the pre-sunset observations and calculated their regional averages, and finally merged the atmospheric condition variables with nightly bat activity data. We found several $\mathrm{R}$ packages indispensable in manipulating and summarizing atmospheric data and radar images, including plyr (version 1.8, CRAN.R-project.org/package=plyr, accessed 7 Dec 2012), reshape (version 0.8.4, CRAN.R-project.org/package=reshape, accessed 20 Nov 2012), lubridate (version 1.2.0, CRAN.R-project.org/package=lubridate, accessed 20 Nov 2012), circular (version 0.4-3, CRAN.R-project.org/package=circular, accessed 20 Nov 2012), data.table (version 1.8.6, CRAN.R-project.org/package=data.table, accessed 20 Nov 2012), fields (version 6.7, CRAN.R-project.org/package=fields), and sp (version 1.02, CRAN.R-project.org/package=sp, accessed 20 Nov 2012). 
Table A1. Sources of weather data used to derive atmospheric conditions for comparison with migratory bat acoustic activity.

\begin{tabular}{|c|c|c|}
\hline Data set ${ }^{\mathrm{a}}$ & Additional information & Data access \\
\hline $1-\min \mathrm{ASOS}$ & http://www.nws.noaa.gov/asos/ & ftp://ftp.ncdc.noaa.gov/pub/data/asos-onemin \\
\hline 5-min ASOS & http://www.nws.noaa.gov/asos/ & ftp://ftp.ncdc.noaa.gov/pub/data/asos-fivemin \\
\hline QCLCD & http://cdo.ncdc.noaa.gov/qclcd & http://cdo.ncdc.noaa.gov/qclcd/QCLCD?prior=N \\
\hline GSOD & http://www.ncdc.noaa.gov/cgi-bin/res40.pl & ftp://ftp.ncdc.noaa.gov/pub/data/gsod/ \\
\hline NEXRAD & http://www.ncdc.noaa.gov/oa/radar/radarproducts.html & http://has.ncdc.noaa.gov/pls/plhas/has.dsselect \\
\hline
\end{tabular}

${ }^{a}$ Weather variables derived from each data set: 1-min ASOS (temperature, $\Delta$ temperature, wind speed, wind profit, relative humidity, $\Delta$ relative humidity, pressure, $\Delta$ pressure, rain), 5-min ASOS (visibility), GSOD (temperature deviation), and NEXRAD (radar reflectivity, rain near radar) 


\title{
CHAPTER 3
}

"Fruit Removal Rate Depends on Neighborhood Fruit Density, Frugivore Abundance, and Spatial Context"

by

\author{
Adam D. Smith ${ }^{5,6}$ and Scott R. McWilliams ${ }^{1}$
}

is in press at Oecologia

${ }^{5}$ Department of Natural Resources Science, University of Rhode Island, 1 Greenhouse Road, Kingston, RI 02881, USA

${ }^{6}$ E-mail: adam.smith@my.uri.edu 
Abstract Fleshy-fruited plants depend fundamentally on interactions with frugivores for effective seed dispersal. Recent models of frugivory within spatially explicit networks make two general predictions regarding these interactions: (1) rate of fruit removal increases (i.e., is facilitated) as densities of conspecific neighborhood fruits increase, and (2) fruit removal rate varies positively with frugivore abundance. We conducted a field experiment that constitutes the first empirical and simultaneous test of these two primary predictions. We manipulated neighborhood abundances of arrowwood (Viburnum recognitum and $V$. dentatum) fruits in southern New England's maritime shrub community and monitored removal rates by autumn migrating birds. Focal arrowwood plants in neighborhoods with high conspecific fruit density sustained moderately decreased fruit removal rates (i.e., competition) relative to those in low density neighborhoods, a result that agrees with most field research to date but contrasts with theoretical expectation. We suggest the spatial contexts that favor competition (i.e., high-abundance neighborhoods and highly aggregated landscapes) are considerably more common than the relatively uniform, low aggregation fruiting landscapes that promote facilitation. Patterns of arrowwood removal by avian frugivores generally varied positively with, and apparently in response to, seasonal changes in migratory frugivore abundance. However, we suggest that dense stands of arrowwood concentrated frugivore activity at the neighborhood scale, thus counteracting geographic patterns of frugivore abundance. Our results underscore the importance of considering spatial context (e.g., fruit distribution and aggregation, frugivory hubs) in plant-avian frugivore interactions. 
Keywords avian frugivory, maritime plant community, neighborhood effects, stopover ecology, Viburnum

\section{Introduction}

Seed dispersal produces important ecological and evolutionary consequences for plants and their communities (Levin et al. 2003; Levine and Murrell 2003). Consider, for example, a temperate shrub producing fleshy fruits to compensate its primarily avian frugivores for seed dispersal services. The interactions between this shrub and its frugivores influence not only the outcome of the crucial mobile phase of its reproduction (i.e., its seed shadow; Janzen 1971), but their aggregate across the community of individuals governs subsequent plant community demographics (e.g., Debussche et al. 1982; Jordano 1994; Lázaro et al. 2005). Plants depend fundamentally on these interactions for effective seed dispersal, and the patterns of fruit consumption by frugivores regulate the frequency of these interactions (Schupp 1993; Russo et al. 2006; Schupp et al. 2010). But the dependence is mutual: the distribution of plants and their fruit resources can dictate the distribution and behavior of frugivores (e.g., activity and feeding decisions; Rey 1995; Moegenburg and Levey 2003; Borgmann et al. 2004). Certainly, frugivores respond to the intrinsic qualities of fruits adapted to encourage fruit selection and removal (reviewed in Herrera 2002). However, factors extrinsic to an individual plant often influence frugivore distribution and behavior profoundly, rendering them largely context-dependent. How this context-dependence influences the strength and direction of species interactions in general is a key gap in our current ecological knowledge (Agrawal et al. 2007). 
Context dependence is nearly ubiquitous in interactions among species (Agrawal et al. 2007), and the extent to which frugivores remove and disperse fruit is no exception (Schupp et al. 2010). Indeed, a given plant's spatial context may effectively determine its dispersal success (Herrera 1984b). In particular, the distribution, density, and species composition of the surrounding fruiting neighborhood can influence patterns of frugivory (and seed dispersal) by altering frugivore abundance and foraging behavior (Levey et al. 1984; Sargent 1990; Saracco et al. 2005). However, the influence of a fruiting neighborhood on fruit removal apparently lacks generality; in some cases, neighborhood fruit facilitates (i.e., increases) fruit removal by attracting frugivores (Sargent 1990; Takahashi and Kamitani 2004) while in others it decreases fruit removal when plants compete for frugivores (Moore and Willson 1982; Manasse and Howe 1983). Identifying generalities within this context dependence is crucial to developing a predictive understanding of seed dispersal efficiency (Carlo et al. 2007; Schupp et al. 2010)

Carlo et al. (2007) suggest that the influences of fruiting neighborhoods on fruit removal may be better understood within the context of a network governed predominantly by the spatial patterning of fruiting plants and the availability of frugivores. Specifically, their frugivory network model expands the concept of plantfrugivore interactions as hierarchical mutualistic networks (e.g., Jordano 1987; Jordano et al. 2003) to incorporate the spatial arrangements of plants explicitly, whereby the movements of frugivores establish the linkage among plants (i.e., the network topology). They implicate two primary factors that largely determine the outcome of the complex interactions between plants and frugivores: the spatial 
patterning of fruiting plants and the availability of frugivores. Spatial patterns of particular import include the density of fruiting neighborhoods at the local scale and plant aggregation (i.e., the clumpiness of, or non-uniformity in, plant and fruit distributions) at larger, landscape scales. The models of Carlo et al. (2007) emphasized frugivore abundance and assumed frugivores consumed only fruits. The more general situation is that frugivores vary in foraging efficiency and fruit preferences, and may switch among alternative prey (e.g., Carnicer et al. 2009); thus, "frugivore activity" better describes the product of both frugivore abundance and the extent to which the frugivores are consuming fruits. Fruiting plant spatial patterns, fruit properties (e.g., quantity and nutritional quality, phenology; reviewed in Levey et al. 2002), and frugivore activity can produce inequalities in visitation among plants; if inequalities are severe, network topologies may be dominated by "hubs" - plants, species, or neighborhoods that receive the majority of frugivory and seed dispersal services (Carlo et al. 2007). Simulations of avian frugivory within this spatiallyexplicit framework (Morales and Carlo 2006; Carlo et al. 2007; Carlo and Morales 2008) predict that fruit removal increases (i.e., facilitation occurs) from a given plant as a function of (1) increasing densities of conspecific fruit in the neighborhood surrounding that plant, and (2) increasing frugivore activity (Fig. 1). However, at typical levels of frugivore activity in highly aggregated landscapes (i.e., when fruits are distributed very non-uniformly on the landscape), fruit removal increases with neighborhood fruit density only to a point; in these landscapes, decreased fruit removal from a given plant (i.e., competition) may be expected at high conspecific neighborhood fruit densities (Carlo and Morales 2008; Fig. 1). Our field experiment 
constitutes the first empirical and simultaneous test of these predictions and their potential interaction.

We evaluated these predictions with two field experiments conducted during autumnal bird migration in the maritime shrub community of southern New England. The maritime shrub community is well-suited to evaluate frugivory network theory because of its abundant fruit availability but low fruiting plant diversity (Enser and Lundgren 2006). Additionally, generalist avian frugivores predominate and exhibit seasonal (Able 1977; Mizrahi et al. 2010; Svedlow et al. 2012) and predictable geographic variation in abundance (Baird and Nisbet 1960, Able 1977). Songbirds are the primary consumers of fruits on Block Island during fall and the majority of these birds are stopping to refuel during migration. Migration is an especially pertinent study context in which to test the stated predictions, as migrating songbirds at stopover sites have a strong impetus to assess and acquire food resources efficiently; autumn migration is also the critical period of interactions between the majority of fleshyfruited plants and their dispersers in this temperate maritime shrub system. Finally, simulations of avian frugivory (Morales and Carlo 2006; Carlo et al. 2007; Carlo and Morales 2008; Morales and Vázquez 2008) occur in a predominantly tropical context; thus we empirically evaluate their applicability in a temperate system.

Our field experiments examined differential fruit removal from individual northern and southern arrowwood (Viburnum recognitum and V. dentatum, respectively) plants relative to neighborhood fruit density and frugivore abundance. Arrowwood is the most important fruit resource for migratory birds within this maritime shrub community (Parrish 1997a; Smith et al. 2007; Bolser et al. 2013). We 
evaluated two specific predictions related to the effects of local neighborhood (i.e., 50

$\mathrm{m}^{2}$ ) and frugivore activity on fruit removal patterns: (1) focal arrowwood plants surrounded by neighborhoods containing natural abundances of conspecific fruits will experience increased rates of fruit removal relative to focal plants surrounded by neighborhoods from which we removed all conspecific fruit (Fig. 1, points a, c); however, if neighborhood fruit density is sufficiently high (the precise threshold is uncertain), rates of fruit removal from focal plants will be reduced, via competition for limited frugivore activity, relative to focal plants in neighborhoods without arrowwood (Fig. 1, points b, d); and (2) fruit removal rates on focal arrowwood plants will vary positively with temporal (seasonal) and geographic patterns of frugivore activity; however, high frugivore activity could decouple fruit removal rates from neighborhood fruit density and result in a high and constant rate of fruit removal, regardless of fruit density (Fig. 1, line e).

\section{Materials and methods}

Study site

The field experiment occurred on Block Island $\left(41^{\circ} 28^{\prime} \mathrm{N}, 71^{\circ} 31^{\prime} \mathrm{W}\right)$, a $25 \mathrm{~km}^{2}$ glacially deposited landmass located approximately $15 \mathrm{~km}$ south of the Rhode Island mainland. The species composition and structure of the maritime shrub community is dictated, in large part, by exposure to salt spray and wind (Enser and Lundgren 2006). Autumnal migrating songbirds rest and refuel extensively in the maritime shrub community of Block Island, consuming large quantities of fruit (Parrish 1997a) and playing a key role in the dispersal of fruiting species (Thompson and Willson 1979). 
The high-energy fruits of northern and southern arrowwood are used nearly ubiquitously by migrant frugivores, which prefer them to fruits of co-occurring plant species (Parrish 1997a, b; Smith et al. 2007; Bolser et al. 2013).

Plot establishment and neighborhood manipulation

In autumn 2009, we thoroughly searched the maritime shrub community and identified 16 arrowwood-dominated stands of adequate size within which to establish a single 5 x $20 \mathrm{~m}$ plot (Fig. 2). Plots were separated by sufficient distances to expect independence; the distance between a plot and its nearest neighboring plot averaged $272 \mathrm{~m}$ and $449 \mathrm{~m}$ on northern and southern Block Island, respectively, with a minimum separation of $65 \mathrm{~m}$. Our plots ranged over $7.5 \mathrm{~km}$ of latitude, nearly the entire latitudinal span $(8.7 \mathrm{~km})$ of the maritime shrub community on Block Island. We expected these uncommonly large stands of arrowwood to concentrate frugivore activity (i.e., that each plot would act essentially as a frugivory hub; sensu Carlo et al. 2007). Consistent with their general distribution on Block Island (Online Resource 1), northern arrowwood dominated all northern plots and southern arrowwood dominated 6 of 7 southern plots; northern arrowwood was more abundant on a single southern plot. To decouple the effect of the geographic location of plots from a potential preference for arrowwood species, we conducted a second experiment the following year (autumn 2010; see below).

To assess neighborhood effects, we paired subplots (i.e., one half of each plot; $5 \times 10 \mathrm{~m}$ ) within plots to control for (1) avian migrants' expected non-uniform use of the maritime shrub community and (2) heterogeneity in the species composition and 
physiognomy of the surrounding maritime shrub community. In each subplot, we monitored avian fruit removal from 8 well-separated, representative arrowwood infructescences (cymes) within a $1 \mathrm{~m}$ radius (ca. $3 \mathrm{~m}^{2}$ ) subplot "center"; we removed all other conspecific fruit within each subplot center. Subsequently in each plot, we removed all arrowwood fruits outside of the subplot center from one subplot, selected at random (hereafter, low density subplot; Fig. 2a). In the other subplot, arrowwood fruits outside of the subplot center were retained at their natural density (hereafter, high density subplot; Fig. 2a). The availability of arrowwood on Block Island dictated our use of only two density treatments: uniformly dense arrowwood stands were too small to evaluate more densities and maintain a reasonable neighborhood size and too few to incorporate them into an incomplete block approach. Hence we did not attempt to delineate the shape of the functional relationship between neighborhood density and fruit removal (Fig. 1) as this was not necessary to test the two general predictions of the frugivory network model. Natural arrowwood fruit densities ranged from 85 to 2185 fruits $\mathrm{m}^{-2}$ (median: 741 fruits $\mathrm{m}^{-2}$ ) and arrowwood fruit mass (wet pulp plus seed) per unit area ranged from 12.4 to $177.6 \mathrm{~g} \mathrm{~m}^{-2}$ (median: $63.6 \mathrm{~g} \mathrm{~m}^{-2}$ ). Our manipulation of the subplot centers controlled adequately for initial crop size (mean \pm SD: $221 \pm 82$ fruits) in paired subplots (paired $t_{15}=0.92, P=0.36$ ).

Monitoring fruit fate

Of the 8 cymes remaining in the center of each subplot, we selected three at random and enclosed them in loose, fine $\left(2.25 \mathrm{~mm}^{2}\right)$ nylon bags to prevent avian consumption. We used enclosed cymes to estimate natural fruit abscission in each 
subplot and the five remaining unenclosed cymes to assess the pattern of fruit removal by migratory songbirds. Fruits were counted every three days (median; range 2-6) from 16 September to 2 November ( $\mathrm{n}=14$ counts), although monitoring did not begin on two southern plots until the third count period; the experiment encompassed the greater part of fall migratory songbird use of the island and the availability of edible arrowwood. We estimated the number of fruits consumed and abscised on each subplot in each count period according to the following rules: (1) if the abscission rate on the enclosed cymes equaled or exceeded the rate of fruit loss on unenclosed cymes, we attributed the change in fruit abundance on unenclosed cymes entirely to abscission; or (2) if abscission rate was lower than the rate of fruit loss on unenclosed cymes, we used the abscission rate from the enclosed cymes to estimate the number of fruits that abscised from the unenclosed cymes with the balance of missing fruits attributed to removal by migratory birds.

\section{Patterns of frugivore activity}

Manipulating or monitoring frugivore activity on arrowwood plots proved logistically impractical. We initially considered point counts to document patterns of frugivore activity at each plot, but the density of the maritime shrub community impaired our ability to visually detect birds, which are likewise less conspicuous vocally during fall migration. Thus we elected to use seasonal fluctuations and islandscale geographic variation in migrant abundance to index frugivore activity. First, westerly winds associated with passing fall cold fronts displace large numbers of migratory songbirds offshore (Baird and Nisbet 1960; Able 1977); this weather 
dependency typically results in widely fluctuating frugivore densities throughout the fall migration on Block Island. We derived seasonal patterns of migrant (and thus frugivore) abundance during our experiment from concurrent radar work on Block Island (Mizrahi et al. 2010; Svedlow et al. 2012); marine surveillance radar is a standard method for estimating temporal patterns of abundance for nocturnally migrating songbirds (e.g., Harmata et al. 1999). Second, frugivore density is not uniform within the island's shrub community, and there exists a well-documented pattern in migrant densities on Block Island: migrants occur in higher densities on the northern half of the island following arrival, where they prepare for reoriented flights to the mainland or subsequent migratory flights to the south (Baird and Nisbet 1960; Able 1977). In support of this general pattern, mist netting capture rates in the maritime shrub community were considerably lower at southern locations (ADS, unpublished data; S. Comings, unpublished data). Indeed, the two migration banding operations on the island (Reinert et al. 2002), United States Fish \& Wildlife, unpublished data) continue to exploit the phenomenon, as have multiple previous studies (Parrish 1997b; Smith et al. 2007; Smith and McWilliams 2010; Bolser et al. 2013). The extent of frugivory by migrants possibly increased as arthropod prey availability decreased throughout the fall (Parrish 2000; ADS, unpub. data); this suggests a seasonal increase in frugivore activity independent of changes in frugivore abundance. Importantly, such an increase likely did not vary geographically, nor did we expect other aspects of frugivore behavior that might influence foraging activity to vary geographically (e.g., foraging efficiency, fruit preferences, risk of predation). 
Thus, in our case, we expect patterns of frugivore abundance represented a reliable proxy for frugivore activity.

Separating arrowwood species and geographic frugivore activity effects

The natural distribution of the two arrowwood species on Block Island potentially confounded or conflated any influence on fruit removal of geographic differences in frugivore activity in 2009. We conducted a second experiment to separate the effects of frugivore activity (as it related to geography) and arrowwood species on patterns of fruit removal, and thus inform inferences in the 2009 experiment. In autumn 2010 we monitored the fate of co-fruiting northern and southern arrowwood fruits at 12 locations (5 northern, 7 southern). At each location, we identified an arrowwood pair comprising single fruit-laden northern and southern arrowwood plants growing within $5 \mathrm{~m}$ of each other; the distance to the nearest neighboring pair averaged $376 \mathrm{~m}$ and $583 \mathrm{~m}$ on northern and southern Block Island, respectively, with a minimum separation of $54 \mathrm{~m}$. On each plant we removed all fruit except for 8 representative cymes distributed evenly throughout the plant, occupying an area similar to 2009 (ca. $3 \mathrm{~m}^{2}$; Fig. 2b; initial crop size mean \pm SD: $173 \pm 60$ fruits; paired $\left.t_{9}=1.23, P=0.25\right)$. We monitored and estimated fruit abscission and removal as described previously, counting fruits every five days (median; range 4-8) from 16Sep to 7-Nov ( $\mathrm{n}=10$ counts). Arrowwood pairs typically occurred in more diverse maritime shrub associations relative to the dense arrowwood-dominated stands used in 2009 (Fig. 2b). We used individuals growing in close proximity to control for 
neighborhood influences around arrowwood pairs, which we neither manipulated nor quantified.

\section{Statistical Analyses}

Arrowwood removal from focal plants varied considerably over time and among plants, with many instances of no removal or extensive removal. We accounted for this overdispersion by modeling counts of fruits removed with the negative binomial distribution; however, the prediction of zero and near-zero removal remained inadequate, particularly in 2009 (see Online Resource 1). Failure to account for excess zeros results in biased parameter and variance estimates (see, e.g., Martin et al. 2005). We thus used zero-inflated negative binomial (ZINB) mixture models (Lambert 1992) to evaluate the influence of fruit neighborhood and the expected geographic effect of frugivore activity on fruit removal rates; such models have proven appropriate in plant-frugivore networks (Carlo and Morales 2008; Morales and Vázquez 2008). To generate the ZINB rate model, we offset counts of arrowwood removal by the number of fruits present at the beginning of a count period, less the number of fruits estimated to have abscised in that count period. We fit the ZINB models using the glmmADMB package (Skaug et al. 2012) in R (R Development Core Team 2011). Examination of removal rates over time within experimental units suggested that random intercepts were justified among plots in 2009 and 2010; we also retained random intercepts for subplots (i.e., treatments within plots in 2009 and species within pairs in 2010) given their role in the experimental design. 
Rather than assess every possible combination of models, we compared a suite of models that addressed specific hypothetical scenarios for arrowwood removal (Table 2 in Online Resource 1). We judged the relative importance of competing models using sample size-corrected Akaike's Information Criterion $\left(\mathrm{AIC}_{\mathrm{c}}\right.$; Akaike 1974) and Akaike weights. If the model with lowest $\mathrm{AIC}_{\mathrm{c}}$ value had an Akaike weight less than 0.9 , we constructed a $95 \%$ confidence set of models with Akaike weights summing to $\geq 0.95$ (Burnham and Anderson 2002). In the interest of parsimony, we excluded any model with a higher $\mathrm{AIC}_{\mathrm{c}}$ value than a simpler, nested model and preferred the simpler of multiple, equally supported models (Burnham and Anderson 2002; Richards 2005).

Subsequent to the ZINB models, we used permutation tests to compare changes in arrowwood removal rates with seasonal patterns of migrant abundance inferred from concurrent marine radar (see above). We calculated, in each year, the average change in fruit removal rate for the count periods following the five nights of highest migratory activity. Our choice of five nights was somewhat arbitrary, but seemed reasonable based on the patterns of migratory activity (Fig. 1 and 2 in Online Resource 1). Using the count period subsequent to the measured migratory activity rather than the coinciding count period allowed us to accommodate an expected short (1-3 days) time lag between the arrival of migrants and detectable fruit removal (i.e., search and settling time; Alerstam and Lindström 1990). We compared this average change in fruit removal rates to 10,000 comparable changes calculated after permuting the nightly radar activity data (see Online Resource 1). 
Finally, we considered post hoc whether the change in spatial context of focal arrowwood plants between years affected the probability of frugivores finding focal arrowwood plants; recall that in 2009 focal plants occurred in plots encompassing large, dense, arrowwood-dominated stands, while in 2010 they occurred in multispecies associations. To do so, we constructed logistic generalized linear mixed models (GLMMs) using the lme4 package (Bates et al. 2011) for each season that evaluated the occurrence of any fruit removal (i.e., we dichotomized zero and nonzero fruit removal rates) as a function of the same suite of hypothetical scenarios (Table 2 in Online Resource 1).

\section{Results}

General patterns of arrowwood fruit loss

In 2009, we monitored the fate of 4,471 and 7,066 fruits on 96 enclosed and 160 unenclosed arrowwood cymes, respectively. Patterns of fruit loss from enclosed (abscission) and unenclosed (abscission and removal) cymes revealed highly episodic fruit removal and suggested that when removal episodes occur, rates of fruit removal are higher on focal plants in low density arrowwood neighborhoods (Fig. 3a, c) than in natural high density neighborhoods (Fig. 3b, d). In 2010, we monitored 3,094 and 4,651 fruits on 72 enclosed and 120 unenclosed arrowwood cymes, respectively. As in 2009, patterns of fruit loss revealed variable and episodic fruit removal and suggested that focal plants on northern arrowwood pairs (Fig. 4a, c) experienced more consistent fruit removal than those on southern arrowwood (Fig. 4b, d). 


\section{Arrowwood removal}

In 2009, arrowwood removal rate varied irregularly during the season and was somewhat influenced by neighborhood fruit density (64\% of the ZINB confidence set; Table 1), with arrowwood fruits surrounded by low density arrowwood neighborhoods sustaining increased removal at 1.5 times (95\% confidence interval: 1.0 to 2.3 ) the rate of fruits surrounded by a high density neighborhood (Fig. 5A). However, nonnegligible support for a model without the neighborhood fruit density effect (36\% of the ZINB confidence set; Table 1) suggested that the decrease in fruit removal rate attributable to neighborhood fruit density was not especially strong (Table 1). A geographic effect (frugivore activity) was not indicated in either supported model (Table 1). In 2010, the rate of arrowwood fruit removal varied episodically over the course of the season, as in the previous year, and varied with geographic differences in frugivore activity (84\% of the ZINB confidence set; Table 1); arrowwood fruits on northern Block Island sustained removal rates 4.1 times higher (95\% confidence interval: 1.2 to 14.4) than fruits on southern Block Island (Fig. 5b). Differences in removal rate related to arrowwood species were negligible; a reduced model without the arrowwood species effect was supported equivalently, thus the effect was superfluous (Table 1). In both years, a consistent relationship emerged between the seasonal fluctuations in fruit removal rate and seasonal changes in migratory bird activity measured via radar (Fig. 5). In general, fruit removal rates increased in the count periods following the nights of highest migratory activity in 2009 (permutation test; $P=0.078$ ) and 2010 (permutation test, $P=0.007$ ). Specifically, the distinct bouts of increased migratory activity were usually followed by distinct and occasionally 
prolonged increases in rates of arrowwood removal (Fig. 5). This pattern is consistent with the predicted positive relationship between frugivore activity and rates of fruit removal.

The probability of any fruit removal occurring in a given time period varied with the spatial context of focal arrowwood plants between years. In 2009, two models received equal support: a constant probability throughout the season for all focal plants and a more complicated linear change in the probability of removal that varied geographically (Table 1). We favored the much simpler, intercept-only model that suggested a statistically constant probability of sustaining removal over time in 2009. In contrast, the probability of fruit removal varied irregularly within arrowwood pairs during the 2010 season (Table 1), and very closely matched the corresponding pattern of fruit removal rates (i.e., Fig. 5b).

\section{Discussion}

The ecological interactions between plants and their avian frugivores are dynamic and complex - avian frugivores respond to and subsequently alter the distribution and abundance of fruit in space and over time, while also engaging in activities unrelated to fruit removal (e.g., foraging on arthropods, vigilance). We found moderate evidence that fruit-laden neighborhoods depressed fruit removal rates from the focal plants they surrounded, which agrees with most field research to date but contrasts with general theoretical expectation that conspecific fruiting neighborhoods facilitate fruit removal rates from focal plants (Carlo et al. 2007; Carlo and Morales 2008). We propose a general solution to this apparent conflict: the spatial 
contexts that favor facilitation are uncommon relative to the high-abundance neighborhoods and highly aggregated landscapes that promote competition. Northtemperate systems that support seasonally abundant frugivores provided a prime example. In agreement with theoretical expectation, we found two independent lines of support for an increase in fruit removal rates with increased frugivore activity; however, we suggest that the landscape context of our neighborhoods influenced frugivore activity and thus the expected pattern of fruit removal in a particular instance. Placed in the context of other work, our results further underscore the importance of considering spatial context (i.e., fruit abundance and aggregation, including the presence and influence of frugivory hubs) as well as frugivore activity in plant-avian frugivore interactions.

Influence of neighborhood fruit density on rate of fruit removal

Most field studies of neighborhood effects on rates of fruit removal or visitation by avian frugivores have documented competition or no discernible effect of neighborhood fruit density (Moore and Willson 1982; Manasse and Howe 1983; Herrera 1984a; Denslow 1987; French et al. 1992; Gryj and Domínguez 1996; García et al. 2001; Saracco et al. 2004; Saracco et al. 2005; Carlo and Morales 2008; Blendinger et al. 2008; Blendinger and Villegas 2011). We likewise found a moderate competitive effect of increased neighborhood fruit density, although spatial context possibly contributed to this effect. Focal plants in our high- and low-density neighborhoods were in close proximity (ca. $10 \mathrm{~m}$ apart) within uniformly dense arrowwood stands that likely concentrated frugivore activity. Whereas this design 
controlled effectively for non-uniformly distributed avian migrants and heterogeneity in the surrounding maritime shrub community, we recognize that such a placement possibly inflated frugivore visitation rates to low-density neighborhoods (relative to naturally low-density neighborhoods). We suggest this further illustrates the importance of spatial context when considering neighborhood influences on fruit removal (see below). We further note, however, that neutral neighborhood effects suggest some level of competition if facilitation is the expected outcome of plantfrugivore interactions as the alternative explanation, frugivore saturation (Fig. 1, line e), is likely uncommon and readily documented (e.g., all fruits consumed). In contrast, few studies have demonstrated that neighborhood fruit density facilitates rates of fruit removal or visitation by avian frugivores, and in most cases the facilitation was weak (Takahashi and Kamitania 2004; Pizo and Almeida-Neto 2009), inconsistent among sites or species (García et al. 2001; Blendinger et al. 2008), or restricted to marginally important heterospecific species (Saracco et al. 2005). Fruit removal facilitated by interspecific neighborhood fruit abundance has been inferred in some host-parasite-frugivore interactions (e.g., van Ommeren and Whitham 2002;

Carlo and Aukema 2005; but see Saracco et al. 2005), although to our knowledge patterns of fruit removal from infected plants as a function of their parasitic neighborhood has not been documented explicitly.

The simulations of Carlo and colleagues (Carlo et al. 2007, Carlo and Morales 2008) suggested that competition can emerge when two neighborhood conditions are met: conspecific fruit is abundant at the neighborhood spatial scale, and the neighborhood occurs in a highly aggregated fruiting landscape. Fruit densities in our 
study system far exceeded those at which competition became manifest in their simulations; for example, our densest $50 \mathrm{~m}^{2}$ neighborhood alone contained more fruit than their entire simulated landscape $\left(25 \mathrm{~km}^{2}\right)$, an area equivalent to all of Block Island. Arrowwood is also very patchily distributed and thus highly aggregated on Block Island (sensu Carlo and Morales 2008); likewise, most work documenting competition or neutral neighborhood effects involves species that are at least moderately aggregated on the landscape (i.e., Moore and Willson 1982; Manasse and Howe 1983; Herrera 1984b; Denslow 1987; Gryj and Domínguez 1996; Saracco et al. 2004; Carlo and Morales 2008; Blendinger et al. 2008); we were unable to evaluate the landscape distribution of focal species in several studies (French et al. 1992; García et al. 2001; Saracco et al. 2005; Blendinger and Villegas 2011). Furthermore, the clearest documented example of facilitation occurred in a highly homogeneous fruiting landscape. Sargent (1990) found that dense fruiting neighborhoods of northern arrowwood facilitated removal relative to low density neighborhoods, but the experimental neighborhoods were carved out of an expansive arrowwood monoculture. Such a landscape with low plant and fruit aggregation strongly favors facilitation (Carlo and Morales 2008) and stands in stark contrast to the distribution of arrowwood on Block Island and fruits in most other research to date.

Although Carlo and colleagues (Carlo et al. 2007, Carlo and Morales 2008) recognized that landscape context influenced the effects of neighborhood fruit density, our review of previous studies and our experience with arrowwood on Block Island suggests potential mechanisms by which neighborhood fruit density and landscape context can interact to produce facilitation or competition. We propose that 
competition is the typical outcome of increased neighborhood fruit density in a landscape in which fruits are highly aggregated, but the reason for competition varies with landscape context. For example, in neighborhoods within frugivory hubs, concentrated frugivore activity within the hub decreases the residual quality of the neighborhood and thus limits the recruitment of additional frugivores, resulting quickly in competition for limited frugivores as neighborhood fruit densities increase. We suggest this reasonably describes the situation for arrowwood on Block Island and possibly other work (e.g., Manasse and Howe 1983, Denslow 1987, Gryj and Dominguez 1996, Carlo and Morales 2008), although it was typically difficult to infer network context of focal plants (e.g., position relative to, and existence of, frugivory hubs). At the other extreme, isolated neighborhoods not associated with frugivory hubs, but occurring within a highly aggregated fruiting landscape, may also experience decreased removal rates as neighborhood fruit densities increase; however, in this case, we suggest the competition with neighboring plants for frugivores results from the difficulty of recruiting frugivores to the isolated neighborhoods. However, when fruits are not highly aggregated on the landscape (e.g., Sargent 1990; Takahashi and Kamitania 2004; Pizo and Almeida-Neto 2009), frugivores, like the fruits they seek, are relatively uniformly distributed and thus easily recruited to neighborhoods with higher fruit density. In these cases, we propose that easy frugivore recruitment and a higher residual quality in the neighborhood makes facilitation the more likely outcome of increased neighborhood fruit density.

Collectively, existing evaluations of neighborhood effects (1) support a prominent influence of the spatial distribution of fruit, on multiple scales, on the 
patterns of fruit removal, (2) rarely document facilitation in contrast to theoretical expectations, and (3) suggest that moderately and highly aggregated plant (and fruit) distributions are prevalent in plant communities. Thus, contemporary theoretical models (e.g., Morales and Carlo 2006; Carlo et al. 2007; Carlo and Morales 2008), while quite useful, may not adequately characterize most empirical work to date, particularly in temperate systems that support seasonally abundant frugivores. As such, models of plant-frugivore interactions will benefit from the exploration of alternative or additional model parameters (see below).

Influence of frugivore activity on rate of fruit removal

Simulations within spatially explicit networks clearly indicate that increased frugivore activity increases average fruit removal from individual plants (Carlo et al. 2007; Carlo and Morales 2008). We evaluated this predicted positive relationship in two ways: using (1) temporal changes in frugivore (migrant) abundance during the migration season, and (2) the well-documented differences in frugivore abundance associated with geography on Block Island. We interpreted geographic effects in 2009 without regard to arrowwood species because the 2010 experiment indicated frugivores did not strongly discriminate among fruits from the two arrowwood species.

Differences in frugivore activity due to patterns of migrant arrival.-Migrant activity on Block Island fluctuated throughout the migration season, often dramatically (Fig. 5; Mizrahi et al. 2010; Svedlow et al. 2012). However, fruit removal rates consistently increased in the days following the most substantial migratory movements 
over Block Island during 2009 and 2010 (Fig. 5), in accordance with the predicted positive relationship between frugivore activity and fruit removal rates (Carlo et al. 2007; Carlo and Morales 2008). A 1-3 day lag was often apparent between the presumed arrival of migrants and the concomitant removal of fruit likely due to search and settling time (Alerstam and Lindström 1990).

Differences in frugivore abundance due to geography. - We expected and documented higher fruit removal rates on northern Block Island in arrowwood pairs in 2010; however, this difference was not evident among arrowwood plots in 2009. Recall that experimental plots were selected to encompass uncommonly dense concentrations of arrowwood, whereas the arrowwood pairs occurred within more typical mixed species maritime shrub stands. We thus considered whether this change in the spatial context of focal plants influenced the distribution of frugivores (logistic GLMMs; Table 1; Online Resource 1). Focal plants in dense arrowwood stands (2009) experienced a consistent probability of incurring fruit removal throughout the season while plants not associated with arrowwood concentrations (i.e., most 2010 focal pairs) sustained lower rates of removal in general and only experienced significant removal when frugivores were abundant (Fig. 5). This discrepancy suggests that the 2009 plots acted as frugivory hubs, concentrating frugivore activity at the plot (neighborhood) scale, effectively counteracting the prevailing differences in frugivore activity at a larger landscape scale.

\section{Conclusions}


Current individual-based frugivory models (Morales and Carlo 2006; Carlo et al. 2007; Carlo and Morales 2008; Morales and Vázquez 2008) establish a strong, though necessarily simplified foundation, but their foremost property is their flexibility. Generating predictions for plant-frugivore interactions in different ecosystem contexts can be accomplished with relative ease by modifying existing parameters of these models and, if necessary, incorporating additional parameters. For example, previous frugivory models possess a distinctly "tropical" inclination, but simple changes in the specification of existing parameters, such as modifying patterns of fruit regrowth (or ripening) and accommodating larger and more variable initial crop sizes and frugivore abundances, would increase the relevance of simulations to temperate systems like the maritime shrub community on Block Island. Likewise, these frugivory models can be customized to anticipate the dynamics of plantfrugivore interactions in particular ecological contexts. Songbird migration stopover provides an example relevant to the current study. The "temperate" frugivory model could be extended to provide simulated foragers with alternative foraging decisions that more adequately capture frugivore activity (e.g. varying abundances, phenologies, and preferences for multiple co-fruiting species and co-occurring arthropod resources; see, e.g., Carnicer et al. 2009) under a particular maximization scheme (e.g., energy intake relative to energy expenditure). Certainly, achieving fully mechanistic models of avian dispersal will be challenging (Muller-Landau et al. 2008), but we argue that there is much to be gained despite this potential limitation. Seeking the general properties of plant-frugivore interactions will require the evaluation of many specific 
ecosystem and ecological contexts, but we expect individual-based frugivory models will play a key role in doing so.

\section{Acknowledgments}

Thanks to the fine assistance of two dedicated field crews, including B. Jones, R.

Alan, S. Bebus, K. Chmiel, J. Cressman, L. Jenkins, and E. Pokrivka. S. Comings and The Nature Conservancy graciously accommodated field staff and provided property access and logistical support on Block Island. New Shoreham Town Manager N.

Dodge facilitated access to town property. Doug Levey and four anonymous reviewers provided valuable criticisms of earlier drafts. This work was funded by the National Science Foundation (IBN-9984920, IOS-0748349), Rhode Island Agricultural Experiment Station (contribution no. 5350), and the U.S. Department of Agriculture (538748) to SRM and a Nature Conservancy grant to ADS. The experiments comply with the current laws of the United States of America.

\section{References}

Able KP (1977) The orientation of passerine nocturnal migrants following offshore drift. Auk 94:320-330

Agrawal AA, Ackerly DD, Adler F, Arnold AE, Cáceres C, Doak DF, Post E, Judson PF, Maron J, Mooney KA, Power M, Schemske D, Stachowicz J, Strauss S, Turner MG, Werner E (2007) Filling key gaps in population and community ecology. Frontiers in Ecology and the Environment 5:145-152. doi:

$10.2307 / 20440610$ 
Akaike H (1974) A new look at the statistical model identification. IEEE Transactions of Automatic Control 19:716-723. doi: 10.1109/TAC.1974.1100705

Alerstam T, Lindström $\AA$ (1990) Optimal bird migration: the relative importance of time, energy and safety. In: Gwinner E (ed) Bird migration: the physiology and ecophysiology. Springer-Verlag, New York, New York, USA, pp 331-351

Baird J, Nisbet ICT (1960) Northward fall migration on the Atlantic coast and its relation to offshore drift. Auk 77:119-149

Bates D, Maechler M, Bolker B (2011) lme4: linear mixed-effects models using S4 classes, R Package version 0.999375-42.

Blendinger PG, Loiselle BA, Blake JG (2008) Crop size, plant aggregation, and microhabitat type affect fruit removal by birds from individual melastome plants in the Upper Amazon. Oecologia 158:273-283. doi: 10.1007/s00442008-1146-3

Blendinger PG, Villegas M (2011) Crop size is more important than neighborhood fruit availability for fruit removal of Eugenia uniflora (Myrtaceae) by bird seed dispersers. Plant Ecol 212:889-899. doi: 10.1007/s11258-010-9873-z

Bolser JA, Alan RA, Smith AD, Li L, Seeram MP, McWilliams SR (2013) Birds select fruits with more anthocyanins and phenolic compounds during autumn migration. Wilson J Ornithol 125:97-108

Borgmann KL, Pearson SF, Levey DJ, Greenberg CH, Stouffer PC (2004) Wintering Yellow-rumped Warblers (Dendroica coronata) track manipulated abundance of Myrica cerifera fruits. Auk 121:74-87. doi: 10.1642/00048038(2004)121[0074:WYWDCT]2.0.CO;2 
Burnham KP, Anderson DR (2002) Model selection and multimodel inference: a practical information-theoretic approach, 2nd ed. Springer-Verlag, New York, New York, USA

Carlo TA, Aukema JE (2005) Female-directed dispersal and facilitation between a tropical mistletoe and a dioecious host. Ecology 86:3245-3251. doi:

$10.1890 / 05-0460$

Carlo TA, Aukema JE, Morales JM (2007) Plant-frugivore interactions as spatially explicit networks: integrating frugivore foraging with fruiting plant spatial patterns. In: Dennis AJ, Schupp EW, Green RJ, Westcott DA (eds) Seed dispersal: theory and its application in a changing world. CAB International, Wallingford, Oxfordshire, UK, pp 369-390

Carlo TA, Morales JM (2008) Inequalities in fruit-removal and seed dispersal: consequences of bird behaviour, neighbourhood density and landscape aggregation. J Ecol 96:609-618. doi: 10.1111/j.1365-2745.2008.01379.x

Carnicer J, Jordano P, Melián CJ (2009) The temporal dynamics of resource use by frugivorous birds: a network approach. Ecology 90:1958-1970. doi: $10.1890 / 07-1939.1$

Debussche M, Escarré J, Lepart J (1982) Ornithochory and plant succession in Mediterranean abandoned orchards. Vegetatio 48:255-266. doi: 10.1007/BF00055269

Denslow JS (1987) Fruit removal rates from aggregated and isolated bushes of the red elderberry, Sambucus pubens. Can J Botany 65:1229-1235. doi: 10.1139/b87170 
Enser RW, Lundgren JA (2006) Natural communities of Rhode Island. Rhode Island Natural History Survey, Kingston, Rhode Island, USA

French K, O’Dowd DJ, Lill A (1992) Fruit removal of Coprosma quadrifida (Rubiaceae) by birds in south-eastern Australia. Aust J Ecol 17:35-42. doi: 10.1111/j.1442-9993.1992.tb00778.x

García D, Zamora R, Gómez JM, Hódar JA (2001) Frugivory at Juniperus communis depends more on population characteristics than on individual attributes. J Ecol $89: 639-647$

Gryj EO, Domínguez CA (1996) Fruit removal and postdispersal survivorship in the tropical dry forest shrub Erythroxylum havanense: ecological and evolutionary implications. Oecologia 108:368-374

Harmata AR, Podruzny KM, Zelenak JR, Morrison ML (1999) Using marine surveillance radar to study bird movements and impact assessment. Wildlife Soc B 27:44-52. doi: 10.2307/3783939

Herrera CM (1984a) Seed dispersal and fitness determinants in wild rose: combined effects of hawthorn, birds, mice, and browsing ungulates. Oecologia 63:386393

Herrera CM (1984b) A study of avian frugivores, bird-dispersed plants, and their interaction in Mediterranean scrublands. Ecol Monogr 54:2-23. doi: $10.2307 / 1942454$

Herrera CM (2002) Seed dispersal by vertebrates. In: Herrera CM, Pellmyr O (eds) Plant-animal interactions: an evolutionary approach, 1st ed. Blackwell, Oxford, UK, pp 185-208 
Janzen DH (1971) Seed predation by animals. Annu Rev Ecol Syst 2:465-492. doi:

$10.2307 / 2096937$

Jordano P (1987) Patterns of mutualistic interactions in pollination and seed dispersal: connectance, dependence asymmetries, and coevolution. Am Nat 129:657-677

Jordano P (1994) Spatial and temporal variation in the avian-frugivore assemblage of Prunus mahaleb: patterns and consequences. Oikos 71:479-491. doi: $10.2307 / 3545836$

Jordano P, Bascompte J, Olesen JM (2003) Invariant properties in coevolutionary networks of plant-animal interactions. Ecol Lett 6:69-81.

Lambert D (1992) Zero-inflated Poisson regression, with an application to defects in manufacturing. Technometrics 1-14

Lázaro A, Mark S, Olesen JM (2005) Bird-made fruit orchards in northern Europe: nestedness and network properties. Oikos 110:321-329

Levey DJ, Moermond TC, Denslow JS (1984) Fruit choice in Neotropical birds: the effect of distance between fruits on preference patterns. Ecology 844-850

Levey DJ, Silva WR, Galetti M (2002) Seed dispersal and frugivory: ecology, evolution, and conservation, 1st ed. CABI Publishing, New York, New York, USA

Levin SA, Muller-Landau HC, Nathan R, Chave J (2003) The ecology and evolution of seed dispersal: a theoretical perspective. Annu Rev Ecol Evol S 34:575-604. doi: $10.2307 / 30033787$

Levine JM, Murrell DJ (2003) The community-level consequences of seed dispersal patterns. Annu Rev Ecol Evol S 34:549-574. doi: 10.2307/30033786 
Link WA, Barker RJ (2006) Model weights and the foundations of multimodel inference. Ecology 87:2626-2635

Manasse RS, Howe HF (1983) Competition for dispersal agents among tropical trees: influences of neighbors. Oecologia 59:185-190

Martin TG, Wintle BA, Rhodes JR, Kurner PM, Field SA, Low-Choy SJ, Tyre AJ, Possingham HP (2005) Zero tolerance ecology: improving ecological inference by modelling the source of zero observations. Ecol Lett 8:1235-1246

Mizrahi D, Fogg R, Magarian T, Elia V, Jodgetts P, La Puma D (2010) Radar monitoring of bird and bat movement patterns on Block Island and its coastal waters. In: McCann J and 28 others (eds) Ocean Special Area Management Plan. University of Rhode Island, Narragansett, Rhode Island, USA, p Technical Report 11, Appendix K

Moegenburg SM, Levey DJ (2003) Do frugivores respond to fruit harvest? An experimental study of short-term responses. Ecology 84:2600-2612. doi: $10.2307 / 3450106$

Moore LA, Willson MF (1982) The effect of microhabitat, spatial distribution, and display size on dispersal of Lindera benzoin by avian frugivores. Can J Bot 60:557-560

Morales JM, Carlo TA (2006) The effects of plant distribution and frugivore density on the scale and shape of dispersal kernels. Ecology 87:1489-1496

Morales JM, Vázquez DP (2008) The effect of space in plant-animal mutualistic networks: insights from a simulation study. Oikos 117:1362-1370. doi: 10.1111/j.2008.0030-1299.16737.x 
Muller-Landau HC, Wright SJ, Calderón O,Condit R, Hubbell SP (2008) Interspecific variation in primary seed dispersal in a tropical forest. J Ecol 96:653-667. doi: 10.1111/j.1365-2745.2008.01399.x

Parrish JD (1997a) Frugivory during autumn migration in Nearctic-Neotropical migrant landbirds: patterns, causes, and consequences. PhD Dissertation, Department of Ecology and Evolution, Brown University

Parrish JD (1997b) Patterns of frugivory and energetic condition in Nearctic landbirds during autumn migration. Condor 99:681-697

Parrish JD (2000) Behavioral, energetic, and conservation implications of foraging plasticity during migration. Stud Avian Biol 20:53-70

Pizo MA, Almeida-Neto M (2009) Determinants of fruit removal in Geonoma pauciflora, an understory palm of neotropical forests. Ecol Res 24:1179-1186. doi: 10.1007/s11284-009-0599-0

R Development Core Team (2011) R: a language and environment for statistical computing. R Foundation for Statistical Computing, Vienna, Austria

Reinert SE, Lapham E, Gaffett K (2002) Landbird migration on Block Island: community composition and conservation implications for an island stopover habitat. In: Paton PW, Gould LL, August PV, Frost AO (eds) The Ecology of Block Island. The Rhode Island Natural History Survey, Kingston, Rhode Island, USA, pp 151-168

Rey PJ (1995) Spatio-temporal variation in fruit and frugivorous bird abundance in olive orchards. Ecology 76:1625-1635. doi: 10.2307/1938163 
Richards SA (2005) Testing ecological theory using the information-theoretic approach: examples and cautionary results. Ecology 86:2805-2814

Russo SE, Portnoy S, Augspurger CK (2006) Incorporating animal behavior into seed dispersal models: implications for seed shadows. Ecology 87:3160-3174. doi: 10.1890/0012-9658(2006)87[3160:IABISD]2.0.CO;2

Saracco JF, Collazo JA, Groom MJ (2004) How do frugivores track resources? Insights from spatial analyses of bird foraging in a tropical forest. Oecologia 139:235-245. doi: 10.1007/s00442-004-1493-7

Saracco JF, Collazo JA, Groom MJ, Carlo TA (2005) Crop size and fruit neighborhood effects on bird visitation to fruiting Schefflera morototoni trees in Puerto Rico. Biotropica 37:81-87

Sargent S (1990) Neighborhood effects on fruit removal by birds: a field experiment with Viburnum dentatum (Caprifoliaceae). Ecology 1289-1298

Schupp EW (1993) Quantity, quality and the effectiveness of seed dispersal by animals. Plant Ecol 107-108:15-29. doi: 10.1007/BF00052209

Schupp EW, Jordano P, Gómez JM (2010) Seed dispersal effectiveness revisited: a conceptual review. New Phytol 188:333-353. doi: 10.1111/j.14698137.2010.03402.x

Skaug H, Fournier D, Nielsen A, et al. (2012) glmmADMB: generalized linear mixed models using AD Model Builder, R package version 0.7.2.5/r186

Smith SB, McPherson KH, Backer JM, Pierce BJ, Podlesak DW, McWilliams SR (2007) Fruit quality and consumption by songbirds during autumn migration. Wilson J Ornithol 119:419-428 
Smith SB, McWilliams SR (2010) Patterns of fuel use and storage in migrating passerines in relation to fruit resources at autumn stopover sites. Auk 127:108118. doi: 10.1525/auk.2009.09139

Svedlow AB, Gilpatrick L, Agius B, Andrews M, Myers P (2012) Pre-construction avian and bat assessment: 2009-2011. In: Tetra Tech EC, Inc. (ed) Block Island Wind Farm and Block Island Transmission System Environmental Report / Construction and Operations Plan. Deepwater Wind, Boston, MA, Appendix O

Takahashi K, Kamitani T (2004) Factors affecting seed rain beneath fleshy-fruited plants. Plant Ecol 174:247-256

Thompson JN, Willson MF (1979) Evolution of temperate fruit/bird interactions: phenological strategies. Evolution 973-982

Van Ommeren RJ, Whitham TG (2002) Changes in interactions between juniper and mistletoe mediated by shared avian frugivores: parasitism to potential mutualism. Oecologia 130:281-288 
Table 1 Results of $95 \%$ confidence set of zero-inflated negative binomial (ZINB) mixture models of fruit removal patterns and logistic generalized linear mixed models (GLMM) evaluating the probability of incurring fruit removal on Block Island in 2009 and 2010. TRT denotes the effect of a neighborhood fruit density manipulation (2009) or arrowwood species (2010) on fruit removal; TIMEF denotes a categorical specification of time (i.e., count period); GEOG denotes the effect of geography on fruit removal. See Online Resource 1 and the text for details

Candidate model $^{\mathrm{a}} \quad \mathrm{k}^{\mathrm{b}} \quad \mathrm{AIC}_{\mathrm{c}} \quad \Delta_{\mathrm{i}}^{\mathrm{c}} \quad w_{\mathrm{i}}{ }^{\mathrm{d}} \quad \Sigma w_{\mathrm{i}}^{\mathrm{e}}$

\section{ZINB}

2009

$\begin{array}{lccccc}\text { (5) } \mathrm{TIMEF}+\mathrm{TRT} & 15 & 2145.6 & 0.0 & 0.64 & 0.64 \\ \text { (2) TIMEF } & 14 & & 1.2 & 0.36 & 1.00\end{array}$

2010

$\begin{array}{lccccc}\text { (4) } \mathrm{TIMEF}+\mathrm{TRT}+\text { GEOG } & 12 & 1132.0 & 0.0 & 0.43 & 0.43 \\ \text { (6) } \mathrm{TIMEF}+\text { GEOG } & 11 & & 0.1 & 0.41 & 0.84 \\ \text { (2) } \mathrm{TIMEF} & 10 & & 2.2 & 0.14 & 0.99\end{array}$

Logistic GLMM

2009
(8) TIME | GEOG
$4 \quad 526.2$
0.0
0.55
0.55 
(1) INTERCEPT ONLY
2010

(2) TIMEF

1

0.4

0.45

1.00

293.0

0.0

0.99

0.99

${ }^{a}$ number preceding model corresponds to model listing in Table 1 of Online Resource 1

${ }^{b}$ number of fixed effect parameters estimated; the random effects structure did not vary among models

${ }^{\mathrm{c}}$ difference in $\mathrm{AIC}_{\mathrm{c}}$ between model $\mathrm{i}$ and best model (lowest $\mathrm{AIC}_{\mathrm{c}}$ )

${ }^{\mathrm{d}}$ Akaike weights, analogous to the probability of model $\mathrm{i}$ being the best approximating model in the set (Burnham and Anderson 2002; but see Richards 2005, Link and Barker 2006)

${ }^{\mathrm{e}}$ cumulative sum of Akaike weights from the best model to model $\mathrm{i}$ 
Fig. 1 Hypothesized changes in fruit removal rate from focal arrowwood (Viburnum sp.) plants at different neighborhood fruit density and frugivore activity scenarios. At low to moderate frugivore activity (solid lines), fruit removal increases from focal plants surrounded by neighborhoods containing conspecific fruit relative to focal plants with no neighborhood fruit. However, increased removal occurs only up to some unknown low or moderate neighborhood density (e.g., points a, c) beyond which fruit removal from focal plants decreases due to competition for frugivores. At very high neighborhood densities (e.g., points b, d), removal rates may fall below that incurred in the absence of neighborhood fruit. Sufficiently high frugivore activity may diminish or eliminate any effect of neighborhood fruit density if most (or all) available fruits are consumed (line e). Note that the exact form of the predictions (e.g., curvilinear or otherwise) between neighborhood fruit density and fruit removal rate is not crucial in this case

Fig. 2 a) In autumn 2009 arrowwood plots, all arrowwood was removed within a low density subplot and a $5 \mathrm{~m}$ circle around the treatment subplot center (broken circle) to ensure a fruitless conspecific neighborhood. Fruit counts occurred on eight representative arrowwood infructescences (filled circles) in the center (solid circle) of each subplot. b) In autumn 2010 arrowwood pairs, a northern arrowwood shrub (Viburnum recognitum; unshaded shrubs) was located adjacent to and within $5 \mathrm{~m}$ of a southern arrowwood shrub ( $V$. dentatum; shaded shrubs). Fruit counts of fruit occurred on eight representative arrowwood infructescences (filled circles) evenly distributed on each focal plant. 
Fig. 3 Percentage fruit lost since the previous fruit count (interquartile range shown in shading) from enclosed (solid line) and unenclosed (dashed line) arrowwood infructescences in a) low and b) high density neighborhoods on northern Block Island and from c) low and d) high density neighborhoods on southern Block Island during autumn 2009

Fig. 4 Percentage fruit lost since the previous fruit count (interquartile range shown in shading) from enclosed (solid line) and unenclosed (dashed line) cymes of northern arrowwood (Viburnum recognitum) on a) northern and b) southern Block Island and from southern arrowwood (V. dentatum) on c) northern and d) southern Block Island during autumn 2010

Fig. 5 Seasonal patterns in arrowwood fruit removal by avian frugivores (lines) and migrant activity based on concurrent marine radar monitoring (gray shading, see text) during fall migration on Block Island in a) low density (solid line) and high density neighborhoods (dashed line) in 2009 and on b) northern (solid line) and southern Block Island (dashed line) in 2010. Dates of fruit counts are indicated by filled circles along the abscissa. Gaps in the radar data indicate missing data; concurrent acoustic data suggested that no considerable migratory activity occurred on these dates (see Online Resource 1). Confidence intervals around removal patterns are omitted for clarity 


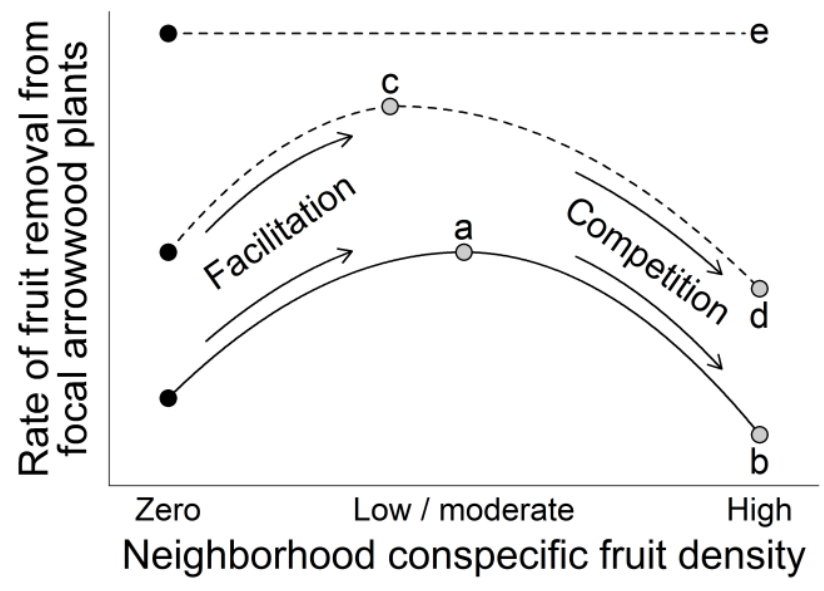

Fig. 1 


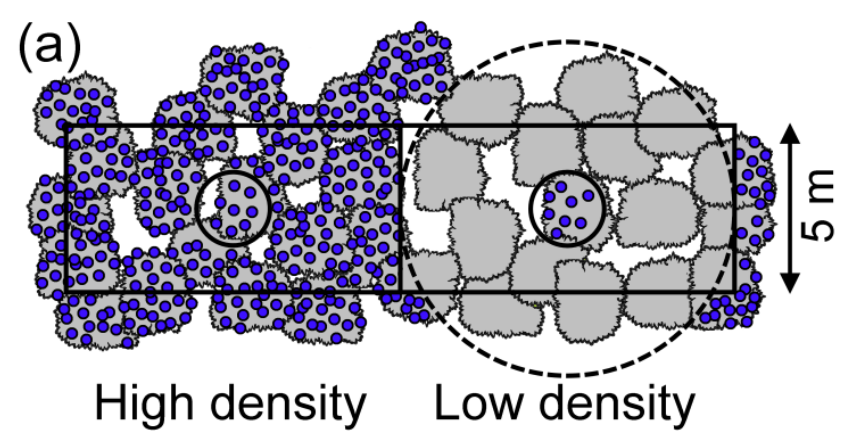

(b)
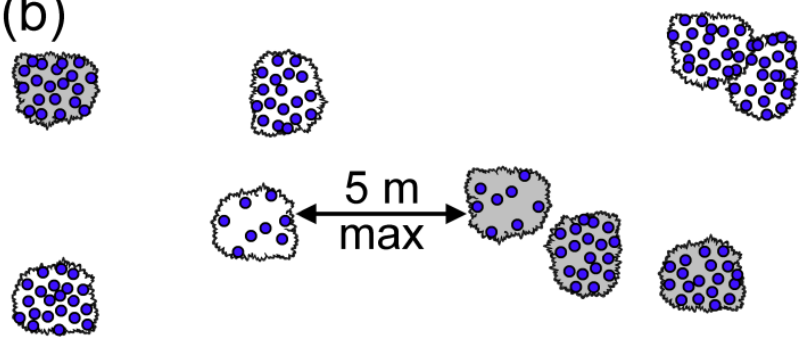

Fig. 2 


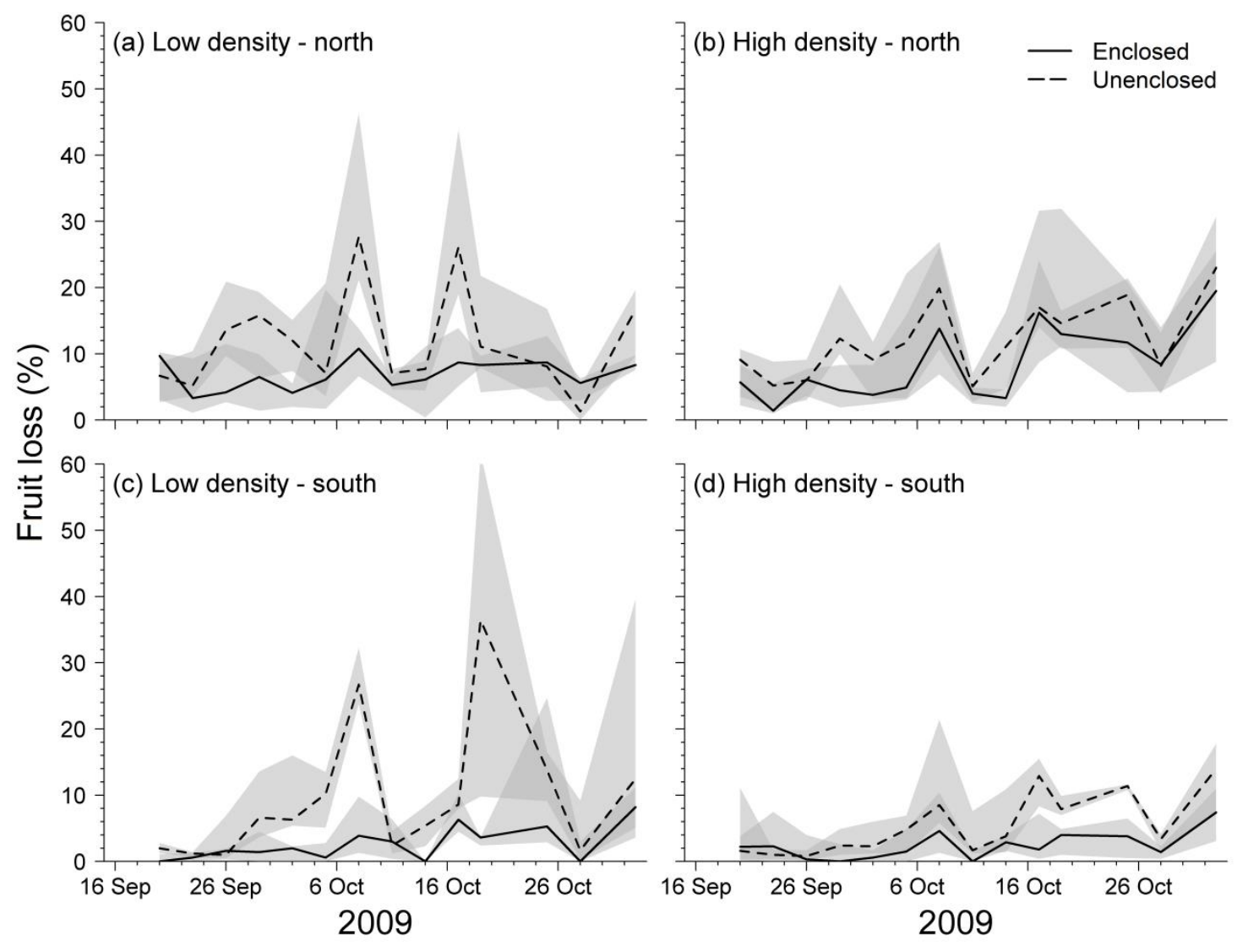

Fig. 3 


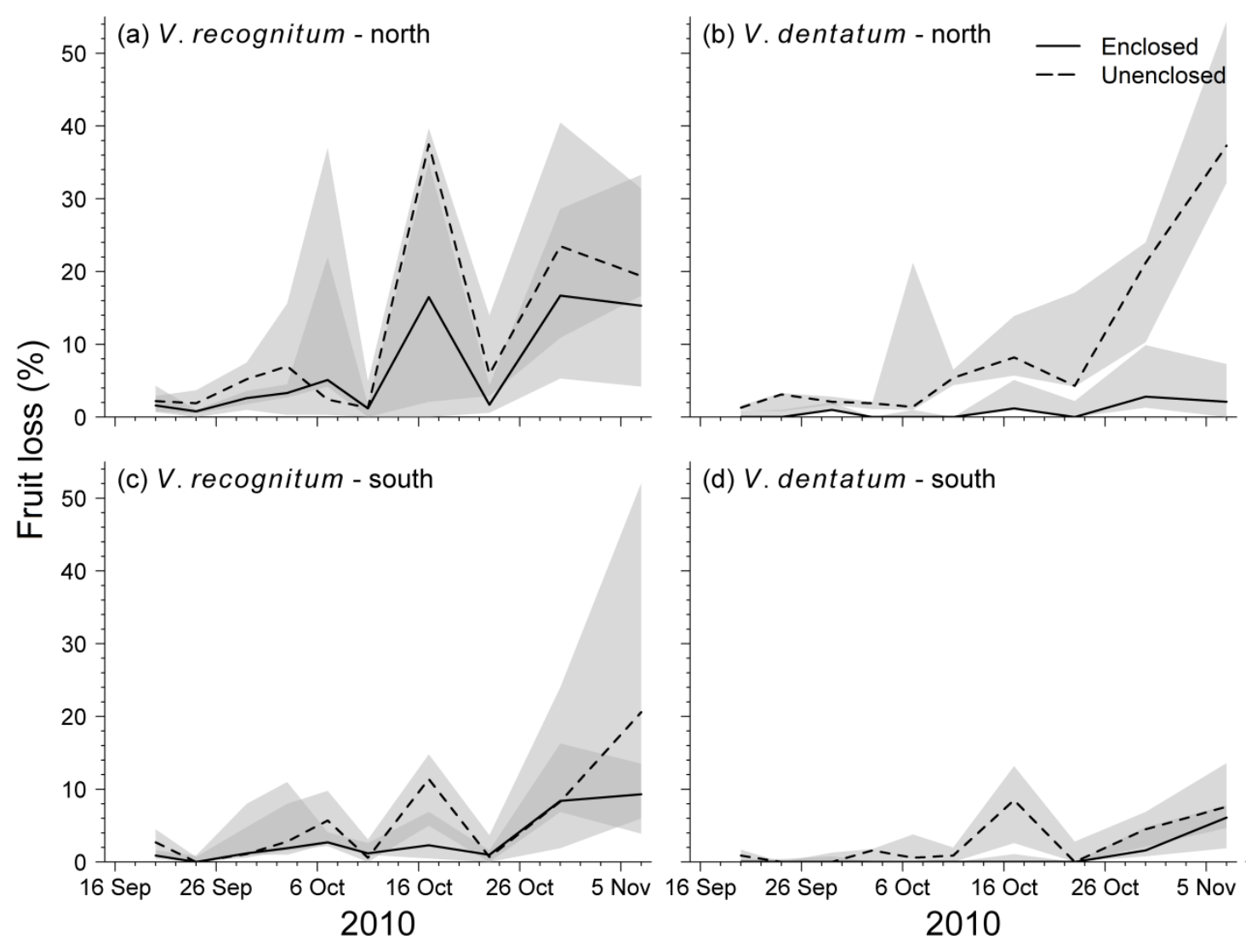

Fig. 4 


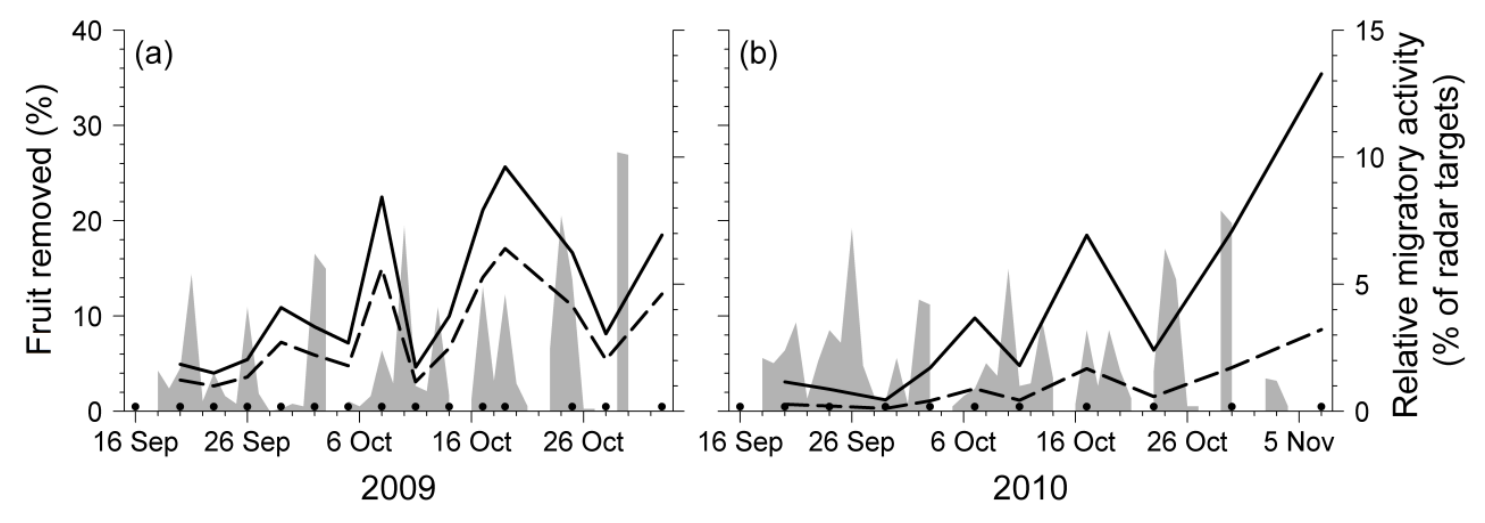

Fig. 5 
Fruit removal rate depends on neighborhood fruit density, frugivore abundance, and spatial context.

Adam D. Smith ${ }^{1}$ and Scott R. McWilliams

Department of Natural Resources Science, University of Rhode Island, Kingston, RI 02881 USA

Online Resource 1 Description of the maritime shrub community and comparison of arrowwood fruit characteristics. More detailed descriptions of the experimental design, radar and acoustic monitoring of frugivore abundance, and statistical methods. Included is our evaluation of binomial generalized linear mixed models (GLMMs) error structures, overdispersion, the necessity of zero-inflated negative binomial (ZINB) mixture models, and post hoc logistic GLMMs.

\section{Materials and Methods}

Study site and study species

The field experiment occurred on Block Island $\left(41^{\circ} 28^{\prime} \mathrm{N}, 71^{\circ} 31^{\prime} \mathrm{W}\right)$, a $25 \mathrm{~km}^{2}$ glacially deposited landmass located approximately $15 \mathrm{~km}$ south of the Rhode Island mainland and $23 \mathrm{~km}$ east northeast of Montauk, New York. The species composition and structure of the maritime shrub community is dictated, in large part, by exposure to salt spray and wind (Enser and Lundgren 2006). Highly exposed areas near the coast are dominated by short-statured $(0.5-2.5 \mathrm{~m})$ bayberry (Morella pennsylvanica), poison ivy (Toxicodendron radicans), and roses (Rosa sp.), brambles (Rubus sp.), and briars (Smilax sp.). More protected areas are dominated by native shadbush (Amelanchier canadensis), northern and southern arrowwood, chokeberry (Aronia prunifolia, A. melanocarpa, and A. arbutifolia), winterberry (Ilex verticillata and $I$. laevigata), bayberry, and Virginia creeper (Parthenocissus quinquefolia), as well as the invasive multiflora rose (Rosa multiflora) and Oriental bittersweet (Celastrus orbiculatus). Although both arrowwood species occur throughout Block Island, northern arrowwood prevails on the northern half of the island while southern arrowwood predominates in the south. The two species exhibit distinct fruiting phenologies, with southern arrowwood ripening 7-10 days later and persisting longer into the fall (ADS, personal observations), and their fruits (single-seeded drupes) also differ somewhat in size and macronutrient content (Table 3.OR1).

2009 experimental plots

In autumn 2009, a thorough search of Block Island's maritime shrub community identified 16 arrowwood-dominated stands of adequate size within which to establish a single 5 x 20 m plot (Figure 3.2 in manuscript) separated by sufficient distances to ensure independence among plots (see below). The rectangular plot dimensions

\footnotetext{
${ }^{1}$ E-mail: adamsmith@my.uri.edu; Telephone: (401) 874-2026; Fax: (401) 874-4561
} 
accommodated the natural shape of large arrowwood stands (e.g., along trails, pond margins, or stone walls). Fruiting plants of other species occurred rarely in the plots. Plots were distributed nearly equally between the northern and southern halves of Block Island ( 9 and 7 plots, respectively). Plots were separated by $272 \mathrm{~m}$ and $449 \mathrm{~m}$, on average, for northern and southern plots, respectively; the minimum plot separation was $65 \mathrm{~m}$. Consistent with their general distribution on Block Island, northern arrowwood dominated all northern plots and southern arrowwood dominated 6 of 7 southern plots; northern arrowwood was more abundant on a single southern plot.

To assess neighborhood effects, we paired subplots (i.e., one half of each plot; $5 \times 10 \mathrm{~m}$ ) within the larger plot to control for (1) migrants' expected non-uniform use of the maritime shrub community and (2) heterogeneity in the species composition and physiognomy of the surrounding maritime shrub community, which would likely have confounded the influence of neighborhood arrowwood density on fruit removal (e.g., Saracco et al. 2004, Carlo 2005, García and Chacoff 2007). In each of the two subplots of a given plot, we monitored avian fruit removal from 8 well-separated, representative arrowwood infructescences (cymes) within a 1 m subplot "center"; we removed all other conspecific fruit within each subplot center. Subsequently in each plot, we removed all arrowwood fruits outside of the subplot center from one subplot, selected at random (hereafter, low density subplot; Fig. 2a in manuscript). In the other subplot, arrowwood outside of the subplot center was retained at its natural abundance (hereafter, high density subplot; Figure 3.2a in manuscript). Natural arrowwood fruit densities ranged from 85 to 2185 fruits $\mathrm{m}^{-2}$ (median: 741 fruits $\mathrm{m}^{-2}$ ) and arrowwood fruit mass (wet pulp plus seed) per unit area ranged from 12.4 to $177.6 \mathrm{~g} \mathrm{~m}^{-2}$ (median: $63.6 \mathrm{~g} \mathrm{~m}^{-2}$ ). Our manipulation of the subplot centers controlled adequately for initial crop size (mean \pm SD: $221 \pm 82$ fruits) in paired subplots (paired $t_{15}=0.92, P=0.36$ ). Centers were located at least $1 \mathrm{~m}$ from the subplot edge, and as near as possible to the geometric center of the subplot. Representative cymes were distributed evenly throughout the centers of the subplots, and included cymes from 1 to 3 individual plants, but always from a single species and the same species in paired subplots.

\section{0 experimental plots}

Any influence of geographic differences in bird abundance on fruit removal was potentially confounded by or conflated with the natural distribution of the two arrowwood species on Block Island in the 2009 experimental plots. To separate the effects of geography (i.e., bird abundance) and arrowwood species on patterns of fruit removal, and thus inform inferences in the 2009 experiment, in autumn 2010 we monitored the fate of northern and southern arrowwood fruits at 12 locations where the two species co-occurred. Arrowwood pairs occurred on northern and southern Block Island (5 and 7 locations, respectively), and the closest pairs occurred an average of $376 \mathrm{~m}$ and $583 \mathrm{~m}$ away for northern and southern pairs, respectively; minimum plot separation was $54 \mathrm{~m}$. Specifically, at each location, we identified an arrowwood pair consisting of fruit-laden northern and southern arrowwood plants growing within $5 \mathrm{~m}$ of each other. We removed all fruit from each pair of arrowwood plants except for 8 representative cymes on each plant distributed evenly throughout the plant rather than a $1 \mathrm{~m}$ center as in 2009 (Figure 3.2b in manuscript; initial crop 
size mean $\pm \mathrm{SD}: 173 \pm 60$ fruits; paired $\left.t_{9}=1.23, P=0.25\right)$. We monitored and estimated fruit abscission and removal as described previously, counting fruits every five days (median; range 4-8) from 16 September to 7 November ( $\mathrm{n}=10$ counts). Arrowwood pairs typically occurred in less dense associations of mixed (nonarrowwood) species composition compared to the dense arrowwood-dominated stands used in 2009. Using individuals in close proximity effectively controlled for any effect of fruit density in the neighborhood around arrowwood pairs, which we neither manipulated nor quantified; our focus in 2010 was not the influence of neighborhood effects on fruit removal, but rather to decouple the influence of geography and arrowwood species on fruit removal.

Seasonal patterns of migrant abundance based on marine radar and nocturnal acoustics

During 2009 and 2010, concurrent marine (X-band) radar monitoring of diurnal and nocturnal movements of birds and bats occurred on Block Island (Mizrahi et al. 2010, Svedlow et al. 2012). We used the nocturnal radar data during the period of fruit monitoring (i.e., $16 \mathrm{Sep}$ to $2 \mathrm{Nov}$ ) to infer patterns of migrant abundance on Block Island in 2009 and 2010 (Figures 3.OR1 and 3.OR2). Specifically, we used nightly total passage rates from onshore radar data from the south end of the island (Svedlow et al. 2012) to be consistent between years (i.e., Mizrahi et al. only recorded during 2009) and to avoid some complicating flight behavior of migrants on the north end (e.g., reorienting migrants circling the north end prior to departing to the mainland or resettling).

We also compared patterns of migrant activity derived from radar to concurrent nocturnal monitoring of flight calls. In 2010, we operated five nocturnal flight call recording stations (similar to that described in Evans and Mellinger 1999) located throughout the island. We extracted high-frequency nocturnal flight calls (i.e., $\geq 6 \mathrm{kHz}$ ) using the band limited energy detector of the Raven Pro 1.3 software (Cornell Lab of Ornithology Bioacoustics Research Program; detector settings available from authors). Unfortunately, the consistent extraction of low frequency flight calls was precluded by ambient noise (e.g., insects, wind). Patterns of migrant activity based on acoustic monitoring agreed generally with patterns of migrant activity derived from radar in 2010 (Fig. 2), particularly the timing of peak migratory events.

\section{Statistical analysis}

We initially evaluated the influence of fruit neighborhood and frugivore abundance on fruit removal rates (estimated number of fruits removed from the number of fruits available) using binomial generalized linear mixed models (GLMMs; reviewed in Bolker et al. 2009). Only the expected geographic effect of frugivore abundance (i.e., migrant densities are assumed to be consistently higher on northern plots relative to southern plots; see manuscript) was evaluated in GLMMs. We expected considerable variation in rates of arrowwood removal from focal plants, as well as many instances of little to no removal on focal plants. We thus extended the GLMMs to 
accommodate overdispersion, and considered the necessity of zero-augmented models (e.g., Mullahy 1986, Lambert 1992).

We focused first on determining the most appropriate error structure for the binomial (i.e., estimated number of fruits consumed from the number of fruits available) GLMMs. Including an observation-level random effect (Elston et al. 2001, Browne et al. 2005) to accommodate overdispersion in the data greatly improved the fit of the binomial GLMM. With the overdispersed GLMM, our examination of removal rates over time within experimental units suggested random intercepts were justified among plots in 2009 and 2010; we also retained random intercepts for subplots (i.e., treatments within plots in 2009 and species within pairs in 2010) given their role in the experimental design. We considered a categorical specification for the effect of time (i.e., count period) in addition to a linear specification when evaluating fixed effects (see below). We fit binomial GLMMs in the lme4 package (Bates et al. 2011) within the R software (R Development Core Team 2011). We selected among competing models using sample size-corrected Akaike's Information Criterion $\left(\mathrm{AIC}_{\mathrm{c}}\right.$; Akaike 1974).

Prior to evaluating fixed effects (i.e., time, neighborhood, geographic, and species effects), we assessed two important GLMM criteria: the assumed normal and homoskedatic distribution of random effects variances, and the ability of the fitted model to predict observed patterns of removal (including zeros) adequately. In 2009 and 2010, the overdispersion variance in the binomial GLMM was distinctly nonnormal and heteroskedatic. Predicting the number of fruits consumed based on a GLMM requires averaging over random effects, which we accomplished via 1000 simulations of the fitted model (Atkins et al., in press). The GLMM poorly predicted zero and near-zero removal, particularly in 2009, suggesting the necessity of zeroaugmented models.

Ecological count data frequently contain excess zeros, and failure to accommodate this deviation from expectation (e.g., from the assumed underlying distribution) typically compromises statistical inference (Martin et al. 2005). Patterns of frugivory are no exception, in simulations (e.g., Morales and Vázquez 2008) or reality (e.g., Carlo and Morales 2008). Zeros can result from ecological processes or sampling/observer insufficiencies; in this study, we assumed most observations of zero fruit removal were "true zeros" (sensu Martin et al. 2005) that resulted from an ecological process. In fact, multiple processes could have produced observations of "true zero" removal - very few frugivores present due to the contingency of offshore displacement during migration, or frugivores present but not consuming fruits in our experimental plots. However, we acknowledge that our method of estimating fruit removal infrequently resulted in an estimation of zero removal when removal may have occurred (i.e., a "false zero"), that is when natural fruit loss on enclosed cymes exceeded that of corresponding unenclosed cymes.

We used ZINB mixture models (Lambert 1992) to account for excess zeros given that multiple processes likely contributed to observations of zero removal. ZINB mixture models attribute zeros to one of two processes, a negative binomial process accounting for non-zero counts of removal and a portion of the zeros, as well as a zero producing process that accounts for the balance of the zeros (Welsh et al. 1996, Martin et al. 2005). In contrast, hurdle models (Mullahy 1986) assume a single 
zero generating process, and we judged them too restrictive given the nature of the study system. Parameter interpretation differs somewhat between the two modeling approaches as well (Welsh et al. 1996, Martin et al. 2005); in our case, the importance of a given effect related jointly to the probability of any removal occurring as well as the rate of fruit removal. Specifically to our application, we used the "NB1" and "NB2" parameterizations of the negative binomial distribution (see Hilbe 2011) in 2009 and 2010, respectively, as they proved superior based on $\mathrm{AIC}_{\mathrm{c}}$. To generate the appropriate ZINB rate model, we offset counts of arrowwood removal by the number of fruits present at the beginning of a count period, less the number of fruits estimated to have abscised in that count period, and we retained the previous random effects structure; inclusion of random slopes in fruit removal over time within subplots or plots did not improve model fit or alter inferences (Schielzeth and Forstmeier 2009) . We also considered the potential influence on removal rates of variation in count period length, but as it did not influence the outcomes of our statistical procedures we do not consider it further. We fit ZINB models using the glmmADMB package (Skaug et al. 2012) in R.

We strategically considered interactions, particularly when using the categorical structure for time, to avoid overfitting models. Rather than assess every possible combination of models, we compared a suite of models that addressed specific hypothetical scenarios for arrowwood fruit removal on Block Island (Table 2). We judged the relative importance of competing models using $\mathrm{AIC}_{\mathrm{c}}$ and Akaike weights. If the model with lowest $\mathrm{AIC}_{\mathrm{c}}$ value has an Akaike weight less than 0.9 , we constructed a $95 \%$ confidence set of models in which the sum of Akaike weights was $>0.95$ (Burnham and Anderson 2002, Symonds and Moussalli 2011). In the interest of parsimony (Burnham and Anderson 2002, Richards 2005, 2008), we excluded from consideration in the confidence set any model with a higher $\mathrm{AIC}_{\mathrm{c}}$ value than a simpler, nested model.

Subsequent to the ZINB models, we used permutation tests to compare changes in arrowwood removal rates with seasonal patterns of migrant abundance inferred from concurrent marine radar (see above). We calculated, in each year, the average change in fruit removal rate for the count periods following the five nights of highest migratory activity. Our choice of five nights was somewhat arbitrary, but seemed reasonable based on the patterns of migratory activity (Fig. 1 and 2). Using the next count period subsequent to the activity, rather than the current count period, allowed us to accommodate an expected short (1-3 days) time lag between the arrival of migrants and detectable fruit removal (i.e., search and settling time; Alerstam and Lindström 1990). However, using the change in fruit removal rates rather than fruit removal rates per se precluded our use of radar data after the penultimate count in each season. This excluded a couple of nights of high migrant activity, but we do not believe that it altered our conclusions. We compared this average change in fruit removal rates to 10,000 similar changes based on permutations of the nightly radar activity data. In each permutation we randomly rearranged radar activity data over the course of the season (we left patterns of fruit removal unchanged), identified the count periods following the five nights of highest activity, and calculated the average change in fruit removal in those count periods. The number of average changes in fruit removal rates greater than or equal to the actual average change, divided by the total 
number or evaluations (i.e., 10,000), gave the probability of observing the relationship by chance.

Post-hoc GLMMs evaluating the probability of fruit removal

We explored the notion that the change in the spatial context of focal plants in part explained the inconsistency in geographic effects on fruit removal between 2009 and 2010. To do so, we evaluated post hoc the success of frugivores in finding the arrowwood plots or pairs as assessed by the probability of focal plants experiencing any removal. We constructed a logistic GLMM for each season that evaluated occurrences of no fruit removal with occurrences of any fruit removal as a function of the same suite of hypothetical scenarios (Table 3.OR2) that were evaluated in ZINB models. We suggest that these models reflected to some extent the concentrating effect of arrowwood plots or pairs. For example, if focal plants occurred within a neighborhood that did not concentrate frugivores, implying that the probability of focal plants experiencing any removal depended primarily on frugivore density, we would expect this probability to closely mirror patterns of fruit removal rates. However, if arrowwood plots or pairs concentrated frugivores (i.e., they either attract frugivores or are more readily found by frugivores), we would expect a relatively constant probability of sustaining removal throughout the migration season with little regard to fluctuations in frugivore abundance. We found support for such a concentrating influence of arrowwood plots during the 2009 migration; a statistically constant probability of removal during the migration season (i.e., intercept-only model) proved the most parsimonious model (Table 1 in manuscript). Conversely during 2010, the preferred model (Table 1 in manuscript) indicated a probability of sustaining removal that mirrored the corresponding pattern of fruit removal rates (i.e., the pattern in Fig. 4B in the manuscript); this pattern suggested the absence of a concentrating influence of arrowwood pairs or their spatial context, and that the probability of focal plants sustaining removal varied positively with changes in the abundance of frugivores.

\section{References}

Akaike, H. 1974. A new look at the statistical model identification. IEEE Transactions of Automatic Control 19:716-723.

Atkins, D. C., S. A. Baldwin, C. Zheng, R. J. Gallop, and C. Neighbors. In press. A tutorial on count regression and zero-altered count models for longitudinal substance use data. Psychology of Addictive Behaviors.

Bates, D., M. Maechler, and B. Bolker. 2011. lme4: linear mixed-effects models using S4 classes, R Package version 0.999375-42.

Bolker, B. M., M. E. Brooks, C. J. Clark, S. W. Geange, J. R. Poulsen, M. H. H. Stevens, and J. S. White. 2009. Generalized linear mixed models: a practical guide for ecology and evolution. Trends in Ecology \& Evolution 24:127-135.

Browne, W. J., S. V. Subramanian, K. Jones, and H. Goldstein. 2005. Variance partitioning in multilevel logistic models that exhibit overdispersion. Journal of the Royal Statistical Society A 168:599-613. 
Burnham, K. P., and D. R. Anderson. 2002. Model selection and multimodel inference: a practical information-theoretic approach, 2nd edition. SpringerVerlag, New York, New York, USA.

Carlo, T. A. 2005. Interspecific neighbors change seed dispersal pattern of an aviandispersed plant. Ecology 86:2440-2449.

Carlo, T. A., and J. M. Morales. 2008. Inequalities in fruit-removal and seed dispersal: consequences of bird behaviour, neighbourhood density and landscape aggregation. Journal of Ecology 96:609-618.

Elston, D. A., R. Moss, T. Boulinier, C. Arrowsmith, X. Lambin, and others. 2001. Analysis of aggregation, a worked example: numbers of ticks on red grouse chicks. Parasitology 122:563-569.

Enser, R. W., and J. A. Lundgren. 2006. Natural communities of Rhode Island. . Rhode Island Natural History Survey, Kingston, Rhode Island, USA.

Evans, W. R., and D. K. Mellinger. 1999. Monitoring grassland birds in nocturnal migration. Studies in Avian Biology 19:219-229.

García, D., and N. P. Chacoff. 2007. Scale-dependent effects of habitat fragmentation on hawthorn pollination, frugivory, and seed predation. Conservation Biology 21:400-411.

Hilbe, J. M. 2011. Negative binomial regression, 2nd edition. Cambridge University Press, New York, New York, USA.

Lambert, D. 1992. Zero-inflated Poisson regression, with an application to defects in manufacturing. Technometrics:1-14.

Levey, D. J., H. A. Bissell, and S. F. O'Keefe. 2000. Conversion of nitrogen to protein and amino acids in wild fruits. Journal of Chemical Ecology 26:1749-1763.

Martin, T. G., B. A. Wintle, J. R. Rhodes, P. M. Kuhnert, S. A. Field, S. J. Low-Choy, A. J. Tyre, and H. P. Possingham. 2005. Zero tolerance ecology: improving ecological inference by modelling the source of zero observations. Ecology Letters 8:1235-1246.

Mizrahi, D., R. Fogg, T. Magarian, V. Elia, P. Hodgetts, and D. La Puma. 2010. Radar monitoring of bird and bat movement patterns on Block Island and its coastal waters. Page Technical Report 11, Appendix K in J. McCann and 28 others, editors. Ocean Special Area Management Plan. . University of Rhode Island, Narragansett, Rhode Island, USA.

Morales, J. M., and D. P. Vázquez. 2008. The effect of space in plant-animal mutualistic networks: insights from a simulation study. Oikos 117:1362-1370.

Mullahy, J. 1986. Specification and testing of some modified count data models. Journal of Econometrics 33:341-365.

R Development Core Team. 2011. R: a language and environment for statistical computing. . R Foundation for Statistical Computing, Vienna, Austria.

Richards, S. A. 2005. Testing ecological theory using the information-theoretic approach: examples and cautionary results. Ecology 86:2805-2814.

Richards, S. A. 2008. Dealing with overdispersed count data in applied ecology. Journal of Applied Ecology 45:218-227.

Saracco, J. F., J. A. Collazo, and M. J. Groom. 2004. How do frugivores track resources? Insights from spatial analyses of bird foraging in a tropical forest. Oecologia 139:235-245. 
Skaug, H., D. Fournier, A. Nielsen, A. Magnusson, and B. Bolker. 2012. glmmADMB: generalized linear mixed models using AD Model Builder, $\mathrm{R}$ package version 0.7.2.5/r186.

Smith, S. B., K. H. McPherson, J. M. Backer, B. J. Pierce, D. W. Podlesak, and S. R. McWilliams. 2007. Fruit quality and consumption by songbirds during autumn migration. The Wilson Journal of Ornithology 119:419-428.

Svedlow, A. B., L. Gilpatrick, B. Agius, M. Andrews, and P. Myers. 2012. Preconstruction avian and bat assessment: 2009-2011. Page Appendix O in Tetra Tech EC, Inc., editor. Block Island Wind Farm and Block Island Transmission System Environmental Report / Construction and Operations Plan. . Deepwater Wind, Boston, MA.

Symonds, M. R. E., and A. Moussalli. 2011. A brief guide to model selection, multimodel inference and model averaging in behavioural ecology using Akaike's information criterion. Behavioral Ecology and Sociobiology 65:1321.

Welsh, A. H., R. B. Cunningham, C. F. Donnelly, and D. B. Lindenmayer. 1996. Modelling the abundance of rare species: statistical models for counts with extra zeros. Ecological Modelling 88:297-308. 
Table 2 Hypothetical models for patterns of fruit removal on Block Island in 2009 and 2010. The following candidate models were assessed in zero-inflated negative binomial mixture models and logistic generalized linear mixed models (see text for details).

Candidate model $^{\mathrm{a}}$

Interpretation

(1) Intercept only

Fruit removal constant over time; no effect of neighborhood/species or geography

(2) TIMEF

Fruit removal varies among count periods, but no effect of neighborhood/species or geography

(3) TIMEF + TRT | GEOG

Fruit removal varies among count periods, and also between neighborhood/species and geographic locations, with the magnitude of neighborhood/species effects dependent upon geography

(4) TIMEF + TRT + GEOG

Fruit removal varies among count periods, and also between neighborhood/species and geographic locations, the effects of which vary independently

(5) $\mathrm{TIMEF}+\mathrm{TRT}$

Fruit removal varies among count periods, and also between neighborhood/species, with no effect of geography

(6) TIMEF + GEOG

Fruit removal varies among count periods, and also between geographic locations, with no effect of neighborhood/species

(7) TIMEF $\mid$ TRT

Fruit removal varies among count periods, and also between neighborhood/species, the magnitude of which varies among count periods, with no effect of geography

(8) TIMEF | GEOG

Fruit removal varies among count periods, and also between geographic locations, the magnitude of which varies among count periods, with no effect of neighborhood/species 
${ }^{a}$ Similar models were evaluated in 2009 and 2010, although the variables changed slightly. TIMEF: categorical count period effect in 2009 and 2010 (we also evaluated a linear alternative, TIME; see text for justification); TRT: dichotomous neighborhood fruit density manipulation in 2009 , dichotomous arrowwood species effect in 2010; and GEOG: dichotomous geographic effect in 2009 and 2010 


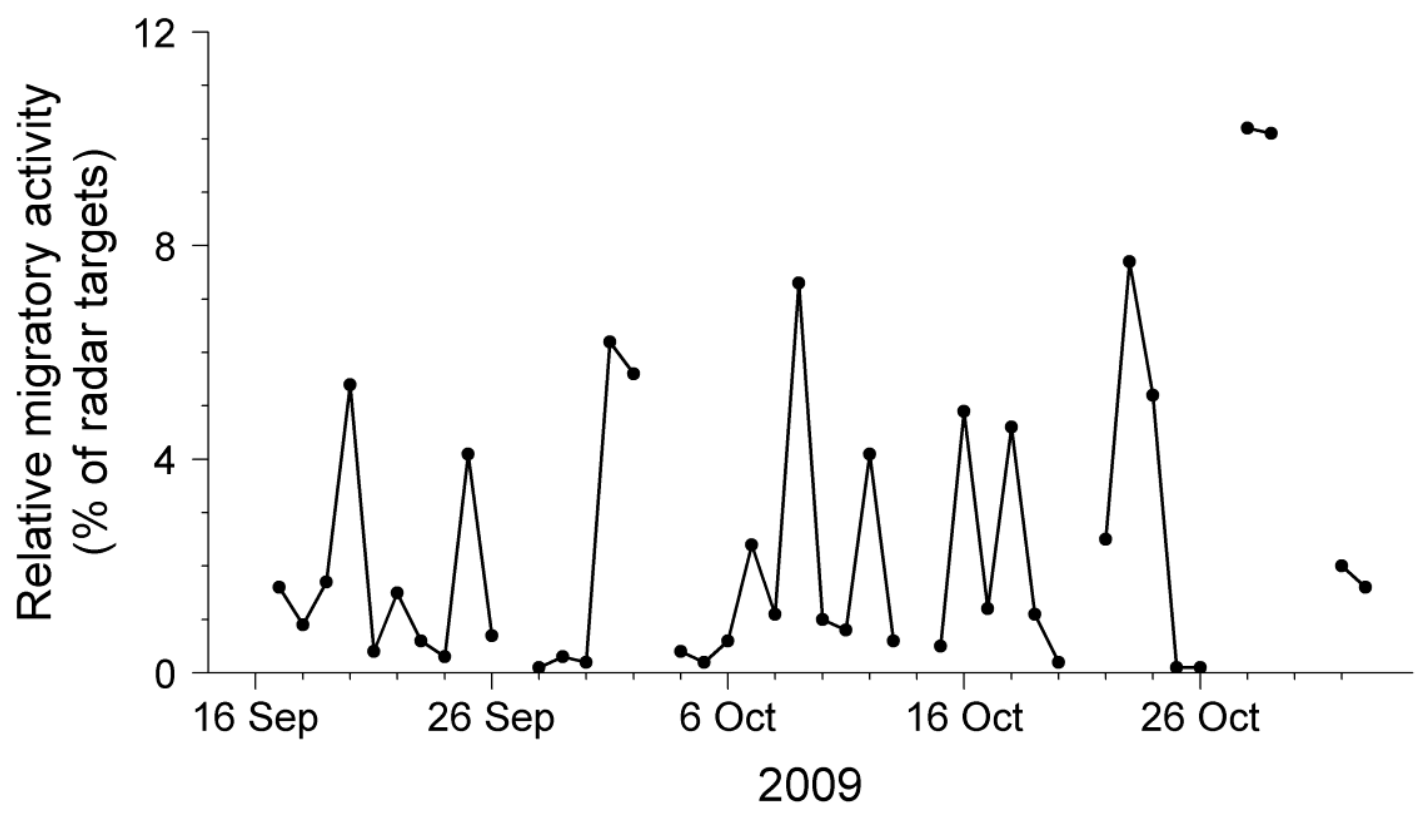

Fig. 1 Marine (X-band) radar data (Svedlow et al. 2012) collected between 16 Sep and 2 Nov 2009 on Block Island 


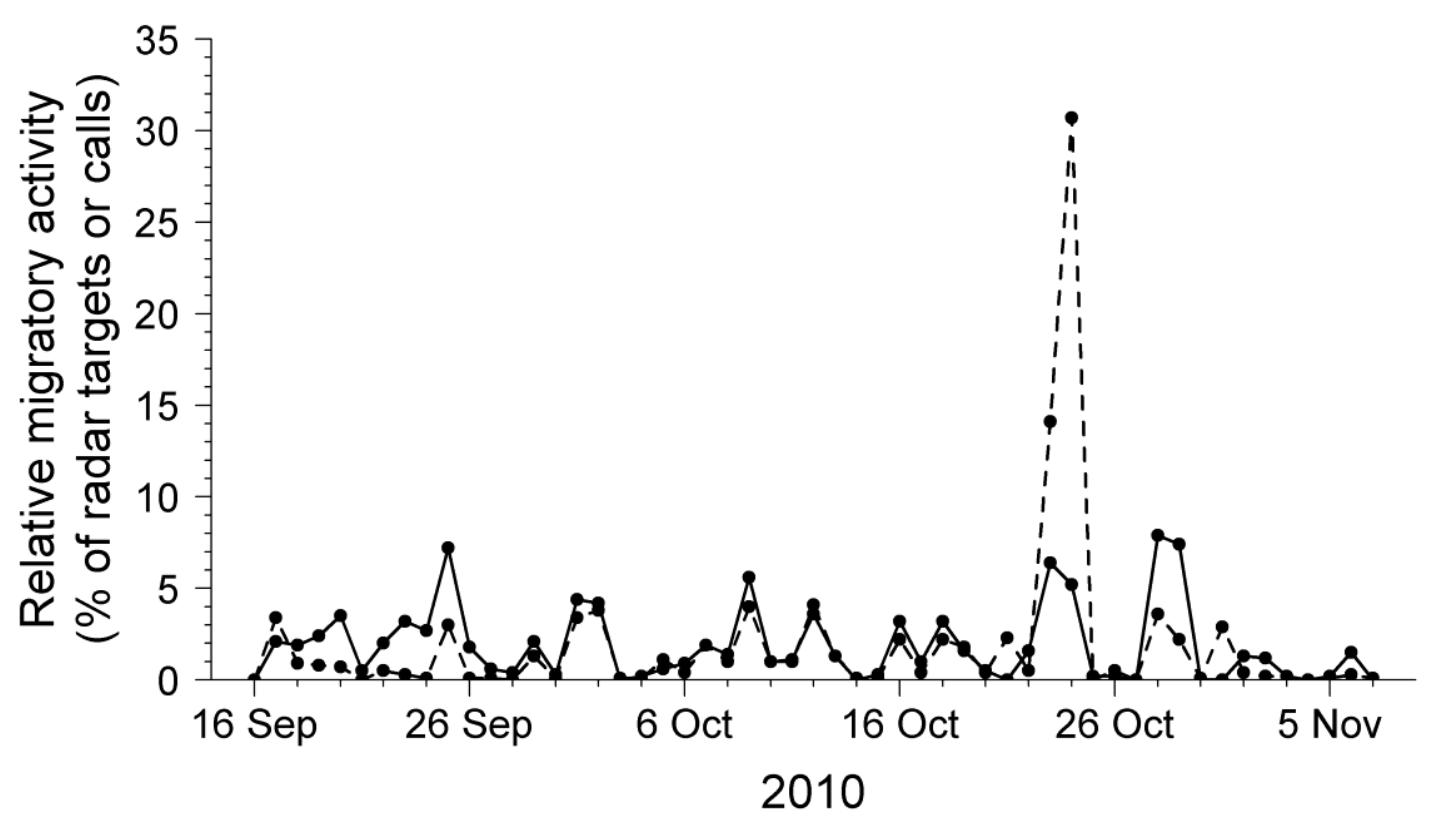

Fig. 2 Marine (X-band) radar data (solid line; Svedlow et al. 2012) and high-frequency nocturnal flight call (NFC) recordings (dashed line) collected between 16 Sep and 7 Nov 2010 on Block Island exhibit good agreement in their patterns of migratory activity (and presumably arrival to Block Island) 


\section{CHAPTER 4}

"What To Do When Stopping Over: Behavioral Decisions of a Migrating Songbird at a Stopover Site are Dictated by Initial Change in Their Body Condition and Mediated by Key Environmental Conditions"

by

Adam D. Smith ${ }^{1,2}$ and Scott R. McWilliams ${ }^{1}$

is to be submitted to Behavioral Ecology

${ }^{1}$ Department of Natural Resources Science, University of Rhode Island, 1 Greenhouse Road, Kingston, RI 02881, USA

${ }^{2}$ E-mail: adam.smith@my.uri.edu 


\section{INTRODUCTION}

Migratory songbirds chase seasonally productive environments, often moving over hundreds to thousands of kilometers as they traverse our rotating world (e.g., Alerstam 1990). Only in exceptional cases do migrants complete the journey in a single flight; most make multiple stopovers during which they rest and refuel for subsequent migratory flights. Typically, these migratory flights terminate at unfamiliar sites of variable quality, and it is there that migrants must secure the extraordinary amount of energy required for migration while balancing costs associated with predation, competition, and inclement weather (Moore et al. 1995; Moore and Aborn 2000). Rebuilding this energetic capital results in roughly twice the time and energy expenditure during stopover than in migratory flight (Fransson 1995; Wikelski et al. 2003; Bowlin, Cochran, and Wikelski 2005; Schmaljohann, Fox, and Bairlein 2012). This disproportionate allocation of time and energy to stopover, within the inherently challenging context of migration (Ketterson and Nolan 1982; Sillett and Holmes 2002; Menu et al. 2005; Strandberg et al. 2010; McKim-Louder et al. 2013; but see Gauthier et al. 2001), underscores the importance of stopover sites to migratory birds and suggests important fitness consequences follow from the choices made by migrants during stopover.

The behavioral decisions of migrants during stopover (e.g., movement dynamics and departure decisions) can markedly influence the pace, efficiency and success of migration and result, in theory, from tradeoffs among competing priorities of an overall migration strategy (i.e., maximizing migration speed, energy conservation, and safety; Alerstam and Lindström 1990; Houston 1998; Weber, Ens, 
and Houston 1998). The typical time constraint on migration (Hedenström 2008; Alerstam 2011) favors migrants that satisfy their energetic requirements efficiently, but resource acquisition and the subsequent transport of accumulated fuel entail energetic and exposure costs (e.g., Metcalfe and Furness 1984; Klaassen and Lindström 1996; Kullberg, Fransson, and Jakobsson 1996; Lind et al. 1999). Consequently, at any time, an individual's fuel stores may determine its behavioral priorities (e.g., foraging or vigilance) and thus dictate subsequent stopover behavior and departure decisions. For example, migrants possessing larger fuel stores typically move less or make more area-restricted movements during stopover (Moore and Aborn 2000; Tietz and Johnson 2007; Ktitorov et al. 2010; Matthews and Rodewald 2010; Seewagen, Slayton, and Guglielmo 2010; Cohen, Moore, and Fischer 2012; but see Chernetsov and Muhkin 2006; Paxton, Van Riper III, and O’Brien 2008; Seewagen, Slayton, and Guglielmo 2010; Arizaga, Andueza, and Tamayo 2013), and more regularly depart stopover sites in a seasonally-appropriate direction (reviewed in Sandberg 2003; (Deutschlander and Muheim 2009; Covino and Holberton 2011; Schmaljohann et al. 2011; Schmaljohann and Naef-Daenzer 2011; Smolinsky et al. 2013). The association between fuel stores and the duration of stopover is less consistent, although migrants with larger fuel stores regularly spend less time at a given stopover site (Biebach 1985; Dierschke and Delingat 2001; Schaub, Jenni, and Bairlein 2008; Goymann et al. 2010; Seewagen and Guglielmo 2010; Matthews and Rodewald 2010b; Morganti et al. 2011; Andueza et al. 2013; Bulyuk and Tsvey 2013; Smolinsky et al. 2013; but see Dierschke and Delingat 2001; Chernetsov and Muhkin 2006; Bolshakov et al. 2007; Salewski and Schaub 2007; Tsvey, Bulyuk, and Kosarev 
2007; Ktitorov et al. 2010; Seewagen, Slayton, and Guglielmo 2010; Andueza et al. 2013). Despite this body of evidence, the work to date is strictly observational or quasi-experimental in that it has related natural variation in migrant body condition to behavioral decisions at stopover sites; no previous study has directly manipulated migrant body condition and explored the consequences of this manipulation on subsequent stopover behavior and departure decisions.

The stopover dynamics of individual migrants vary also with environmental conditions. Atmospheric conditions, wind and precipitation in particular, profoundly influence the timing, intensity, energetics, and geography of avian migration (Richardson 1978; Alerstam 1990; Richardson 1990). During fall migration in the northern hemisphere, for example, many birds migrate preferentially in the days following cold fronts when winds typically provide some tailwind assistance (Able 1973; Richardson 1978; Richardson 1990; but see Karlsson et al. 2011). This benefit is likewise expected to influence individual decisions to resume migration (Liechti and Bruderer 1998; Weber and Hedenström 2000), although empirical work is more equivocal (e.g., Fransson 1998; Åkesson and Hedenström 2000; Schmaljohann et al. 2011; Smolinsky et al. 2013). Nonetheless, these otherwise favorable conditions can concentrate migrants along topographic barriers (Åkesson 1993; Hüppop et al. 2006; Gagnon et al. 2011), where the importance of fuel stores and atmospheric conditions on stopover decisions may be more profound (Jenni and Schaub 2003; Tsvey, Bulyuk, and Kosarev 2007; Schaub, Jenni, and Bairlein 2008).

We explored the dynamics of songbird stopover in relation to fuel stores, atmospheric conditions, and resource availability in the context of naïve migrants 
displaced to an offshore island in southern New England, USA (Block Island, Rhode Island). We experimentally manipulated the fuel stores of newly arrived birds and tracked their subsequent movements and departure decisions via radio telemetry. Relative to mark-recapture data and their associated probability models (e.g., Salewski and Schaub 2007; Schaub, Jenni, and Bairlein 2008; Arizaga, Belda, and Barba 2011), telemetry dramatically improves certainty in estimates of stopover duration (Tsvey, Bulyuk, and Kosarev 2007; Seewagen and Guglielmo 2010) and, moreover, enables the estimation of movement dynamics during stopover. We tested the following hypotheses related to the condition-dependence of behavioral decisions made by migrating songbirds at stopover sites: birds released with larger fuel stores (1) move less and make less linear, directed movements during stopover. However, (2) condition-dependent differences in movements abate during extended stopover after release, and (3) leaner individuals, in particular, increase the quantity and scale of their movements under increased time constraints and declining food resources later in the fall. Fuel stores also dictate departure decisions - birds with larger fuel stores (4) are more likely to depart than leaner birds on any given night and resume migration sooner, and (5) depart more regularly in a seasonally-appropriate direction (i.e., south of west in the present study). We also tested the following hypotheses related to how atmospheric conditions mediate the movement and departure decisions of migrating songbirds at stopover sites: (6) precipitation generally inhibits diurnal movements and departure of individuals, and (7) wind speed and direction influence an individual's decision to depart as well as the direction of departure. The simultaneous release of individual migrants with manipulated fuel stores and their subsequent tracking 
controlled for important confounding variables at the time of release (e.g., resource abundance, predation risk, weather, and endogenous time program) and so provides the most direct test to date of these hypotheses regarding the condition-dependence of behavioral decisions of migrating songbirds.

\section{METHODS}

\section{Study area}

The field experiment occurred on Block Island $\left(41^{\circ} 28^{\prime} \mathrm{N}, 71^{\circ} 31^{\prime} \mathrm{W}\right)$, a $25 \mathrm{~km}^{2}$ glacially deposited landmass located approximately $15 \mathrm{~km}$ south of the Rhode Island mainland and $23 \mathrm{~km}$ east northeast of Long Island, New York (Figure 1A) during the autumnal migrations of 2009 and 2010. During fall migration, westerly winds associated with passing cold fronts displace large numbers of migratory songbirds, particularly hatching year birds, to the coast and offshore islands such as Block Island (e.g., Baird and Nisbet 1960; Able 1977). Once on Block Island, migrating songbirds rest and refuel extensively in the maritime shrub community, consuming large quantities of fruit in the process (Parrish 1997; Smith et al. 2007; Bolser et al. 2013). The species composition and structure of the maritime shrub community is dictated largely by exposure to salt spray and wind (Enser and Lundgren 2006). Highly exposed areas near the coast are dominated by short-statured bayberry (Morella pennsylvanica), poison ivy (Toxicodendron radicans), and roses (Rosa sp.), brambles (Rubus sp.), and briars (Smilax sp.). More protected areas are dominated by native shadbush (Amelanchier canadensis), arrowwood (Viburnum recognitum and $V$. dentatum), chokeberry (Aronia prunifolia, A. melanocarpa, and A. arbutifolia), 
winterberry (Ilex verticillata and I. laevigata), bayberry, and Virginia creeper (Parthenocissus quinquefolia), as well as the invasive multiflora rose (Rosa multiflora) and Oriental bittersweet (Celastrus orbiculatus). Pokeweed (Phytolacca americana), a large berry-producing perennial herbaceous plant, is also locally common throughout the maritime shrub community.

\section{Bird capture}

We used mist nets to capture Hermit Thrushes (Catharus guttatus) at the northern extent of the maritime shrub community on Block Island, a location where recently arrived songbirds congregate (e.g., Baird and Nisbet 1960; Able 1977; Figure 1, filled circle). Hermit Thrushes (hereafter thrushes) are common temperate migrants that use the fruits of the maritime shrub community extensively during stopover on Block Island (Parrish 1997; Smith and McWilliams 2010). We captured thrushes for this field experiment in a way that maximized the likelihood that individuals were new arrivals to Block Island with limited prior experience with the distribution or quality of resources. First, we used only hatch-year thrushes captured on mornings ( $1 \mathrm{~h}$ before to $1 \mathrm{~h}$ after local sunrise) following nights favorable for the arrival of migratory birds to Block Island (i.e., westerly or northerly winds in the day(s) following cold front passage). Second, we broadcasted thrush flight calls (Evans and O'Brien 2002) throughout the night until $1 \mathrm{~h}$ before sunrise, at which time we switched to mixed thrush songs and calls (Elliott, Stokes, and Stokes 2000); previous work suggests that newly arrived birds are likely more influenced (and attracted) by broadcasted calls than settled migrants (Schaub, Schwilch, and Jenni 1999; Fransson et al. 2008). 
Thrushes possessed reduced fat and breast muscle scores at capture (see results) which further supports our assumption that these individuals were recent arrivals.

\section{Field captivity and fuel stores manipulation}

After capture, we measured wing chord $( \pm 0.5 \mathrm{~mm})$ and body weight $( \pm 0.1 \mathrm{~g})$, and assessed visible subcutaneous fat on a 8-point scale (DeSante et al. 2003) and breast musculature on 4-point scale (Bairlein 1995); we regularly assigned both measures in half-score increments. On a given morning, we transported up to 12 hatching year birds less than $1 \mathrm{~km}$ from the capture site and placed them in a holding aviary for the manipulation of fuel stores (Figure 1, filled triangle). We housed birds individually in stainless steel cages $(36 \mathrm{~cm} \times 43 \mathrm{~cm} \times 60 \mathrm{~cm}$ ) in an enclosed permanent structure that protected thrushes from the elements but nonetheless exposed them to natural photoperiod and temperature fluctuations. We paired birds with similar initial size and condition metrics and then assigned one thrush of each pair randomly into one of two feeding regimes: (1) a 'maintenance' group provided 8-9 $\mathrm{g}$ (wet) of live wax moth larvae (waxworms; Pyralidae) each day, and (2) an 'ad libitum' group provided more waxworms than could be consumed each day (up to $20 \mathrm{~g}$ ); we provided all thrushes with water ad libitum. We monitored food consumption and body mass daily. Field captivity typically lasted $3-4 \mathrm{~d}$ ( $80 \%$ of thrushes), although some thrushes remained in captivity from $2 \mathrm{~d}$ to $6 \mathrm{~d}$ (the latter due to inclement weather conditions).

\section{Transmitter attachment, release, and tracking}

We fitted thrushes with a $0.77 \mathrm{~g}$ (maintenance) or $1.00 \mathrm{~g}$ (ad libitum) radio transmitter (Holohil® BD-2) less than an hour prior to placement into a release aviary (see below). We glued (Torbot ostomy bonding cement; Cranston, Rhode Island) the 
transmitter between the shoulders after trimming a small patch of feathers nearly to the skin. Transmitters represented on average $2.8 \pm 0.2 \%$ of the release weight of thrushes. Capture, handling, and transmitter attachment activities were approved by our Institutional Animal Care and Use Committee (A98-09-012).

We released thrushes in cohorts of on average 2 or 4 thrushes comprising equal numbers of birds from each diet treatment with identical capture, captivity, and release histories. To standardize releases among individuals, we located a release aviary in contiguous maritime shrub habitat (Figure 1, filled square). We constructed the release aviary by surrounding a mature bayberry shrub with a wooden frame $(2.5 \mathrm{~m}$ tall $\mathrm{x} 1.5 \mathrm{~m}$ wide $\mathrm{x} 1.5 \mathrm{~m}$ long); we fabricated the sides and ceiling from heavy canvas. We left the bottom $1 \mathrm{~m}$ of the enclosure open to the environment and provided numerous perches (in the form of downed limbs, brush, etc.) around the base of the aviary to encourage a controlled exit from the aviary. We placed thrushes by hand into the enclosed bayberry shrub in total darkness within a few hours of sunset. Thrushes never attempted escape during the night and exited the enclosure via the unenclosed bottom the subsequent morning. Our observations of exiting thrushes suggest this release method eliminated the occurrence of 'agitation dispersal,' an increase in movement and activity associated with release after captivity and marking (Buler 2006).

After thrushes exited the aviary (morning of day 1), we recorded their locations throughout the day (from morning to evening civil twilight) for up to four days of stopover $(\mathrm{n}=29)$. If individuals stayed on island longer than four days $(\mathrm{n}=21)$, we checked their status (i.e., location and health) daily until they departed. Our protocol 
for locating individuals throughout the day varied between the two years of the study. In 2009, three observers triangulated the location of each thrush $(n=18)$ every 45 min (median; interquartile range [IQR]: 21 - $75 \mathrm{~min}$ ). In 2010, observers tracked and estimated the location of individual thrushes $(\mathrm{n}=32)$ every $11 \mathrm{~min}(\mathrm{IQR}: 9-14 \mathrm{~min})$. We recorded the bearing and estimated distance to thrushes $(<50 \mathrm{~m})$ from points georeferenced with a handheld Global Positioning System and used trigonometry to derive the location estimates. Prior to tracking each year, we tested observers' ability to locate transmitters hidden throughout the maritime shrub community; tests suggested that the two methods provided thrush locations accurate to approximately 19 m (median; IQR: $14-31 \mathrm{~m}$ ) and $8 \mathrm{~m}$ (median; IQR: $4-10 \mathrm{~m}$ ), respectively.

We also monitored at-large thrushes every $1-4 \mathrm{~h}$ throughout the night to determine the timing and direction of their departure from Block Island. We tracked departing thrushes over the open ocean from a slightly elevated $(3-10 \mathrm{~m}$ above sea level) position near the shoreline. We recorded departure direction as the bearing at which the signal was lost. We estimated the signal range over the ocean at $\sim 6 \mathrm{~km}$ by holding a transmitter in a position similar to a flying thrush atop a ferry leaving Block Island. We typically maintained contact with thrushes departing Block Island over open water for well over 10 min which suggests, assuming some wind assistance and an air speed of $10 \mathrm{~m} \mathrm{~s}^{-1}$ (Cochran and Kjos 1985), that our $6 \mathrm{~km}$ estimate represented a minimum detection range during departure. On days subsequent to a recorded departure, we checked for the presence of each individual to ensure that they had left the island rather than returned and relocated.

\section{Abundance of arthropods and fruits during fall migration}


From 16 Sep - 12 Nov 2010, we monitored seasonal patterns of abundance in fruiting plants and ground-dwelling arthropods in a ca. 12 ha study area around the release aviary. We assessed resource abundance around the release aviary because the location where migrants 'land' is likely to be critical in determining the resources ultimately available at a stopover (Paxton, Van Riper III, and O'Brien 2008). We monitored arthropod abundance with pitfall traps at 17 sites, randomly located within three habitat strata: small $(<0.1$ ha) mixed annual and perennial grasses and herbs $(\mathrm{n}=$ 5), upland maritime shrub $(\mathrm{n}=6)$, and wetland maritime shrub (within $10 \mathrm{~m}$ of permanent water, usually a kettle pond; $n=6$ ). Pitfall traps consisted of large tin cans (15.3 cm diameter) buried such that the rim was slightly below soil (not leaf litter) level and surrounded with three drift fences ( $0.6 \mathrm{~m}$ lengths of aluminum flashing) spaced at approximately 120 degrees around the rim's circumference. We placed a circular resin-coated (Tanglefoot; Contech Enterprises, Victoria, British Columbia) board in the bottom of each can to trap arthropods falling into the can and facilitate the counting of individual arthropods. To operate, we installed the resin-coated inserts for a period of $8-9 \mathrm{~h}$ beginning within one hour of sunrise, after which we counted the arthropods, removed and cleaned the inserts and raised the top of the can above ground level. We operated pitfall traps approximately weekly throughout the study period ( $\mathrm{n}=8$ sampling occasions) on days with no precipitation and light to moderate winds.

We monitored the abundance of fruits on six plant species consumed regularly by migrant songbirds on Block Island (northern arrowwood, Virginia creeper, pokeweed, bayberry, winterberry and multiflora rose; Parrish 1997; Smith et al. 2007; 
Bolser et al. 2013). We located the nearest healthy, fruiting individual of each species within $15 \mathrm{~m}$ of eight random sites within the study area. We continued to add random sites until each species was represented by $6-8$ individual plants. On each individual, we counted fruits on $1-3$ representative marked branches approximately weekly throughout the study period ( $\mathrm{n}=8$ sampling occasions).

\section{Atmospheric conditions}

We gathered weather data from the Block Island State Airport, which reported conditions every 15 minutes (National Climatic Data Center QCLCD 2.5.4; http://cdo.ncdc.noaa.gov/qclcd/QCLCD?prior=N, accessed 28 July 2013). We first calculated wind profit from wind direction and wind speed (Erni et al. 2002); wind profit represents the distance a bird is drifted towards a migratory goal in a fixed time interval through only the effect of wind. Wind profit calculations require the user to specify the direction of this migratory goal. We calculated two versions of wind profit to capture the two primary migratory goals for thrushes leaving Block Island: (1) an 'onward migration' wind profit with the nearest land point of Long Island, NY, as the migratory target $\left(240^{\circ}\right)$, and (2) a 'reverse migration' wind profit with the nearest point of the Rhode Island mainland as the migratory target $\left(345^{\circ}\right)$. We propose that these definitions adequately captured those combinations of wind direction and speed that facilitate 'onward' or 'reverse' migration, respectively. We calculated nightly averages of wind profit variables from 35 - 39 observations throughout a given night (evening civil twilight to the subsequent morning civil twilight). We also calculated the proportion of hours during a given night or day (morning civil twilight to evening civil twilight) that the weather station reported any measurable precipitation. 


\section{Statistical analysis}

Rather than use changes in fat and breast musculature scores as our measure of thrush fuel stores, we constructed a predictive generalized additive mixed model (GAMMs; Wood 2006) for thrush body mass using wing chord, subcutaneous fat score and breast musculature score. GAMMs accommodated potential nonlinear changes in body mass with the predictor variables (fit using shrinkage-penalized splines) while accommodating multiple measurements from the same individual (Wood 2006). We used this model to estimate the fat free mass (hereafter, lean mass) and fat mass (the difference of lean mass from total mass) of each thrush at capture and release. Because the change in thrush body mass during captivity was due predominantly to changes in fat mass (see results) and fat is the primary fuel of migration (Blem 1990; McWilliams et al. 2004) we used the estimated fat mass at release as our measure of thrush fuel stores in all subsequent analyses.

We quantified multiple aspects of thrush movement. We evaluated the quantity of daily movement (i.e., the cumulative summed distance between estimated locations; total distance) and the straight-line distance from the initial morning location to the final (typically roosting) location (i.e., linear displacement). An index of area-restricted movement is often calculated as the quotient of linear displacement and total distance moved (e.g., Williamson and Gray 1975; Paxton, Van Riper III, and O’Brien 2008). However, linear displacement and this index were highly correlated in thrushes $\left(\mathrm{r}=0.91, \mathrm{t}_{58}=24.6, \mathrm{P}<0.001\right.$; within subject correlation sensu Bland and Altman 1995), so we used only linear displacement in all our analyses. 
We modeled total movement and linear displacement as functions of thrush fat mass at release, the time since release (i.e., day of stopover, up to four days), ordinal date (i.e., seasonal effects), and the proportion of the day with reported precipitation. We also fitted the two-way interactions between fat mass and both stopover day and seasonal effects. We estimated these associations in linear mixed effect models (LMM) that included a random effect for thrush pairs within cohorts and a random intercept and slope (over stopover day) for each thrush (Schielzeth and Forstmeier 2009). In our evaluation of total distance moved each day, we included an offset term for the time (h) an individual was tracked each day (typically all day, although day length shortened as the season progressed) as well as the number of daily estimated locations and tracking method as covariates. We applied a log transformation to both response variables to improve the normality of model residuals.

We modeled the nightly decision to depart (i.e., the hazard of departure) as a function of fat mass at release and its interaction with the current length of stopover, ordinal date and the nightly average values of wind profit for onward and reverse migration using a mixed effects Cox regression model (Cox 1972; Therneau 2000). Current stopover length, wind profit variables and ordinal date were time-varying covariates (changing nightly). We did not consider the proportion of the night with reported precipitation because only one of the 44 thrushes with known departures left on a night with measurable precipitation (and it left prior to the occurrence of precipitation); this observation dictated the parameter estimate for the precipitation effect and, furthermore, its removal made the parameter inestimable. The stopover 
record for six thrushes (see above) was right-censored. We included random effects (Gaussian frailty terms; Therneau 2000) for thrush pairs within cohorts.

We evaluated stopover duration (days) as a function of fat mass at release, ordinal date of release and their interaction using a generalized (Poisson) LMM. We included a random intercept for thrush pairs within cohorts. We used the minimum stopover duration for six thrushes with incomplete departure information - four thrushes failed to depart prior to 13 Nov 2009 when field work ended, one thrush lost its transmitter after four days (with no indication of depredation or fatality), and one thrush apparently sustained an injury after six days that made sustained flight impossible.

We further explored departure decisions among 25 thrushes with known departure times and directions. We dichotomized these departures into two categories: 'onward' migration towards Long Island (departure directions between $219^{\circ}$ and $270^{\circ}$ ) and 'reverse' migration towards the Rhode Island mainland (departure directions between $287^{\circ}$ and $10^{\circ}$ ). The small sample size (i.e., 13 onward migration 'events') greatly restricted the analysis; we thus constructed a mixed effects logistic model that included only fat mass at release and random effects for thrush pairs within cohorts and interpret this model tentatively. We finally evaluated how time of departure (proportion of night elapsed) varied with fat mass at release, stopover duration, or the departure direction (i.e., onward or reverse) using a LMM that included random effects for thrush pairs within cohorts and the night of departure (to account for environmental conditions). 
We conducted all analyses in R 3.0.1 (R Core Team 2013). We implemented generalized additive mixed models using the gamm4 package (Wood 2012). We evaluated LMMs and generalized (Poisson and logistic) LMMs using the lme4 package (Bates et al. 2013). We estimated the mixed effects Cox model using the coxme package (Therneau 2012); we evaluated fixed effects with likelihood ratio tests. Residuals in several linear analyses were somewhat heavy-tailed at one end of the distribution, so we compared parameter estimates and their associated variation with the corresponding estimates from 1000 non-parametric bootstraps of the model fit (Ren et al. 2010). Estimates compared favorably between the two methods, so we based estimates, confidence intervals, and associated figures on the maximum likelihood estimates (or adaptive Gauss-Hermite quadrature approximations in the logistic model), although we report the significance of parameters based on 1000 parametric bootstraps of a reduced model excluding the parameter. Finally, we evaluated the importance of covariate interactions with fat mass based primarily on plots of the marginal effects of fat mass on the response variable (and their associated uncertainty) across the range of values of the covariates, as assessing interactions using only the significance test risks missing important conditional relationships (Brambor, Clark, and Golder 2006).

\section{RESULTS}

\section{Manipulation of thrush fuel stores}

Thrushes assigned to different diet regimes initially possessed similar subcutaneous fat and breast musculature scores (Figure 2A). As expected, maintenance birds retained 
similar condition scores during captivity, while ad libitum birds significantly increased their fat scores and, to a lesser extent, breast musculature scores (Figure 2A). The body mass of ad libitum thrushes increased at a rate of $1.6 \mathrm{~g} \mathrm{~d}^{-1}( \pm 0.6 \mathrm{SD}$; range: $0.8-$ $2.9 \mathrm{~g} \mathrm{~d}^{-1}$ ) whereas the mass of maintenance birds remained stable while in captivity $\left(0.1 \mathrm{~g} \pm 0.3 \mathrm{SD}\right.$; range: $\left.-0.5-0.6 \mathrm{~g} \mathrm{~d}^{-1} ; \mathrm{Fig} .2 \mathrm{~B}\right)$. The rate of mass gain in ad libitum thrushes was similar to the maximum rate of mass gain observed in non-experimental thrushes recaptured in the study area $\left(1.7 \mathrm{~g} \mathrm{~d}^{-1}\right)$. Wing chord, fat score, and breast muscle score related strongly and positively to thrush body mass and together explained ca. $61 \%$ of the variation in body mass, although the form of the relationship varied among the three measurements (Figure 3). Using this model to estimate the lean mass of a thrush given its wing chord and breast musculature score, changes in thrush mass during captivity were due largely to gains in fat (Figure 2B). Specifically, changes in fat typically comprised more than $90 \%$ (median; IQR: $69-100 \%$ ) of the total change in body weight. Thrushes assigned to the maintenance treatment were released with a median estimated fat mass of $1.9 \mathrm{~g}$ (IQR: $1.0-3.0 \mathrm{~g}$ ) compared to 6.3 g (IQR: $5.2-7.6 \mathrm{~g}$ ) for ad libitum thrushes. Fat mass at release correlated strongly with fuel load (i.e., estimated fat mass divided by estimated lean mass; $r=1.00, t_{48}=$ $118.92, \mathrm{P}<0.001$ ) and fuel deposition rate during captivity ( $\Delta$ fuel load $\mathrm{d}^{-1} ; \mathrm{r}=0.78$, $\left.t_{48}=8.58, \mathrm{P}<0.001\right)$.

\section{Thrush movements}

Fuel stores affected the aggregate of daily movements in migrating thrushes, but the effect varied seasonally (fat $\mathrm{x}$ season interaction; parametric bootstrap $\mathrm{P}\left[\mathrm{P}_{\mathrm{pb}}\right]=$ 0.052). Fuel stores exerted little influence on thrush movements early in migration 
(Figure 4A). However, thrushes decreased their total daily movement by on average ca. $11 \% \mathrm{~g}^{-1}$ of fuel stores late in the migratory period, corresponding to ca. $60 \%$ more total daily movement for a thrush with a $2 \mathrm{~g}$ fat mass (a typical maintenance thrush) relative to a thrush with $6 \mathrm{~g}$ fat mass (a typical ad libitum thrush; Figure 4C). Thrushes released with more substantial fuel stores exhibited a consistent pattern of movement during stopover throughout the migratory season, whereas leaner thrushes exhibited a considerable seasonal increase in their daily movements, particularly in the first day(s) of stopover (Figure 4). All thrushes reduced their total daily movement approximately $14 \% \mathrm{~d}^{-1}\left(95 \%\right.$ confidence interval $\left.[\mathrm{CI}]: 8-19 \% ; \mathrm{P}_{\mathrm{pb}}=0.002\right)$ as stopover progressed, and the effect varied little with fuel stores (Figure 4; fat x stopover day interaction; $\mathrm{P}_{\mathrm{pb}}=0.262$ ). We also found evidence that every $10 \%$ increase in the proportion of the day with reported precipitation associated with an additional $8 \%$ (CI: $\left.3-12 \% ; \mathrm{P}_{\mathrm{pb}}=0.009\right)$ reduction in total daily movement.

The fuel stores of thrushes at release likewise influenced the extent of their linear, presumably exploratory, movements. However, this influence applied primarily to leaner thrushes and varied with stopover and seasonal contexts. Lean thrushes quickly restricted the directedness of their movements as stopover progressed, whereas thrushes released with more substantial fuel stores exhibited consistent patterns of linear displacement with little regard to stopover context (fat $\mathrm{x}$ stopover day interaction; $\mathrm{P}_{\mathrm{pb}}=0.052$; Figure 5). For example, a thrush released with a $2 \mathrm{~g}$ fat mass reduced its linear displacement roughly $26 \%$ with each successive stopover day compared to an approximately $6 \%$ daily reduction in a thrush with a $6 \mathrm{~g}$ fat mass at release (Figure 5). Furthermore, leaner thrushes used increasingly linear 
movements as migration progressed. Late in migration, the typical maintenance thrush (i.e., $2 \mathrm{~g}$ fat mass) ranged ca. twice as far on its first day of stopover as a similar thrush early in migration (cf. solid lines in Figure 5A and 5C); daily displacement movements of thrushes carrying more substantial fuel stores remained consistent throughout the migration period (Figure 5). The consequence of these conditional relationships on the use of linear movements is straightforward - thrushes exhibit relatively similar ranging behavior early in migration, with little regard to fuel stores, whereas later in migration lean thrushes become increasingly more mobile than fatter thrushes albeit primarily in the first day(s) of stopover. Increased precipitation reduced linear displacement as it did total movement; every $10 \%$ increase in the proportion of the day with reported precipitation was associated with an additional $16 \%$ (CI: $\left.7-24 \% ; \mathrm{P}_{\mathrm{pb}}=0.003\right)$ reduction in linear displacement.

\section{Thrush departure decisions and stopover duration}

Thrushes departed Block Island 1 - 13 days (median: 4 days) following their release. Sixteen thrushes (12 ad libitum and 4 maintenance) left after the first day of stopover. Fat mass influenced the length of thrush stopover more generally as well. Stopover duration decreased approximately $9 \% \mathrm{~g}^{-1}$ of fat $\left(\mathrm{CI}: 3-15 \% \mathrm{~g}^{-1} ; \mathrm{P}_{\mathrm{pb}}=0.002\right)$, a relationship that remained consistent throughout migration (fat x season interaction; $\mathrm{P}_{\mathrm{pb}}=0.93$ ). Thus, a thrush with a $6 \mathrm{~g}$ fat mass at release was estimated to stay approximately 3 days compared to $4-5$ days for a thrush with a $2 \mathrm{~g}$ fat mass released at the same time, or roughly a $48 \%$ increase in stopover duration for the leaner thrush. Thrush stopover duration did not vary appreciably throughout the fall migration period $\left(\mathrm{P}_{\mathrm{pb}}=0.62\right)$. 
Fat mass at release influenced nightly decisions to depart Block Island. The hazard for departure on the first night of stopover increased $24 \% \mathrm{~g}^{-1}$ of fat (CI: $2-$ $\left.51 \% \mathrm{~g}^{-1} ; \chi^{2}=6.91, \mathrm{P}=0.009\right)$, suggesting more than a twofold higher hazard of departure for a thrush released with a $6 \mathrm{~g}$ fat mass relative to that of a thrush with a $2 \mathrm{~g}$ fat mass. This hazard did not effectively change as stopover progressed (fat $\mathrm{x}$ stopover day interaction; $\left.\chi^{2}=0.28, \mathrm{df}=1, \mathrm{P}=0.59\right)$. Thrushes departed under a variety of wind speeds, although most left on nights with average wind speeds under 5 $\mathrm{m} \mathrm{s}^{-1}$ (median: $4.7 \mathrm{~m} \mathrm{~s}^{-1}$; range: $1-9 \mathrm{~m} \mathrm{~s}^{-1}$ ); indeed, departure hazard decreased $18 \%$ for every $\mathrm{m} \mathrm{s}^{-1}$ increase in wind speed $\left(\mathrm{CI}: 1-31 \% \mathrm{~m} \mathrm{~s}^{-1} ; \chi^{2}=4.66, \mathrm{P}=0.03\right)$. Thrush departure hazard decreased in wind conditions favoring a reverse migration to the mainland $\left(\chi^{2}=1.79, \mathrm{df}=1, \mathrm{P}=0.18\right)$ and increased in wind conditions favoring onward migration to the southwest $\left(\chi^{2}=2.23, \mathrm{df}=1, \mathrm{P}=0.14\right)$, but not consistently. Only thrushes returning to the mainland departed into headwinds, although the vanishing direction of most thrushes was profoundly influenced by wind direction during departure.

We documented the departure time and direction of 25 thrushes: $13(52 \%)$ left Block Island to the west or southwest in apparent onward migration whereas the other $12(48 \%)$ departed to the northwest or north in apparent reverse migration. Fat mass at release influenced the decision to undertake onward versus reverse migration. Specifically, the odds of onward migration increased $\sim 52 \% \mathrm{~g}^{-1}$ of fat at release (CI: $1 \%$ decrease $-133 \% \mathrm{~g}^{-1}$ increase), corresponding to 0.69 and 0.30 predicted probabilities of undertaking onward migration for thrushes released with $6 \mathrm{~g}$ and $2 \mathrm{~g}$ of fat, respectively. Thrushes departed Block Island $1.3-5.6 \mathrm{~h}$ after sunset (median: 
$3.0 \mathrm{~h}$ ). Time of departure varied with the departure direction with thrushes making onward migrations towards Long Island leaving $13 \%\left(\mathrm{CI}: 4-21 \% ; \mathrm{P}_{\mathrm{pb}}=0.01\right)$ nearer to sunset than those returning to the mainland, but there was little evidence to suggest that the time of departure varied with thrush fat mass at release $\left(\mathrm{P}_{\mathrm{pb}}=0.73\right)$ or stopover length $\left(\mathrm{P}_{\mathrm{pb}}=0.36\right)$.

\section{Patterns of resource abundance}

Ground-dwelling arthropod abundance varied considerably throughout the fall migration (Figure 6A), but provided little indication of a consistent decline (or increase). In contrast, fruit abundance declined throughout the fall for all species, once fruits had ripened (Figure 6B).

\section{DISCUSSION}

We conducted the first experimental manipulation of songbird fuel stores during migration stopover and evaluated its subsequent influence on multiple aspects of movement behavior and departure decisions at a stopover site along a migratory barrier. We found that the influence of fuel stores (or possibly fuelling rate; see below) pervaded migrant stopover behavior including the amount and directedness of daily movement, stopover duration, nightly decision to depart and the direction of that departure. Nonetheless, the relationship between fuel stores at release and stopover behavior often varied within the context of stopover and season. Atmospheric conditions likewise influenced patterns of movement and departure decisions.

\section{Manipulation of thrush fuel stores}


Experimental manipulation of body mass produced changes predominately in the stored fat mass of thrushes. Thus, we evaluated stopover behavior and departure decisions in the context of this absolute measure of fuel stores. However, migrants may base behavioral decisions during stopover on other intrinsic conditions rather than absolute fat stores. For example, given the important energetic contributions of protein during migration (Jenni and Jenni-Eiermann 1998; Bauchinger and Biebach 2001), migrants may also monitor changes in lean mass, which suggests that a composite measure of condition that accounts for changes in protein or muscle mass during stopover (e.g., Fusani et al. 2009; Seewagen and Guglielmo 2010; McWilliams and Whitman 2013) may be relevant. Alternatively, migrants may base decisions on relative changes in condition such as the rate of fuel accumulation (i.e., fuel deposition rate; Hedenström and Alerstam 1998; Schaub and Jenni 2000; Eikenaar and Schläfke 2013), or the rate of fuel loss prior to stopover (Eikenaar and Bairlein), though the latter is practically impossible to measure. We were unable to evaluate the potential importance of these different measures of individual fuelling state due to minimal changes in estimated lean mass and strong correlations between fuel deposition rate and mass change during captivity and estimated fat mass at release.

\section{Condition-dependence of thrush movement}

When we detected condition-dependent differences in thrush movements, thrushes with more fat stores generally moved less and made more tortuous movements. However, lean thrushes moved similarly to fat thrushes early in the migration period, and the quantity and directedness of their movements only increased as migration progressed (Figures 4 and 5). Movements of fat thrushes during stopover remained 
consistent throughout the migratory period, perhaps reflecting an innate tendency to restrict diurnal movements when carrying fuel stores adequate for continued migration (Ktitorov et al. 2010).

Declining seasonal resources seems a plausible explanation for more apparent condition-dependent differences in movements later during the migration period. Food resources (especially fruit) were abundant and widely-distributed early in migration and this allowed lean thrushes to secure adequate resources without making large exploratory movements (Ktitorov et al. 2010). However, while ground-dwelling arthropod abundance remained relatively consistent throughout the fall (Figure 6A), fruit resources declined rapidly (Figure 6B). In particular, the highly nutritious fruits of arrowwood and Virginia creeper, preferred fruits among songbird migrants on Block Island (Smith et al. 2007; Bolser et al. 2013), were essentially absent by the end of the migratory period (Figure 6B). Thrushes are highly omnivorous and rely extensively on fruit during fall migration on Block Island (Parrish 1997; Smith and McWilliams 2010; A. Smith, pers. obs.), and thus may have been particularly sensitive to declining fruit abundance and nutritional quality of remaining fruits. Shortening day length may also have elicited the endogenous time program, increasing foraging activity (Jenni and Schaub 2003; Bayly 2006), which seemingly obligates more extensive movements as resources decline. Fat birds may have been capable of foraging locally and minimally to maintain fuel stores and thus responded less sensitively to declining food resources and their endogenous time program.

Lean thrushes sharply decreased the magnitude and scale of their daily movements as stopover progressed (Figures 4). The decrease in total movement and, 
in particular, increasingly localized movements of lean thrushes is consistent with expectations and suggests that leaner thrushes identified a core foraging area of adequate quality as they transitioned from an initial exploratory period (Aborn and Moore 1997). The transition to more tortuous movements also suggests lean birds were able to acquire fuel during stopover. While fat thrushes maintained a consistent scale of movement during stopover (Figure 5), they nonetheless decreased total movement comparably to lean thrushes (Figure 4). This decrease possibly represented a similar albeit attenuated search and settling pattern. Songbirds occasionally decrease foraging activity and fuelling rates in the day(s) leading up to departure (e.g., Fransson 1998; Bayly 2006; Bayly 2007), but it is not a consistent syndrome (Lindstrom and Alerstam 1992; Dänhardt and Lindström 2001). Moreover, as food is not available ad libitum on stopover (Ktitorov et al. 2010), thrushes with large fuel stores presumably needed to forage to some extent even if intending to depart the initial night after release (e.g., Biebach 1985).

\section{Condition-dependence of thrush departure decisions}

Fuel stores are posited to influence departure decisions especially when the departure location preceeds the crossing of migratory barriers (Alerstam 1978; Jenni and Schaub 2003; Sandberg 2003). In agreement with this expectation, fat mass at release exerted a significant influence on the nightly decision to depart Block Island. The persistence of this effect throughout stopover, despite most stopovers lasting four or more days, is noteworthy given that all thrushes possessed ample fuel stores at release to make either the return flight to the mainland or the onward flight towards Long Island (Figure 1; Yong and Moore 1993; Woodrey and Moore 1997). That increased fuel 
stores at release positively influenced the nightly decision to depart suggests that leaner thrushes found Block Island suitable for stopover or perceived the ocean crossing as a barrier requiring additional fuel stores.

Stopover duration varied negatively with thrush fuel stores at release, an expected association that seems straightforward for a time-limited bird during migration. However, the association between fuel stores at arrival and stopover duration is often ambiguous (e.g., Salewski and Schaub 2007; Tsvey, Bulyuk, and Kosarev 2007). We expect that resolving the typically small duration differences (i.e., $1-2$ days) between fat and lean birds is complicated by the challenge of accurately determining when migrants arrive and their fuel stores upon arrival. Nonetheless, studies purporting to know both arrival fuel stores and stopover duration with relative certainty provide equivocal results (e.g., Buler 2006; Chernetsov and Muhkin 2006; Bolshakov et al. 2007; Tsvey, Bulyuk, and Kosarev 2007; Goymann et al. 2010; Ktitorov et al. 2010; Matthews and Rodewald 2010b). Patterns of fuel accumulation during stopover likewise play a role in determining stopover duration (Eikenaar and Schläfke 2013), but are similarly difficult to assess (e.g., Schaub, Jenni, and Bairlein 2008; but see Bulyuk and Tsvey 2013; Schmaljohann et al. 2013). Stopover duration seems to us subject to myriad intrinsic and environmental influences, and the variable association with initial fuel stores is perhaps unsurprising (Jenni and Schaub 2003).

Stopover duration of migrating songbirds decreases consistently as migration proceeded in spring (e.g., Yong and Moore 1997; Dierschke and Delingat 2001; Matthews and Rodewald 2010b) and fall (e.g., Ktitorov et al. 2010; Morganti et al. 2011; Andueza et al. 2013), presumably in response to increasing time constraints. 
However, we found no indication of a seasonal pattern in stopover duration. To our knowledge, the only other exception to this otherwise ubiquitous pattern of decreasing stopover duration with migration period was a study of Northern Wheatears (Oenanthe oenanthe leucorhoa) faced with a substantial migratory barrier that required, of most individuals, substantial fuel stores and favorable atmospheric conditions (Dierschke and Delingat 2001). This scenario fails to describe the situation for songbirds such as thrushes stopping over on Block Island. We speculate that the endogenous time program may have been less crucial with temperate migrant thrushes. Individuals later in the season conceivably were near the end of their migratory journey and perhaps largely freed from the endogenous time program. The time program is perhaps even less relevant for immature migrants with a reduced incentive to reach wintering areas early only to be displaced by more dominant adults (e.g., Marra 2000).

Fuel stores generally influenced thrush decisions to continue migration in a seasonally-appropriate direction. However, the migratory dynamics of Block Island makes it reasonable to question whether thrush departures from Block Island represent true oriented migrations or extended landscape-level stopover movements (e.g., Mills et al. 2011; Taylor et al. 2011). For instance, most birds using Block Island as a stopover are immature birds that presumably have been displaced offshore after having failed to correct for wind drift (e.g., Baird and Nisbet 1960; Ralph 1978). Long Island and the mainland are both visible from Block Island on clear nights and within the maximum reported range of extended stopover movements by thrushes in the region (Taylor et al. 2011); reverse migrants can move on similar scales (Åkesson et al. 1996), and reverse migration may simply be a specific case of geographically- 
constrained extended stopover (Ktitorov et al. 2010). Regardless of whether onward migration towards Long Island demonstrated the ability of some inexperienced thrushes to correct for displacement (Thorup et al. 2011), we suggest that variation in the timing of departures related to departure direction support the idea that seasonallyappropriate departures represented true migratory movements.

Thrushes leaving towards Long Island left earlier in the night than reorienting birds. This is consistent with evidence that birds undertaking true migratory departures leave earlier in the night to maximize the time available for migration (Bolshakov et al. 2007; Mills et al. 2011; Schmaljohann and Naef-Daenzer 2011; Smolinsky et al. 2013). Nonetheless, thrushes did not depart particularly close to sunset, which may reasonably be explained by increased flexibility to accomplish flights of the scale that thrushes might reasonably be undertaking (e.g., Cochran and Wikelski 2005) given the increasing night lengths of fall (Bolshakov et al. 2007). Furthermore, later departure times of thrushes reorienting towards the mainland corroborates similar reorientation or risk-sensitive movements at migratory barriers or landscape-scale stopover movements rather than true onward migrations (Mills et al. 2011; Schmaljohann and Naef-Daenzer 2011; Smolinsky et al. 2013).

\section{Environmental influences on thrush movements and departure decisions}

We documented an association between increased precipitation and reduced diurnal movements. To our knowledge, no such influence on stopover behavior has been previously documented, and so ours is the first study to explore this association. However, precipitation was relatively uncommon during the study (11\% of days with monitoring), and only on half of those days did it rain for more than half of the 
daylight hours. We thus suggest precipitation played only a small role in modifying thrush movement behavior during stopover, although it may play a more important role in birds that forage exclusively on (particularly aerial) arthropods. Nonetheless, the influence of precipitation seems far more relevant to departure decisions.

Thrushes distinctly avoided departing during precipitation. Measureable precipitation occurred on $27 \%$ of all monitored nights, yet only 1 out of 44 birds departed on a night with precipitation (a maintenance bird reorienting towards the mainland), and that bird left prior to the precipitation. This supports an important role of precipitation in modifying departure decisions (Richardson 1978; Dänhardt and Lindström 2001; Erni et al. 2002; Schaub, Liechti, and Jenni 2004; Van Belle et al. 2007), and is not surprising given that flying during precipitation likely imposes severe energetic and possibly survival costs on migrants (Schaub, Liechti, and Jenni 2004).

Birds that depart on nights with favorable wind directions can greatly reduce their energetic costs of flight (Richardson 1978; Liechti 2006). Interestingly, most such work supports a primary influence of wind speed rather than wind direction, although tailwinds may be more important at migratory barriers (e.g., Åkesson and Hedenström 2000; Dänhardt and Lindström 2001; Dierschke and Delingat 2001; Tsvey, Bulyuk, and Kosarev 2007; Morganti et al. 2011; Schmaljohann and NaefDaenzer 2011). Birds can make migratory progress, even in headwinds, so long as wind speeds remain below migrant airspeeds. Thrushes preferentially departed Block Island on nights with lower average wind speeds. Thrushes typically maintain a consistent heading rather than correct for wind drift (Cochran and Wikelski 2005) and, 
in general agreement, the vanishing directions of thrushes in this study occasionally deviated considerably from their departure direction due to prevailing wind directions, at least for the $6-10 \mathrm{~km}$ we could detect their departures. Thrushes continuing migration to the southwest consistently selected light or weak tailwinds, whereas reorienting thrushes departed under considerably variable wind conditions.

\section{Conclusions}

The simultaneous release of individual migrants with manipulated fuel stores allowed us to directly test hypotheses about the condition-dependence of behavioral decisions of songbirds during migratory stopover. Our experiments supported the hypotheses that thrushes with increased fat stores moved less and made less directed movements, that these differences in movements abate over the course of a given stopover, and that the condition-dependent differences in movements are accentuated in late-migrating individuals because of declining resource availability. Consistent lengths of stopover throughout the migratory period suggested that time constraints may be less important in fall temperate migrants. With further regard to departure decisions, our results supported the hypothesis that birds with more substantial fat stores were more likely to resume migration earlier and in a seasonally-appropriate direction relative to individuals released with little change in fuel stores. As expected, precipitation suppressed thrush movements during stopover and, more decisively, inhibited thrush departure. Departure decisions were influenced primarily by wind speed, although thrushes continuing migration in a seasonally-appropriate direction indicated some preference for tailwinds. The pervasive influence of fuel stores on migrant stopover 
behavior underscores the importance of high-quality stopover sites and the central role of fuel acquisition in the dynamics, speed, and success of migration.

\section{FUNDING}

This work was supported by the National Science Foundation (IBN-9984920 and IOS0748349 to S.R.M.), the U.S. Department of Agriculture (538748 to S.R.M.), the Rhode Island Agricultural Experiment Station (contribution no. XXXX).

\section{ACKNOWLEDGMENTS}

Special thanks to two industrious and diligent field crews, including B. Jones, R. Alan,

K. Barnes, S. Bebus, K. Chmiel, J. Cressman, L. Jenkins, B. Jones, C. Knoll, and E.

Pokrivka. S. Comings and The Nature Conservancy graciously accommodated field staff and provided property access and logistical support on Block Island.

\section{REFERENCES}

Able KP. 1973. The role of weather variables and flight direction in determining the magnitude of nocturnal bird migration. Ecology 54:1031-1041.

Able KP. 1977. The orientation of passerine nocturnal migrants following offshore drift. Auk 94:320-330.

Aborn DA, Moore FR. 1997. Pattern of movement by summer tanagers (Piranga rubra) during migratory stopover: a telemetry study. Behaviour 134:10771100. 
Åkesson S, Hedenström A. 2000. Wind selectivity of migratory flight departures in birds. Behav. Ecol. Sociobiol. 47:140-144.

Åkesson S, Karlsson L, Walinder G, Alerstam T. 1996. Bimodal orientation and the occurrence of temporary reverse bird migration during autumn in south Scandinavia. Behav. Ecol. Sociobiol. 38:293-302.

Åkesson S. 1993. Coastal migration and wind drift compensation in nocturnal passerine migrants. Ornis Scand. 24:87-94.

Alerstam T, Lindström Å. 1990. Optimal bird migration: the relative importance of time, energy and safety. In: Gwinner E, editor. Bird migration: physiology and ecophysiology. New York, New York, USA: Springer-Verlag. p. 331-351.

Alerstam T. 1978. Reoriented bird migration in coastal areas: dispersal to suitable resting grounds? Oikos 30:405-408.

Alerstam T. 1990. Bird migration. Cambridge, United Kingdom: Cambridge University Press.

Alerstam T. 2011. Optimal bird migration revisited. J. Ornithol. 152:5-23.

Andueza M, Arizaga J, Belda EJ, Barba E. 2013. The role of extrinsic and intrinsic factors on the departure dicisions of a long-distance migratory passerine. Ardeola 60:59-72.

Arizaga J, Andueza M, Tamayo I. 2013. Spatial behaviour and habitat use of first-year bluethroats Luscinia svecica stopping over at coastal marshes during the autumn migration period. Acta Ornithol. 48:17-25.

Arizaga J, Belda EJ, Barba E. 2011. Effect of fuel load, date, rain and wind on departure decisions of a migratory passerine. J. Ornithol. 152:991-999. 
Baird J, Nisbet ICT. 1960. Northward fall migration on the Atlantic coast and its relation to offshore drift. Auk 77:119-149.

Bairlein F. 1995. Manual of field methods. European-African songbird migration network. Wilhelmshaven, Germany: Institut für Vogelkunde.

Bates D, Maechler M, Bolker B, Walker S. 2013. Linear mixed-effects models using Eigen and S4. R package version 1.0-4. http://CRAN.R-project.org/package$\underline{\operatorname{lme} 4}$.

Bauchinger U, Biebach H. 2001. Differential catabolism of muscle protein in garden warblers (Sylvia borin): flight and leg muscle act as a protein source during long-distance migration. J. Comp. Physiol. B 171:293-301.

Bayly NJ. 2006. Optimality in avian migratory fuelling behaviour: a study of a transSaharan migrant. Anim. Behav. 71:173-182.

Bayly NJ. 2007. Extreme fattening by sedge warblers, Acrocephalus schoenobaenus, is not triggered by food availability alone. Anim. Behav. 74:471-479.

Biebach H. 1985. Sahara stopover in migratory flycatchers: fat and food affect the time program. Experientia 41:695-697.

Bland JM, Altman DG. 1995. Statistics notes: calculating correlation coefficients with repeated observations. Part 1--correlation within subjects. BMJ 310:446-446.

Blem CR. 1990. Avian energy storage. In: Power DM, editor. Current ornithology, volume 7. New York, New York, USA: Plenum Press. p. 59-113.

Bolser JA, Alan RA, Smith AD, Li L, Seeram NP, McWilliams SR. 2013. Birds select fruits with more anthocyanins and phenolic compounds during autumn migration. Wilson J. Ornithol. 125:97-108. 
Bolshakov CV, Chernetsov N, Mukhin A, Bulyuk VN, Kosarev V, Ktitorov P, Leoke D, Tsvey A. 2007. Time of nocturnal departures in European robins, Erithacus rubecula, in relation to celestial cues, season, stopover duration and fat stores. Anim. Behav. 74:855-865.

Bowlin MS, Cochran WW, Wikelski MC. 2005. Biotelemetry of New World thrushes during migration: physiology, energetics and orientation in the wild. Integr. Comp. Biol. 45:295-304.

Brambor T, Clark WR, Golder M. 2006. Understanding interaction models: improving empirical analyses. Polit. Anal. 14:63-82.

Buler JJ. 2006. Understanding habitat use by landbirds during migration along the Mississippi Gulf Coast using a scale-dependent approach. Hattiesburg, MS, USA: Unversity of Southern Mississippi.

Bulyuk VN, Tsvey A. 2013. Regulation of stopover duration in the European Robin Erithacus rubecula. J. Ornithol. 154:1115-1126.

Chernetsov N, Muhkin A. 2006. Spatial behavior of European Robins during migratory stopover: a telemetry study. Wilson J. Ornithol. 118:364-373.

Cochran WW, Kjos CG. 1985. Wind drift and migration of thrushes: a telemetry study. Ill. Nat. Hist. Surv. Bull. 33:297-330.

Cochran WW, Wikelski MC. 2005. Individual migratory tactics of New World Catharus thrushes. In: Greenberg R, Marra PP, editors. Birds of two worlds: the ecology and evolution of migration. Johns Hopkins University Press. p. $274-289$. 
Cohen EB, Moore FR, Fischer RA. 2012. Experimental evidence for the interplay of exogenous and endogenous factors on the movement ecology of a migrating songbird. PLoS ONE 7:e41818.

Covino KM, Holberton RL. 2011. The influence of energetic condition on flight initiation and orientation of migratory songbirds in the Gulf of Maine region. Auk 128:313-320.

Cox DR. 1972. Regression models and life-tables. J. R. Stat. Soc. Ser. B 34:187-220.

Dänhardt J, Lindström Å. 2001. Optimal departure decisions of songbirds from an experimental stopover site and the significance of weather. Anim. Behav. 62:235-243.

DeSante D, Burton K, Velez P, Froehlich D. 2003. MAPS manual: instructions for the establishment and operation of constant-effort bird-banding stations as part of the Monitoring Avian Productivity and Survivorship (MAPS) Program. Point Reyes Station, California, USA: Institute for Bird Populations.

Deutschlander ME, Muheim R. 2009. Fuel reserves affect migratory orientation of thrushes and sparrows both before and after crossing an ecological barrier near their breeding grounds. J. Avian Biol. 40:85-89.

Dierschke V, Delingat J. 2001. Stopover behaviour and departure decision of northern wheatears, Oenanthe oenanthe, facing different onward non-stop flight distances. Behav. Ecol. Sociobiol. 50:535-545.

Eikenaar C, Bairlein F. 2013. Food availability and fuel loss predict Zugunruhe. J. Ornithol. In press. 
Eikenaar C, Schläfke JL. 2013. Size and accumulation of fuel reserves at stopover predict nocturnal restlessness in a migratory bird. Biol. Lett. 9:20130712.

Elliott L, Stokes L, Stokes D. 2000. Stokes field guide to bird songs: eastern region.

Enser RW, Lundgren JA. 2006. Natural communities of Rhode Island. Kingston, Rhode Island, USA: Rhode Island Natural History Survey.

Erni B, Liechti F, Underhill LG, Bruderer B. 2002. Wind and rain govern the intensity of nocturnal bird migration in Central Europe - a log-linear regression analysis. Ardea 90:155-166.

Evans WR, O'Brien M. 2002. Flight calls of migratory birds: eastern North American landbirds (CD-ROM).

Fransson T, Barboutis C, Mellroth R, Akriotis T. 2008. When and where to fuel before crossing the Sahara desert - extended stopover and migratory fuelling in firstyear garden warblers Sylvia borin. J. Avian Biol. 39:133-138.

Fransson T. 1995. Timing and speed of migration in north and west European populations of Sylvia warblers. J. Avian Biol. 26:39-48.

Fransson T. 1998. Patterns of migratory fuelling in whitethroats Sylvia communis in relation to departure. J. Avian Biol. 29:569-573.

Fusani L, Cardinale M, Carere C, Goymann W. 2009. Stopover decision during migration: physiological conditions predict nocturnal restlessness in wild passerines. Biol. Lett. 5:302-305.

Gagnon F, Ibarzabal J, Savard JL, Bélisle M, Vaillancourt P. 2011. Autumnal patterns of nocturnal passerine migration in the St. Lawrence estuary region, Quebec, Canada: a weather radar study. Can. J. Zool. 89:31-46. 
Gauthier G, Pradel R, Menu S, Lebreton J-D. 2001. Seasonal survival of greater snow geese and effect of hunting under dependence in sighting probability. Ecology 82:3105-3119.

Goymann W, Spina F, Ferri A, Fusani L. 2010. Body fat influences departure from stopover sites in migratory birds: evidence from whole-island telemetry. Biol. Lett. 6:478-481.

Hedenström A, Alerstam T. 1998. How fast can birds migrate? J. Avian Biol. 29:424432.

Hedenström A. 2008. Adaptations to migration in birds: behavioural strategies, morphology and scaling effects. Philos. Trans. R. Soc. B Biol. Sci. 363:287299.

Houston AI. 1998. Models of optimal avian migration: state, time and predation. J. Avian Biol. 29:395-404.

Hüppop O, Dierschke J, Exo K-M, Fredrich E, Hill R. 2006. Bird migration studies and potential collision risk with offshore wind turbines. Ibis 148:90-109.

Jenni L, Jenni-Eiermann S. 1998. Fuel supply and metabolic constraints in migrating birds. J. Avian Biol. 29:521-528.

Jenni L, Schaub M. 2003. Behavioural and physiological reactions to environmental variation in bird migration: a review. In: Berthold P, Gwinner E, Sonnenschein E, editors. Avian migration. Berlin: Springer. p. 155-171.

Karlsson H, Nilsson C, Bäckman J, Alerstam T. 2011. Nocturnal passerine migration without tailwind assistance. Ibis 153:485-493. 
Ketterson ED, Nolan V. 1982. The role of migration and winter mortality in the life history of a temperate-zone migrant, the dark-eyed junco, as determined from demographic analyses of winter populations. Auk 99:243-259.

Klaassen M, Lindström Å. 1996. Departure fuel loads in time-minimizing migrating birds can be explained by the energy costs of being heavy. J. Theor. Biol. 183:29-34.

Ktitorov P, Tsvey A, Mukhin A. 2010. The good and the bad stopover: behaviours of migrant reed warblers at two contrasting sites. Behav. Ecol. Sociobiol. 64:1135-1143.

Kullberg C, Fransson T, Jakobsson S. 1996. Impaired predator evasion in fat blackcaps (Sylvia atricapilla). Proc. R. Soc. Lond. B Biol. Sci. 263:16711675.

Liechti F, Bruderer B. 1998. The relevance of wind for optimal migration theory. J. Avian Biol. 29:561-568.

Liechti F. 2006. Birds: blowin' by the wind? J. Ornithol. 147:202-211.

Lind J, Fransson T, Jakobsson S, Kullberg C. 1999. Reduced take-off ability in robins (Erithacus rubecula) due to migratory fuel load. Behav. Ecol. Sociobiol. $46: 65-70$.

Lindstrom A, Alerstam T. 1992. Optimal fat loads in migrating birds: a test of the time-minimization hypothesis. Am. Nat. 140:477-491.

Marra PP. 2000. The role of behavioral dominance in structuring patterns of habitat occupancy in a migrant bird during the nonbreeding season. Behav. Ecol. 11:299-308. 
Matthews SN, Rodewald PG. 2010a. Movement behaviour of a forest songbird in an urbanized landscape: the relative importance of patch-level effects and body condition during migratory stopover. Landsc. Ecol. 25:955-965.

Matthews SN, Rodewald PG. 2010b. Urban forest patches and stopover duration of migratory Swainson's Thrushes. Condor 112:96-104.

McKim-Louder MI, Hoover JP, Benson TJ, Schelsky WM. 2013. Juvenile survival in a Neotropical migratory songbird is lower than expected. PLoS ONE 8:e56059.

McWilliams SR, Guglielmo C, Pierce B, Klaassen M. 2004. Flying, fasting, and feeding in birds during migration: a nutritional and physiological ecology perspective. J. Avian Biol. 35:377-393.

McWilliams SR, Whitman M. 2013. Non-destructive techniques to assess body composition of birds: a review and validation study. J. Ornithol. 154:597-618.

Menu S, Gauthier G, Reed A, Holberton RL. 2005. Survival of young greater snow geese (Chen caerulescens) during fall migration. Auk 122:479-496.

Metcalfe NB, Furness RW. 1984. Changing priorities: the effect of pre-migratory fattening on the trade-off between foraging and vigilance. Behav. Ecol. Sociobiol. 15:203-206.

Mills AM, Thurber BG, Mackenzie SA, Taylor PD. 2011. Passerines use nocturnal flights for landscape-scale movements during migration stopover. Condor 113:597-607.

Moore FR, Aborn DA. 2000. Mechanisms of en route habitat selection: how do migrants make habitat decisions during stopover? Stud. Avian Biol. 20:34-42. 
Moore FR, Gauthreaux SA, Kerlinger P, Simons TR. 1995. Habitat requirements during migration: important link in conservation. In: Martin TE, Finch DM, editors. Ecology and management of Neotropical migratory birds: a synthesis and review of critical issues. Oxford University Press. p. 121-144.

Morganti M, Mellone U, Bogliani G, Saino N, Ferri A, Spina F, Rubolini D. 2011. Flexible tuning of departure decisions in response to weather in black redstarts Phoenicurus ochruros migrating across the Mediterranean Sea. J. Avian Biol. $42: 323-334$.

Parrish JD. 1997. Patterns of frugivory and energetic condition in Nearctic landbirds during autumn migration. Condor 99:681-697.

Paxton KL, Van Riper III C, O’Brien C. 2008. Movement patterns and stopover ecology of Wilson's Warbler during spring migration on the lower Colorado River in southwestern Arizona. Condor 110:672-681.

Ralph CJ. 1978. Disorientation and possible fate of young passerine coastal migrants. Bird-Band. 49:237-247.

Richardson WJ. 1978. Timing and amount of bird migration in relation to weather: a review. Oikos 30:224-272.

Richardson WJ. 1990. Timing of bird migration in relation to weather: updated review. In: Gwinner E, editor. Bird migration. Berlin: Springer-Verlag. p. 78101.

Salewski V, Schaub M. 2007. Stopover duration of Palearctic passerine migrants in the western Sahara - independent of fat stores? Ibis 149:223-236. 
Sandberg R. 2003. Stored fat and the migratory orientation of birds. In: Berthold P, Gwinner E, Sonnenschein E, editors. Avian migration. Springer. p. 515-525.

Schaub M, Jenni L, Bairlein F. 2008. Fuel stores, fuel accumulation, and the decision to depart from a migration stopover site. Behav. Ecol. 19:657-666.

Schaub M, Jenni L. 2000. Fuel deposition of three passerine bird species along the migration route. Oecologia 122:306-317.

Schaub M, Liechti F, Jenni L. 2004. Departure of migrating European robins, Erithacus rubecula, from a stopover site in relation to wind and rain. Anim. Behav. 67:229-237.

Schaub M, Schwilch R, Jenni L. 1999. Does tape-luring of migrating Eurasian reedwarblers increase number of recruits or capture probability? Auk 116:10471053.

Schielzeth H, Forstmeier W. 2009. Conclusions beyond support: overconfident estimates in mixed models. Behav. Ecol. 20:416-420.

Schmaljohann H, Becker P, Karaardic H, Liechti F, Naef-Daenzer B, Grande C. 2011. Nocturnal exploratory flights, departure time, and direction in a migratory songbird. J. Ornithol. 152:439-452.

Schmaljohann H, Fox JW, Bairlein F. 2012. Phenotypic response to environmental cues, orientation and migration costs in songbirds flying halfway around the world. Anim. Behav. 84:623-640.

Schmaljohann H, Korner-Nievergelt F, Naef-Daenzer B, Nagel R, Maggini I, Bulte M, Bairlein F. 2013. Stopover optimization in a long-distance migrant: the role of 
fuel load and nocturnal take-off time in Alaskan northern wheatears (Oenanthe oenanthe). Front. Zool. 10:26.

Schmaljohann H, Naef-Daenzer B. 2011. Body condition and wind support initiate the shift of migratory direction and timing of nocturnal departure in a songbird. J. Anim. Ecol. 80:1115-1122.

Seewagen CL, Guglielmo CG. 2010. Effects of fat and lean body mass on migratory landbird stopover duration. Wilson J. Ornithol. 122:82-87.

Seewagen CL, Slayton EJ, Guglielmo CG. 2010. Passerine migrant stopover duration and spatial behaviour at an urban stopover site. Acta Oecologica 36:484-492.

Sillett TS, Holmes RT. 2002. Variation in survivorship of a migratory songbird throughout its annual cycle. J. Anim. Ecol. 71:296-308.

Smith SB, McPherson KH, Backer JM, Pierce BJ, Podlesak DW, McWilliams SR. 2007. Fruit quality and consumption by songbirds during autumn migration. Wilson J. Ornithol. 119:419-428.

Smith SB, McWilliams SR. 2010. Patterns of fuel use and storage in migrating passerines in relation to fruit resources at autumn stopover sites. The Auk 127:108-118.

Smolinsky JA, Diehl RH, Radzio TA, Delaney DK, Moore FR. 2013. Factors influencing the movement biology of migrant songbirds confronted with an ecological barrier. Behav. Ecol. Sociobiol.:1-11.

Strandberg R, Klaassen RHG, Hake M, Alerstam T. 2010. How hazardous is the Sahara Desert crossing for migratory birds? Indications from satellite tracking of raptors. Biol. Lett. 6:297-300. 
Taylor PD, Mackenzie SA, Thurber BG, Calvert AM, Mills AM, McGuire LP, Guglielmo CG. 2011. Landscape movements of migratory birds and bats reveal an expanded scale of stopover. PLoS ONE 6:e27054.

Therneau TM. 2000. Modeling survival data: extending the Cox model. Springer.

Therneau TM. 2012. coxme: mixed effects Cox models. R package version 2.2-3. http://CRAN.R-project.org/package=coxme.

Thorup K, Ortvad TE, Rabøl J, Holland RA, Tøttrup AP, Wikelski M. 2011. Juvenile songbirds compensate for displacement to oceanic islands during autumn migration. PLoS ONE 6:e17903.

Tietz JR, Johnson MD. 2007. Stopover ecology and habitat selection of juvenile Swainson's thrushes during fall migration along the northern California coast. Condor 109:795-807.

Tsvey A, Bulyuk VN, Kosarev V. 2007. Influence of body condition and weather on departures of first-year European robins, Erithacus rubecula, from an autumn migratory stopover site. Behav. Ecol. Sociobiol. 61:1665-1674.

Van Belle J, Shamoun-Baranes J, Van Loon E, Bouten W. 2007. An operational model predicting autumn bird migration intensities for flight safety. J. Appl. Ecol. 44:864-874.

Weber TP, Ens BJ, Houston AI. 1998. Optimal avian migration: a dynamic model of fuel stores and site use. Evol. Ecol. 12:377-401.

Weber TP, Hedenström A. 2000. Optimal stopover decisions under wind influence: the effects of correlated winds. J. Theor. Biol. 205:95-104. 
Wikelski M, Tarlow EM, Raim A, Diehl RH, Larkin RP, Visser GH. 2003. Avian metabolism: costs of migration in free-flying songbirds. Nature 423:704-704.

Williamson P, Gray L. 1975. Foraging behavior of the starling (Sturnus vulgaris) in Maryland. Condor 77:84-89.

Wood SN. 2006. Generalized additive models: an introduction with R. Boca Raton, FL, USA: Chapman and Hall/CRC.

Woodrey MS, Moore FR. 1997. Age-related differences in the stopover of fall landbird migrants on the coast of Alabama. Auk 114:695-707.

Yong W, Moore FR. 1993. Relation between migratory activity and energetic condition among thrushes (Turdinae) following passage across the Gulf of Mexico. Condor 95:934-943.

Yong W, Moore FR. 1997. Spring stopover of intercontinental migratory thrushes along the northern coast of the Gulf of Mexico. Auk 114:263-278. 


\section{FIGURE LEGENDS}

Figure 1. Geographical context of Block Island, Rhode Island (RI), USA, where we experimentally investigated the role of fuel stores on stopover movements and departure decisions in Hermit Thrushes during the fall migrations of 2009 and 2010. Thrushes continued migration towards Long Island, New York (NY) or returned to mainland Rhode Island or Connecticut (CT); both options involved flights of ca. 20 $30 \mathrm{~km}$. (INSET) We captured thrushes (filled circle) at the northern extreme of the maritime shrub community (shaded areas). After capture, thrushes were placed in temporary captivity (filled triangle) for $2-6$ days, after which they were released in contiguous maritime shrub habitat from a soft release aviary (filled square). Bodies of water are indicated by cross-hatching.

Figure 2. Hermit Thrush fuel stores were modified by feeding regime (maintenance vs. ad libitum) provided to short-term captive birds over on average $3-4$ days during the fall migrations of 2009 and 2010 on Block Island, Rhode Island, USA. (A) Thrushes possessed similar fuel stores at initial capture as assessed by indices of subcutaneous fat and breast musculature. At release, thrushes fed waxworms ad libitum possessed considerably greater fat scores and increased breast musculature. Horizontal lines within the bean plots indicate the relative number of individuals with a given condition score ( $\mathrm{n}=25$ in each feeding regime). (B) Changes (or lack thereof) in fat and breast musculature were indicated in patterns of body mass change during captivity. Body composition estimated from thrush wing chord and fat and breast musculature scores indicated that mass changes were attributable largely to changes in stored body fat, 
particularly in ad libitum thrushes. See text for details of diet treatment and body composition estimation.

Figure 3. Relationships between body mass and (A) wing chord, (B) subcutaneous fat score, and (C) breast musculature score from 484 observations on 294 Hermit Thrushes captured on Block Island, Rhode Island, USA during the fall migrations of 2009 and 2010. The solid line indicates the relationship (penalized spline) between a variable and body mass while other variables are held at their medians; shaded areas around this line indicate the $95 \%$ confidence interval for the relationship. The dashed horizontal line indicates the predicted body mass when all measures are at their medians. The rug plot along the abscissa indicates observed values of a given variable. The model explained $\sim 61 \%$ of the variation in thrush body mass.

Figure 4. Total daily movements of Hermit Thrushes with reduced body fat ( $2 \mathrm{~g}$ fat mass; solid line) and substantial body fat (6 g fat mass; dashed line) on Block Island, Rhode Island, USA, during (A) early, (B) middle and (C) late thrush migration in autumn 2009 and 2010. Movements are scaled relative to a thrush with reduced body fat early in the season on its first day of stopover (i.e., after release) to facilitate comparisons. All thrushes reduced total daily movements as their stopover progressed. Fat mass influenced movements primarily later in migration (B and C) leaner thrushes made increasingly more substantial movements as migration progressed while fatter thrushes moved similar distances throughout the migration 
period. Lines and shading indicate the fitted conditional relationships and their associated standard error, respectively.

Figure 5. Daily linear displacement of Hermit Thrushes with reduced body fat ( $\mathrm{g}$ fat mass; solid line) and substantial body fat (6 $\mathrm{g}$ fat mass; dashed line) on Block Island, Rhode Island, USA, during (A) early, (B) middle and (C) late thrush migration in autumn 2009 and 2010. Linear displacement was scaled relative to a thrush with reduced body fat early in the season on its first day of stopover (i.e., after release) to facilitate comparisons. Relative to lean thrushes, those with more substantial fat mass maintained consistent patterns of linear displacement during stopover and throughout the migration period. The movements of lean thrushes became increasingly linear as migration progressed, but decreased sharply during the course of stopover. These conditional relationships resulted in relatively similar patterns of displacement between fat and lean thrushes early in migration, but more discrepant patterns later in migration, particularly in the first few days after release (C). Lines and shading indicate the fitted conditional relationships and their associated standard error, respectively.

Figure 6. Change in (A) ground-dwelling arthropod and (B) fruit resource abundance on Block Island, Rhode Island, USA, during the 2010 fall migration. (A) Boxplots indicate the median and interquartile range (IQR; box) and whiskers extend 1.5 times beyond the IQR; raw data values are indicated by dots. (B) Lines indicate the median proportion of fruit remaining. The shaded area in each panel indicates when 
telemetered thrushes used the area. Fruit species abbreviations (see text for scientific names): MR - multiflora rose; WB - winterberry; BB - bayberry; PW - pokeweed; VC - Virginia creeper; and AW - arrowwood. 


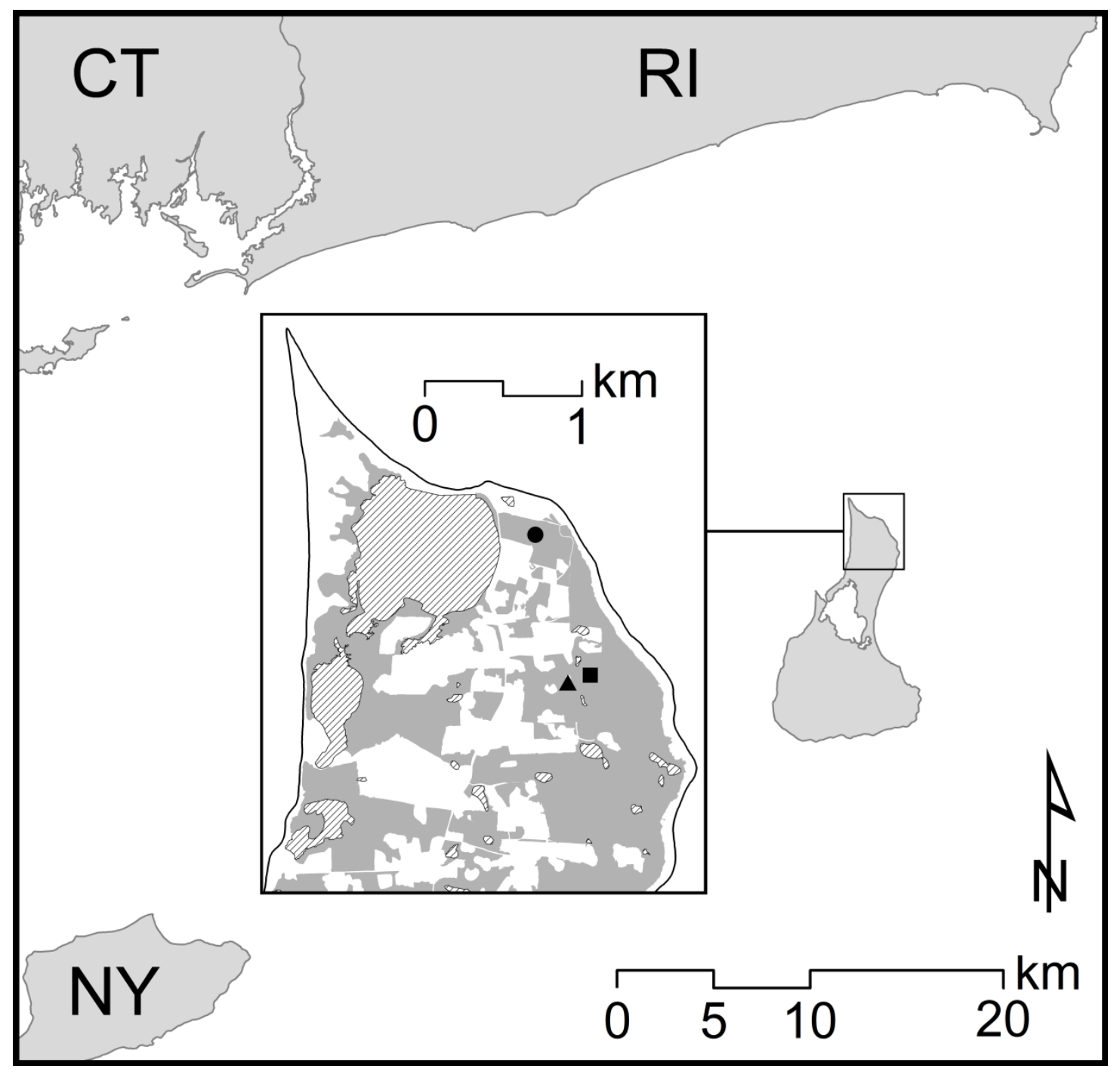

Figure 1. 


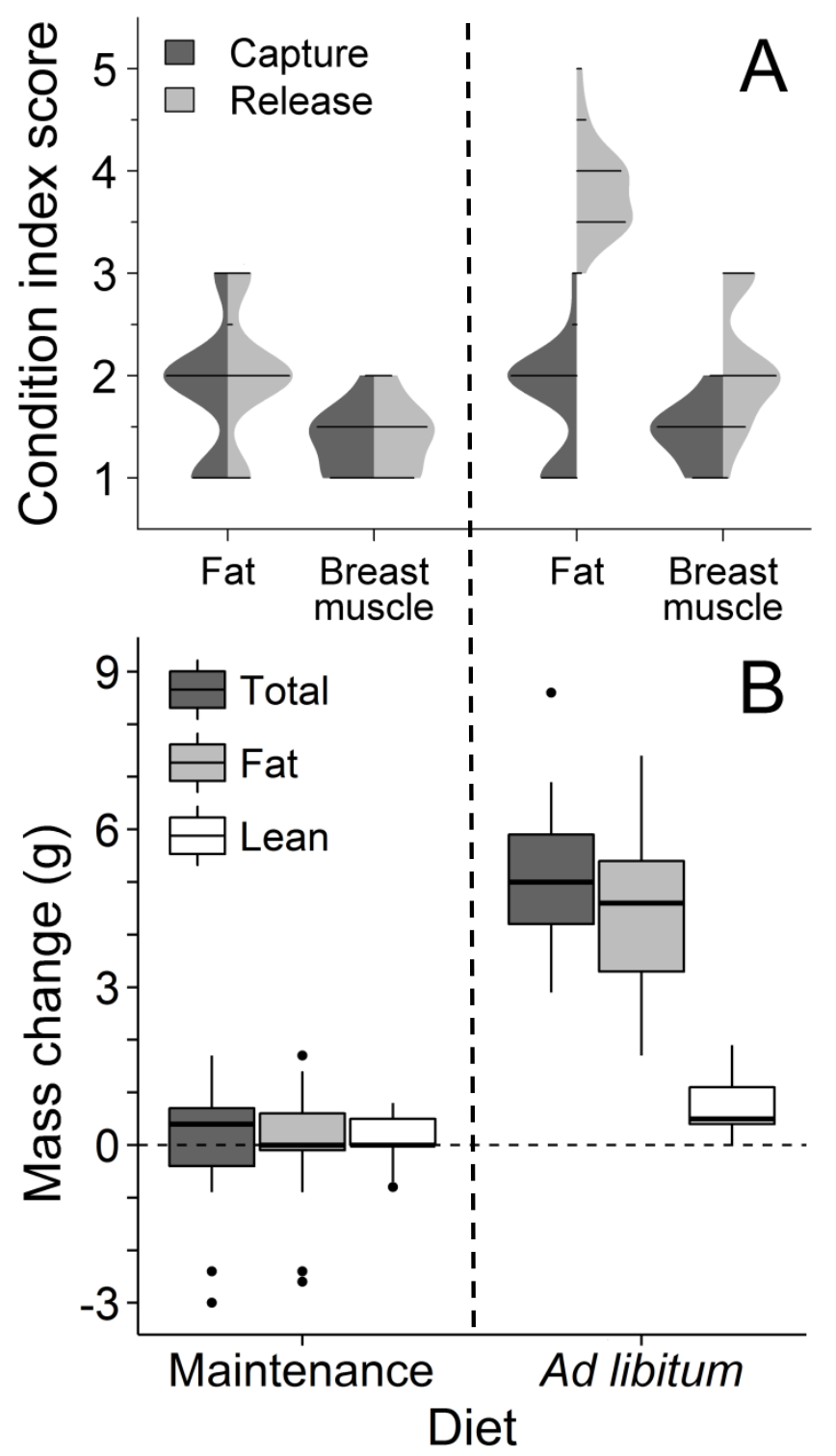

Figure 2. 


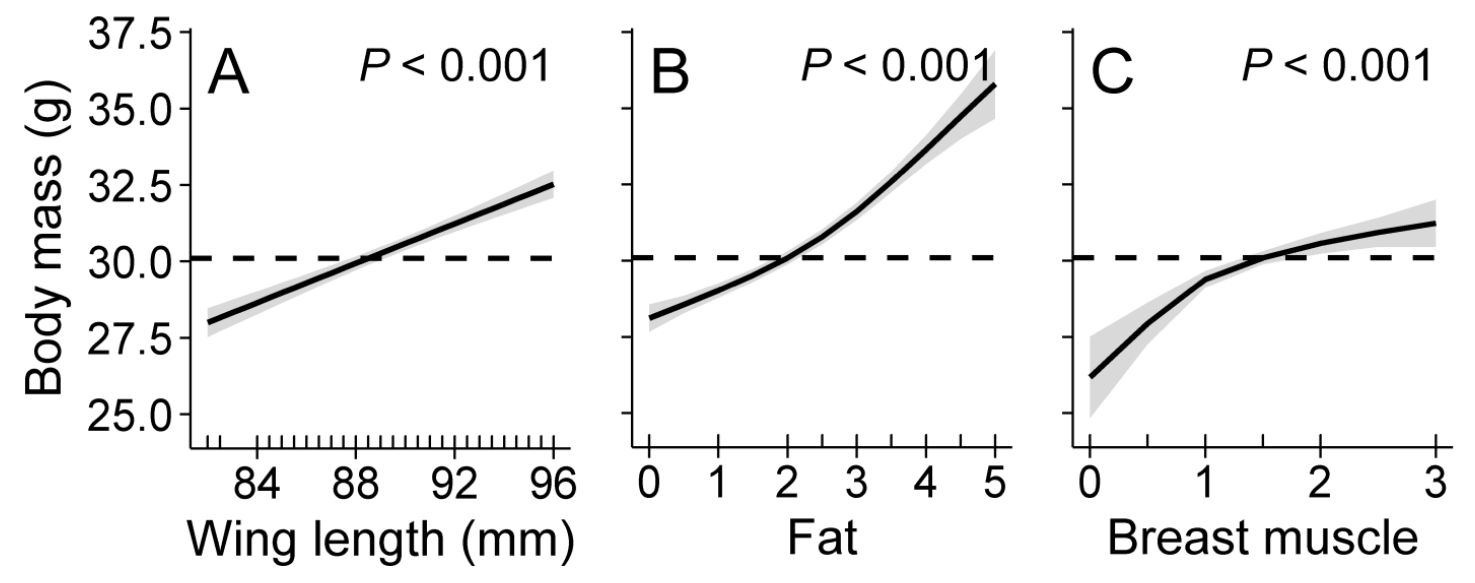

Figure 3. 


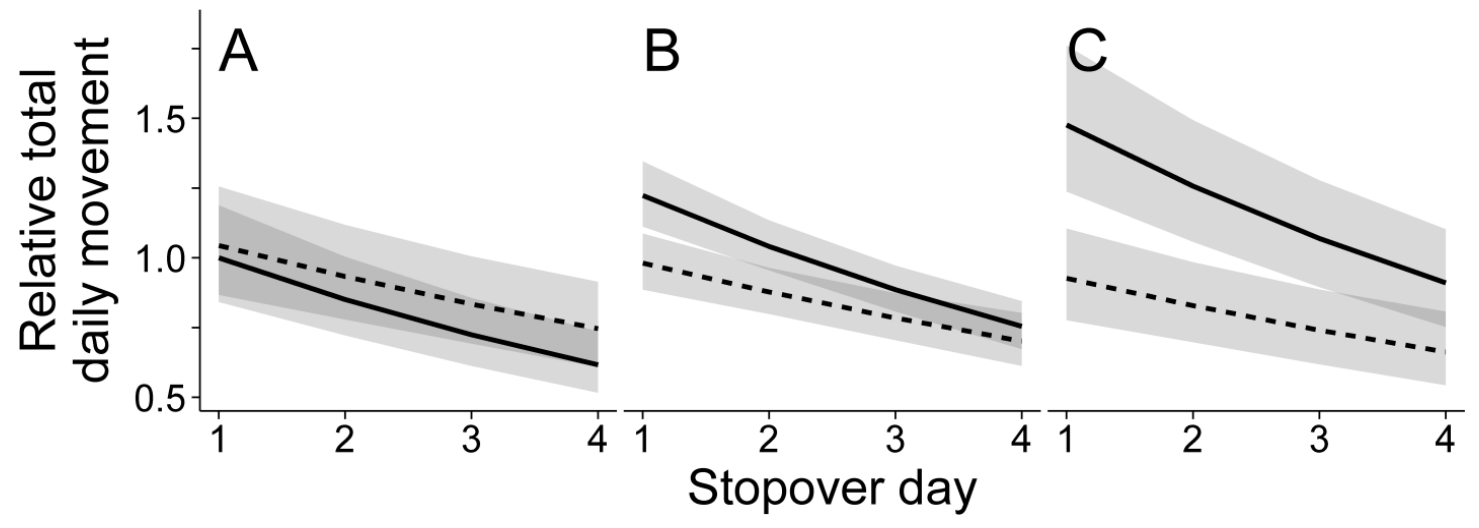

Figure 4 


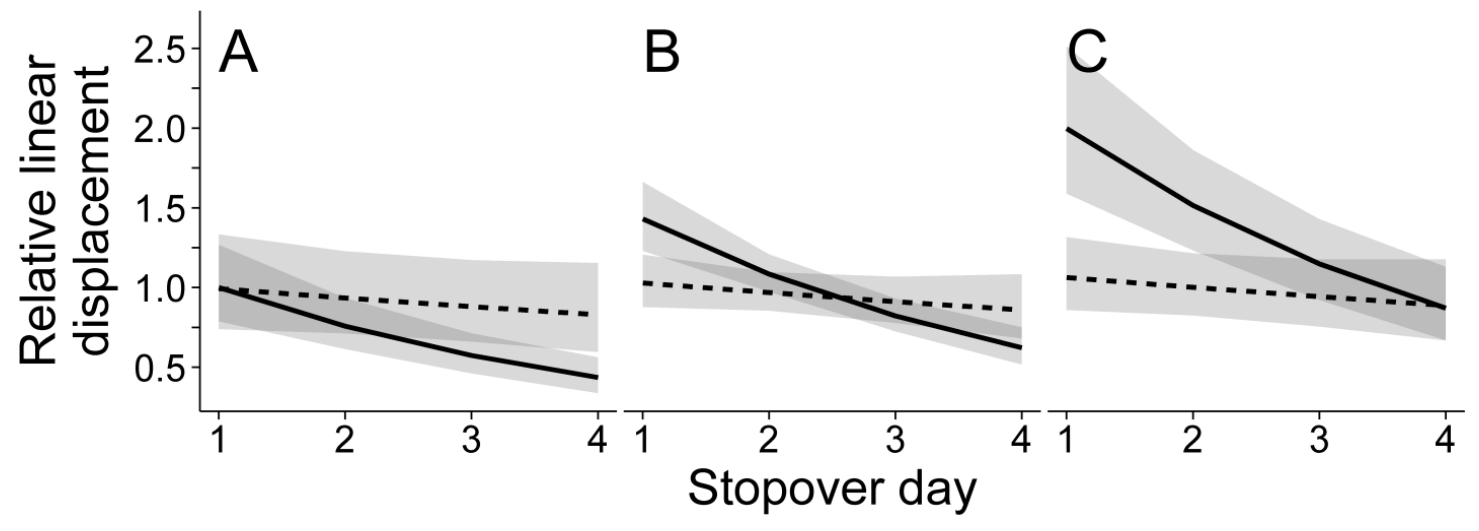

Figure 5 


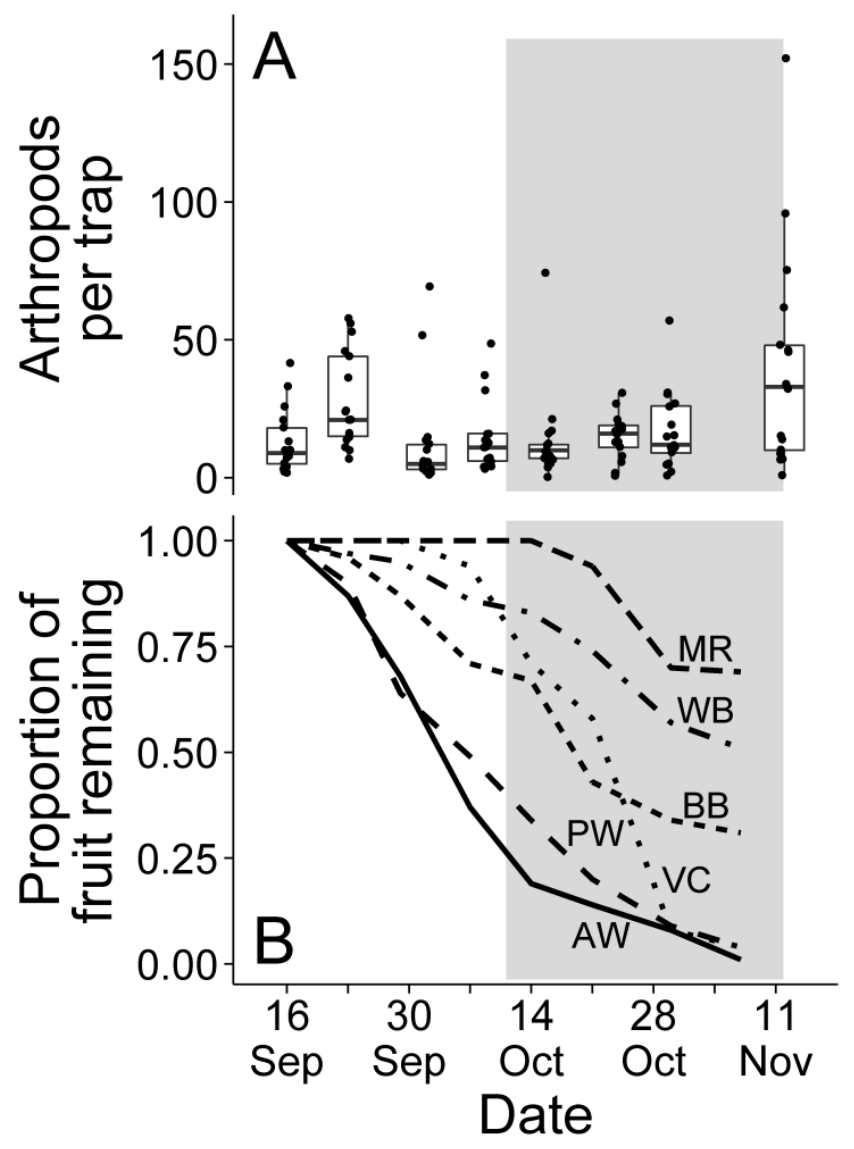

Figure 6. 